\title{
The Pleasure Principle: Why (Some) People Develop a Taste for Politics Evidence from a pre-registered experiment
}

\section{Alexander Wuttke'}

\begin{abstract}
Often, citizens talk politics or watch political shows solely for the pleasure they derive from these activities. Yet, existing theories struggle to explain why (some) individuals engage with politics as an end in itself even if the behavior does not produce any separable instrumental value. Integrating psychological theories from motivation studies, this study deduces a need-based theory of political motivation in order to explain intrinsic political engagement. The model proposes that intrinsic political motivation has roots in the seemingly apolitical processes of need satisfaction which are deeply ingrained in the human psyche. Providing a theoretical framework for existing political science findings, this study argues that citizens seek behaviors they previously experienced as pleasurable. Differences in intrinsic political motivation are therefore theorized to reflect whether political engagement was previously experienced as satisfying basic psychological needs which is argued to predict both whether and how individuals engage with politics. By manipulating need-related situational features before and during political engagement, a pre-registered survey experiment tested the basic tenet that need-related experiences with politics affect the quality and quantity of future activities in the political domain. However, 14 out of 15 analytical tests do not yield the expected evidence in line with the need-based model of political motivation. Showcasing a step-wise approach for dealing with null-results in hypothesis-driven research to assess and increase the information value of the conducted analysis, the presented evidence calls into question the accuracy of the presented theory and the previous insights in psychology and political science on which it was built. This study thus adds a new piece to the puzzle of understanding what does and what does not underlie intrinsic motivation for political engagement.
\end{abstract}

\section{Pre-Print Notice}

This is a study draft that has not yet undergone the peer review process. Feedback is welcome.

\section{Keywords}

Political Participation; Civic Engagement; Motivation Studies; Open Science

'Department of Social Science, University of Mannheim, Germany

Corresponding Author:

Alexander Wuttke, Email: alexander.wuttke@uni-mannheim.de; @kunkakom; Website: www.alexander-wuttke.de 
Pre-Print

\section{Introduction}

2 Be it for a hobby or a cherished food, some people can trace the origins of their personal taste. In most

3 cases, however, tastes develop over time, progressively and rarely noticed. Like more profane tastes,

4 some citizens have developed a taste for politics; they find pleasure in talking about or reading about

5 political matters. Different from other tastes, finding joy in political engagement is not only a matter

6 of personal inclinations but it has societal implications because valuing something for its inherently

7 rewarding qualities foreshadows frequent and sustained enactment of that activity. If we consider

8 reading and knowing about politics and engaging with the public life as qualities of good citizenship

9 and if it is a goal to promote such qualities among the citizenry, then it is crucial to understand how

I0 to foster the taste for politics so that people fulfill their duties as good citizens not merely as a chore

II but as a source of joy.

I2 Admittedly, political engagement out of joy and pleasure is not the only pathway to political

13 action. Citizens engage with politics in order to comply with social pressures, to act in accordance

14 with their inner sense of selves or to make a difference through one's behavior. Political science has

I5 much to say about these and other motivational pathways to political engagement all of which posit

16 goals that are separable from the behavior itself (Blais and Daoust, 2020). In contrast, the taste for

17 politics and, more specifically, political engagement as an inherently rewarding experience is not well

18 understood. Although a powerful motivator (Prior, 2019), dedicated studies of political engagement

19 as an end in itself are rare (Hamlin and Jennings, 2011; Opp, 2015; Prior, 2019). As a consequence,

20 political science struggles to explain situational and individual variation in so motivated engagement.

21 That is, we do not have a good understanding of why citizens uniformly experience political action in

22 some environments as more satisfying than in others or why some citizens experience a given en-

23 counter with politics as more enjoyable than other citizens. 
The line of literature which is closest to systematically examine the role of joy and other self-

25 sustained drivers in politics are studies on political interest. Political interest is attracting increasing

26 attention as of late, contributing to an empirical and theoretical groundwork for the study of political

27 engagement as its own reward (Bougher, 2017; Shani, 2009). For instance, recent studies showed that

28 curiosity towards politics is rather stable and suggested that dispositional interest in politics has non-

29 political roots (Shani, 2009; Wuttke, 2019a). What is more, these proclivities may have resulted from

30 initially fleeting but repeatedly confirmed situational experiences that made political encounters feel

31 rewarding (Prior, 2019). While these studies help to understand the transition from situational to dis-

32 positional political interest, the concept of political interest is not a perfect fit to approach political

33 activities that are enacted for their own sake. Political interest is both too broad a concept as it also

34 subsumes attention towards politics for instrumental material considerations (Prior, 2019) and too

35 narrow a concept as interest is not the only conceivable motivator with inherently satisfying condi-

36 tions that may drive self-sustained behaviors. Therefore, I suggest taking advantage of the conceptual

37 toolkit of motivation science and to employ the concept of intrinsic motivation for understanding self-

38 sustained engagement in the political domain.

39 Action for its own sake has long been studied in motivation science under the label of intrin-

40 sically motivated behavior (Kruglanski et al., 2018). In the tradition of self-determination theory, for

4I instance, intrinsic motivation is used to describe behaviors that are conducted for their inherently

42 satisfying conditions' (Ryan and Deci, 2017). Similarly, means-ends-fusion theory conceptualizes a

43 behavior's degree of intrinsicallity as the perceived fusion between the activity and its end (Kruglan-

44 ski et al., 2018). Adopting this perspective may help to overcome conceptual problems inherent in

45 previous attempts to get a grasp of self-sustained behaviors in the political domain. For instance, one

46 conceptualization that was brought forward to approach inherently satisfying behaviors is to 
Pre-Print

47 distinguish between instrumental and expressive behavior (Hamlin and Jennings, 2011). However,

48 considering the inevitability of instrumental motives in social scientific explanations (Marx and

49 Tiefensee, 2015), separating instrumental from non-instrumental motives inadvertently renders in-

50 trinsic action as inaccessible to all inquiries that presuppose intentional actors. In contrast, the con-

5I cept of intrinsic motivation acknowledges that intrinsic behaviors do provide instrumental values but

52 merely considers them as inseparable from the behavior itself and as materializing during the behav-

53 ior. From this perspective, intrinsically motivated behaviors no longer pose conceptually problems

54 even for actors who follow some instrumental motives. Another prominent distinction is between

55 internal and external motivators (Opp, 2015). Yet, this distinction entails unclear conceptual bound-

56 aries because all motivators must be processed internally for eliciting behavioral ramifications. There-

57 fore, the concept of intrinsic motivation avoids theoretical pitfalls compared to other concepts that

58 have previously been used and may prove useful to explain political engagement for its own reward.

59 What is more, the concept of intrinsic motivation provides distinct explanatory value as it helps to

60 distinguish intrinsic motivation from other motivational pathways and thus to predict their distinct

61 behavioral outcomes. For instance, a large body of psychological literature has shown that additional

62 extrinsic incentives such as the provision of monetary rewards often increases the propensity to con-

63 duct a behavior but at the expense of undermining the afforded efforts (Deci et al., 1999; Kruglanski

64 et al., 2018; Kurzban et al., 2013). In contrast, a distinctive property of intrinsic motivation is to stip-

65 ulate both the quantity and quality of behavior (Cerasoli et al., 2014). Therefore, understanding how

66 to increase intrinsic political motivation may help to cultivate environments in which citizens not

67 only superficially engage with politics but in which they fully embrace engagement with politics.

Explaining the origins of intrinsic political motivation departs from the simple idea -often

69 called the pleasure principle (Freud, 1961; Higgins, 2012)- that human beings enact activities they 
70 previously experienced as satisfying. To explain the resulting question of what we experience as pleas-

7I urable, this study proposes basic psychological needs as the theoretical centerpiece. Building upon

72 existing motivation theories that employ basic psychological needs for identifying the properties of

73 inherently satisfying behaviors (Dweck, 2017; Maslow, 1970; Ryan and Deci, 2017), this study joins a

74 growing political science literature that identifies nonpolitical origins of political engagement

75 (Bougher, 2017; Galais, 2018; Holbein, 2017; Holbein et al., 2019; Prior, 2019; Shani, 2009). Integrating

76 these motivation theories and applying their insights to the political domain, the need-based theory

77 of political motivation posits that seemingly apolitical processes of need satisfaction, which are deeply

78 ingrained in the human psyche predict which political acts citizen experience as inherently satisfying.

79 Specifically, political activities are expected to elicit sensations of joy or gratification when conducted

80 in need-satisfying contexts. Individual differences in intrinsic motivation, then, derive from past

8I need-related experiences with politics and reflect a person's expectations towards the anticipated

82 need satisfaction that future encounters will provide. In this vein, a taste for politics echoes whether

83 people experienced previous encounters with politics as satisfying their basic psychological needs and

84 thus as inherently satisfying.

85 In order to test the predictions of the need-based model of political motivation, in a survey

86 experiment situational contexts were manipulated to induce more or less need satisfaction to then

87 assess consequences for whether participants sought out political information during the survey and

88 how they processed these information that were conveyed in a video clip. Against expectations, re-

89 spondents in the need-supportive and need-thwarting experimental conditions did not differ substan-

90 tially in the quality or quantity of political engagement. Multiple follow-up analyses were conducted

91 to strengthen the confidence that these reported findings represent a decisive falsification of the pro-

92 posed theory that are unlikely to result from alternative explanations. Showcasing how to engage with 
93 null-results in hypothesis-testing research, these analyses show that imperfect measurement of out-

94 comes, treatment heterogeneity, low power or survey attrition cannot explain the absence of the ex-

95 pected findings. Yet, various manipulation checks reveal that not all experimental conditions meet

96 the conditions for a decisive hypothesis test. Nonetheless, this experiment fails to provide any con-

97 sistent evidence in line with the theoretical prediction, suggesting the refutation of most derived hy-

98 potheses. This study thus cannot offer a definitive explanation of intrinsic political motivation. Yet,

99 considering the scant knowledge about political engagement as an end in itself, the proposed theory

100 and the demonstrated findings may thus serve as a stepping stone to inform further research on this

I0I crucial topic of research.

\section{Political motivation and Basic Needs}

103 We seek activities that made us feel good in the past (Silvia, 2005; Skinner, 1976). Different lines of

104 thought in psychological science acknowledge the relevance of the pleasure principle both in classical

105 (Freud, 1961; Skinner, 1976) and contemporary work (e.g., Milyavskaya et al., 2018b). While useful

106 as a starting point, explaining behavior solely by the pleasure principle merely pushes the explanatory

107 burden one rung down the latter as it begs the question of why some activities are experienced as

108 pleasurable, and others are not. Moreover, the crucial aspect of individual differences remains unre-

109 solved. I propose to overcome this explanatory deficit by combining the pleasure principle's theoret-

II0 ical proposition with additional insights from motivation science on core desires that drive human

III behavior.

II2 What kind of behaviors do human beings find satisfying and are therefore likely to be pursued

II3 again? Along with a burgeoning literature on human universals in other life domains (Bloom, 2011;

II4 Christakis, 2019; Mehr et al., 2019), there is a growing consensus that human beings share certain

115 'core motives' (Fiske, 2014) or 'psychological needs' (Ryan and Deci, 2017). While disagreement 
II6 persists about essential concept characteristics and about the resulting list of supposedly universal

II7 motivational propensities (Dweck, 2017; Higgins, 2012; Kruglanski et al., 2018; Ryan and Deci, 2017;

II8 Sheldon et al., 2001), a functionalist definition of basic needs has proven useful for exploiting univer-

I19 sal motivators in applied research. Understanding basic psychological needs as ,areas of chronically

I20 high value that are critical to well-being and optimal development" (Dweck, 2017) allows the abduc-

I2I tion of a list of needs, based on observed empirical regularities. Human desires thus qualify as basic

I22 psychological needs if they are found irreducible to other needs and if they can be shown to be of high

I23 value for optimal functioning and well-being across cultures and life stages (Dweck, 2017; Ryan and

I24 Deci, 2017). One basic need that is acknowledged by most motivation theories (Bandura, 2010;

I25 Dweck, 2017; Higgins, 2012; Ryan and Deci, 2017) is the need for competence, which goes back to

I26 early work by White (1959) and Piaget (1952) who argued that from childhood onwards human be-

I27 ings express the desire to feel efficacious and impactful in the world. Another need that has roots in

I28 early writings on the human condition (Ryan and Deci, 2017), particularly concerning human beings

I29 as political persons who are embedded in larger groups (Blühdorn, 2019), is the need for autonomy.

I30 Advocated most prominently by self-determination theory (Ryan and Deci, 2017), the human "desire

131 to self-organize experience and behavior and to have activity be concordant with one's integrated

I32 sense of self" (Deci and Ryan, 2000: 231) is argued to drive human behavior across cultures and life

I33 stages (Chen et al., 2014; Sheldon et al., 2001). Although no list of basic needs is definitive, a large pile

I34 of prior research thus suggests the existence of universal needs for competence and autonomy so that,

I35 all else equal, activities that are coupled with elements which satisfy these needs are experienced

I36 more positively than without the experience of need satisfaction.

137 Based on the idea that need-satisfying activities are experienced as more pleasurable and are

I38 therefore more likely to be re-enacted in various life domains, it is conceivable that the degree to 
139 which activities fulfill basic psychological needs may also help to explain inherently gratifying behav-

140 iors in the political domain. In this vein, the origins of intrinsic political motivation, that is the pro-

14I pensity for embracing and enjoying an activity, is argued to lie in previous need-related political ex-

142 periences (see Figure 1). More specifically, the expectations and beliefs derived from previous need-

143 related encounters with politics feed into a person's level of political motivation and determine one's

144 approach to politics in the future (Dweck, 2017). Previous political science findings support this no-

I45 tion and can be re-interpreted along the lines of a need-based model of political motivation. For in-

I46 stance, multiple political science findings have shown that respondents who were randomly induced

I47 to fail political knowledge questions subsequently report lower levels of political interest (Bishop,

148 1987; Prior, 2019; Schwarz and Schuman, 1997). From a need-based perspective, these findings can

149 be understood as previous experiences with the political domain which thwarted or satisfied the need

150 for competence, thereby fostering or undermining a person's intrinsic motivation towards that do-

I5I main. Consequently, when political engagement has previously contributed to satisfying our basic

I52 needs such as the need for competence then we will want more of it. 
Figure I. Need-based model of political motivation

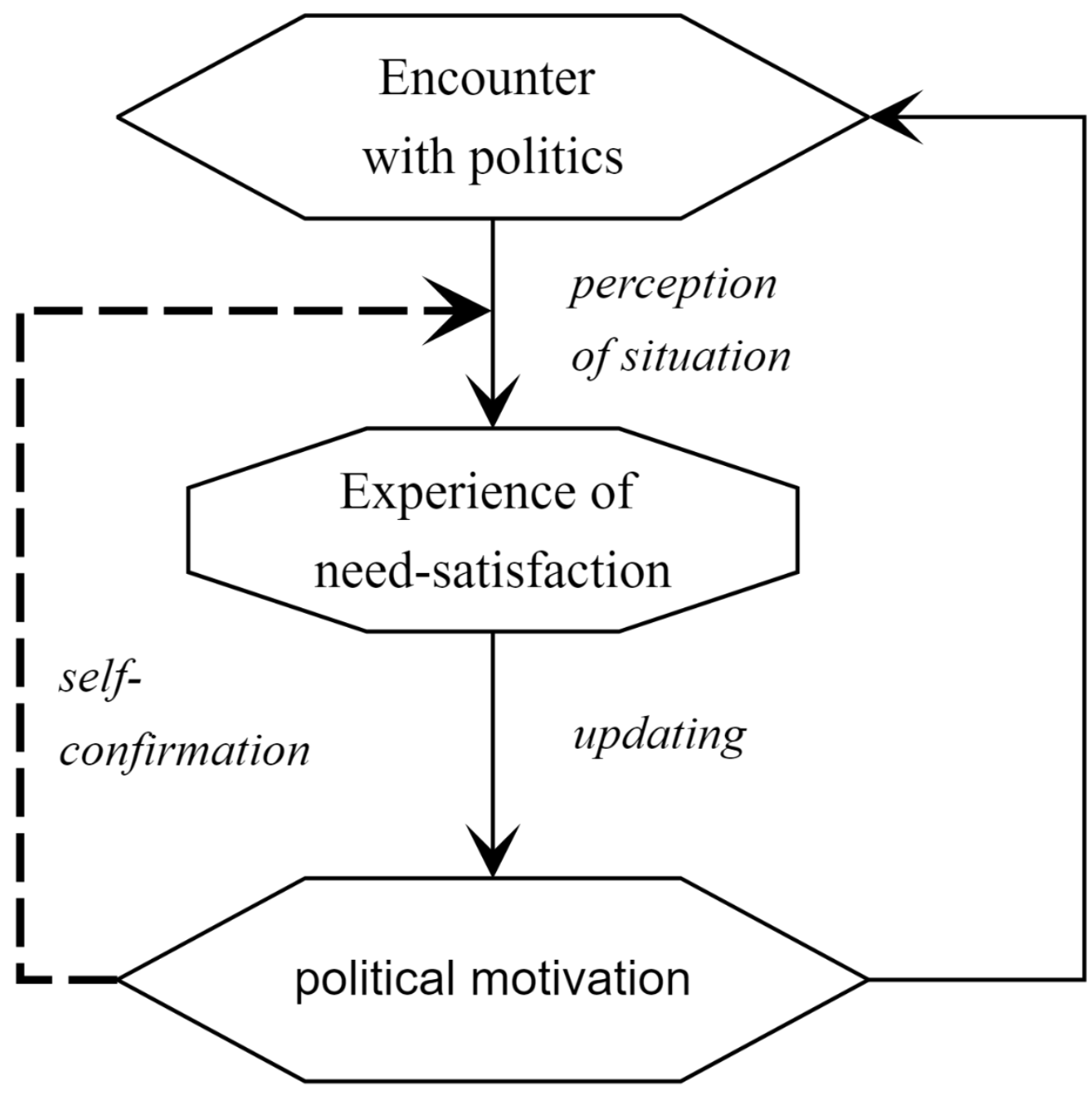

154

155

I56 How can we reconcile the proposition that universal basic needs determine the degree of pleasure

157 provided by an activity with the observation that the motivation to enact a specific political behavior

I58 is not universal but varies remarkably between individuals? Notably, certain situational characteris-

I59 tics uniformly facilitate need satisfaction, reflecting that they are more or less conducive to need sat-

160 isfaction. For instance, providing a rationale or giving a sense of choice usually contributes to the

16I satisfaction of a persons' need for autonomy (Chatzisarantis et al., 2012; Deci et al., 1994; Nelson et 
162 al., 2015; Patall et al., 2008; Spray et al., 2006). Importantly, however, individuals make different ex-

163 periences with politics as some will experience politics in a more need-satisfying context than others.

164 These prior experiences will then feed into the tally of politics-related beliefs and expectations which

165 form a person's level of domain-specific motivation. Cohort studies suggest that these mechanisms

166 are most forceful during the impressionable years of adolescence when individuals do not yet hold

167 crystallized attitudes towards the political domain (Prior, 2019; Wuttke, 2019a). Yet, there is no reason

168 not to assume that, to a lower degree, these mechanisms may be at play throughout the entire life

169 course, changing one's level of political motivation in reaction to new need-supportive or need-

170 thwarting experiences with politics.

17I What is more, once motivational proclivities towards politics have crystallized in a person, we I72 may expect a self-confirmatory psychological tendency through which expectations create perceived

173 reality (Murayama, 2019), thereby exacerbating already existing differences in political motivation

I74 (self-confirmation, see Figure 1). It is well known that individuals experience a glass of wine as more

I75 delightful when the individuals were manipulated to believe tasting a high-quality wine (Bloom,

I76 2011). Similarly, citizens who have developed favorable attitudes towards politics may be more likely

I77 than others to see their expectations of political engagement as an enjoyable activity confirmed even

I78 when engaging in the same political activity. This proposition is consistent with political science evi-

I79 dence that exogenously induced political encounters stimulate political interest more strongly among

I80 individuals with favorable predispositions towards politics (Prior, 2019). Hence, a self-reinforcing

I8I feedback loop may foster the polarization of individual differences of political motivation, seemingly

I82 confirming a person's expectations about whether it is valuable to engage with politics.

I83 Because individual differences in political motivation are argued to be ultimately rooted in

I84 need-related experiences, need-satisfying experiences with politics help explain why individuals want 
I85 to engage with politics for its own sake. Interestingly, as need-satisfying experiences give more reason

I86 to again experience the satisfaction associated with behavior, need-related activities change a person's

187 goals. In the wake of perceiving a behavior as serving need-fulfilling goals, fusion occurs between the 188 general goal of need-fulfillment and the specific reasons for conducting the behavior (Figure 2). No-

189 tably, the degree to which fusion occurs between goals and reasons for action is the definition of in190 trinsicallity of action (Kruglanski et al., 2018). In other words, the more a person perceives political 191 engagement as serving need-fulfilling goals, the more political engagement is enacted for no other

192 reason than the behavior's inherent need-satisfying conditions. Hence, intrinsic political motivation

193 is at its maximum when need-fulfilling goals and behavioral reasons fully align, for instance, when 194 someone watches a political TV show solely for the activities' inherently need-satisfying properties. 
Figure 2. Updating of Domain-Related Mental Representations after Need-Supportive Experiences

\section{HOW POLITICAL BNCOUNTHRS FOSTHR INTRINSIC MOTIVATION}

\section{INITIAL. MOTIVATION \\ politics not \\ perceived as serving \\ need-fulfilling goals goals} need-fulfilling

\section{NHFD-}

SATISFYING FNGOUNTHR

with the political domain

reasons for pol. engagement
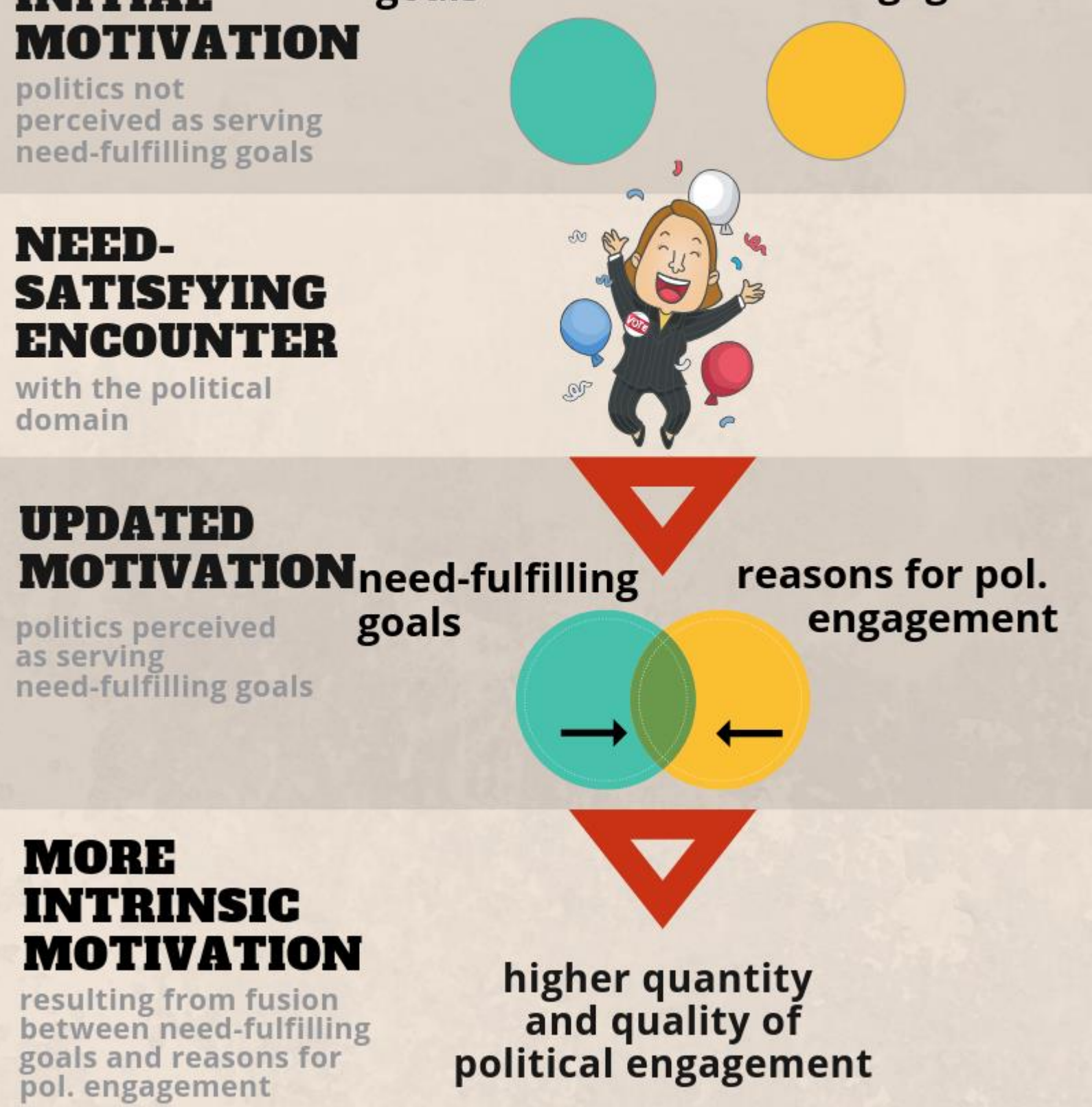
198 Understanding the link between need satisfaction and intrinsic motivation paves the way not only to

199 explain whether but also how behavior is enacted. According to the law of low effort, when facing

200 otherwise identical behavioral choices, individuals usually opt for the more effortless route (Kurzban,

201 2016). However, as intrinsic motivation is characterized by the fusion between an activity and its end,

202 the logic of effort minimization does not apply to intrinsically motivated individuals. Instead of min-

203 imizing the invested effort, individuals embrace the activity they enact for its inherently satisfying

204 conditions. This is consistent with political science evidence that curiosity towards politics goes along

205 with more effortful processing and deeper understanding of political affairs (Prior, 2019). Conse-

206 quently, intrinsic motivation does not only go along with a strong inclination to enact a behavior but

207 enacting a behavior for its own sake entails doing it effortfully and attentively rather than superfi208 cially.

209 The present study

210 Procedures

2II The need-based theory of political motivation is tested in a survey-experiment in which participants'

212 motivation to engage with politics is assessed in varying situational contexts that provide higher or

213 lower degrees of need satisfaction. In the experiment, political engagement refers to the consumption

2I4 of political media, more specifically to an online video that respondents watch during survey partici-

215 pation. Quantity refers to the participants' choice of watching political media content over seemingly

216 non-political alternatives. Quality refers to the level of cognitive involvement when processing polit-

217 ical media content.

218 The experiment consists of a two-arm design (see Supplement 1 for a consort diagram), in

219 which those two basic psychological needs are manipulated that studies have identified as crucial for

220 fostering intrinsic motivation (Ryan and Deci, 2017): 1) the need for autonomy which seeks self- 
22I endorsed and volitional action and which is thwarted in the face of external coercion, 2) the need for

222 competence which seeks the experience of effectance and mastery and which is thwarted in the face

223 of pervasive overload.

224 At the beginning of the survey, respondents participated in a political knowledge quiz with 225 manipulated difficulty and manipulated competence feedback (need for competence manipulation).

226 Following the knowledge quiz, participants had the chance to watch a video during the survey, re227 ceiving four media options to choose from (two political, two seemingly apolitical). Each video option

228 is described verbally, containing ostensibly different media content (e.g., political option: "Political

229 Video on Social Policy"; seemingly apolitical option: "YouTube-Video: Funny Old Man”). Im-

230 portantly, despite the four options, all individuals watched the identical video because the different

23I choice descriptors merely refer to different facets of the media content (a comedian delivering a 30-

232 seconds stand-up set on a political topic). Therefore, indicators measured after media consumption

233 are not influenced by differences in video content but only by differences in how the content was

234 individually processed, depending on the experimentally manipulated need-related situational char-

235 acteristics. The questionnaire page to choose the media content also contained the need for autonomy

236 manipulation which frames the respondents' choice as either volitional or externally enforced. After

237 choosing and watching the video, the outcome variables were measured and the respondents were 238 debriefed.

239

240 Experimental Conditions

24 Need for competence manipulation. Participants in the need-for-competence-supportive (thwart-

242 ing) condition were induced to feel efficacious (inefficacious) with regards to the political domain,

243 thereby facilitating (undermining) situational satisfaction of the need for competence (Milyavskaya 
244 et al., 2018a). Following previous work (Bishop, 1987; Bowey et al., 2015; Preece, 2016; Schwarz and

245 Schuman, 1997), a politics quiz and competence feedback was used to induce domain-related need-

246 satisfaction of competence. Specifically, participants in the need-for-competence-supportive (thwart-

247 ing) condition received easier (more difficult) questions. In addition, they were given manipulated

248 feedback of domain-related knowledge that is allegedly far above (below) average.

249 Need for autonomy manipulation. When offering the choice between media options, participants 250 assigned to the control group received no further information other than the instruction to choose one

25 I video. Following previous work (Kadous and Zhou, 2019), on the preceding questionnaire page, par-

252 ticipants in the need-for-autonomy-supportive condition were prompted to explain the importance of

253 political awareness, which should raise the salience of self-endorsed reasons for political media con-

254 sumption and thus facilitate volitional choices of political media content. Following previous work

255 (Grant and Berry, 2011; Patall et al., 2008), participants in the no-choice condition read that they were

256 assigned to a group of respondents that is not allowed to freely choose from all videos but must watch

257 a political video to receive the monetary incentive for survey participation.

258

259 Hypotheses

260 Importantly, all respondents watch the identical political video and receive identical descriptions on

$26 \mathrm{I}$ the media content. Therefore, on the surface, the value of watching the political video should not

262 differ across experimental conditions. From a rational choice perspective with narrow rationality

263 (Hamlin and Jennings, 2011; Marx and Tiefensee, 2015; Opp, 2015), one might expect that partici-

264 pants will make identical media choices independent of experimental conditions and will process the

265 video in the same way. One might even expect higher motivation to watch and process political con-

266 tent in need-thwarting conditions as individuals who are induced to perceive themselves as having 
267 below-average political knowledge should derive higher marginal utilities from information acquisi-

268 tion. In contrast, the need-based theory of political motivation predicts that political encounters in

269 need-supportive contexts will stimulate a person's intrinsic motivation to re-engage with politics,

270 thereby promoting whether and with how much effort they will engage with politics in the future.

27I Both the competence and autonomy manipulations are predicted to influence respondents'

272 need-related expectations and beliefs about whether politics serves need-fulfilling goals, which will

273 then materialize as individual differences in intrinsic motivation to choose and effortfully process the

274 political media content. Hence, depending on the previous need-related experiences with politics,

275 participants in each experimental condition will experience the video differently, albeit watching

276 identical content. Specifically, the competence-manipulation can be understood as changing prior

277 need-related experiences with politics. The autonomy-manipulation can be understood as changing

278 need-related perceptions of the current situation in which the political activity unfolds. Both experi-

279 mental arms have in common that respondents in the respective need-satisfying conditions will per-

280 ceive the political media content as more in line with need-fulfilling goals than respondents in the

28I need-thwarting conditions. As a consequence, by manipulating previous domain-related experiences

282 or current situational perceptions, both manipulations change the perceived intrinsically of the polit-

283 ical activity under observation.

284 H1: Need-supportive situational contexts increase intrinsic political motivation.

285

286 Because need-supportive experiences shape beliefs and expectations, need-supportive experiences

287 shape whether a future activity is anticipated to serve need-fulfilling goals. Reflecting this self-con-

288 firmatory tendency, individuals who previously experienced their encounters with politics as need- 
289 satisfying are more likely to seek encounters with politics than individuals with previous need-

290 thwarting experiences.

29I H2a: Individuals who previously experienced the political domain as satisfying their need for com-

292 petence, want to engage with politics more frequently than individuals with need-thwarting domain293 related experiences.

295 Similarly, we also expect a positive effect of the autonomy-supportive priming on the frequency of 296 political engagement compared to the control group.

297 H2b: Individuals in an autonomy-supportive context want to engage with politics more frequently 298 than individuals in neutral situational contexts.

299

300 Resembling most everyday situations of political media consumption, no information of immediate 30I relevance is conveyed the experiment's video. As the personal stakes are not very high, outcome302 oriented considerations presumably do not carry much weight in the inclination to invest cognitive 303 efforts into watching the experiment's political video (Green and Shapiro, 1994). In contrast, the de-

304 gree of intrinsicallity of the behavior is likely to matter because individuals who experience the activ305 ity as aligned with need-fulfilling goals will engage in the activity for its own sake, therefore bypassing 306 the human inclination for effort minimization.

307 H3a: Individuals who previously experienced the political domain as satisfying their need for com308 petence, are more inclined to effortfully process the political information conveyed in the video than 309 individuals with need-thwarting domain-related experiences. 
3II H3b: Individuals in autonomy-supportive contexts are more inclined to effortfully process the politi-

312 cal information conveyed in the video than individuals in neutral situational contexts.

313 The no-choice condition plays a unique role as the manipulation serves to test the relevance of dis-

3I4 tinguishing quantity and quality of motivation. Here, we expect that coercion into political engage-

3I5 ment will be effective in increasing the frequency of political engagement among respondents. Yet,

316 compared to the control group who received no autonomy-thwarting message, individuals in the no-

317 choice experimental group are expected to invest fewer efforts into the political activity they feel co-

318 erced into. In other words, need-thwarting motivational stimuli may increase the quantity of political

319 engagement but at the cost of undermining its quality.

320 H4: Forcing individuals into political engagement will increase the frequency of political engagement

32I but will decrease the level of cognitive involvement.

322

323 Methods

324 Ethics Statement

325 This study was approved by the Ethics Board of the University of Mannheim. Participants were pro-

326 vided informed consent and were be debriefed at the conclusion of the study (see Supplement 2 for 327 study materials).

328 Measures

329 Dependent variables.

330 To strengthen the robustness of the statistical tests, this study complements self-reported measures

33I of the outcome variable with cognitive and behavioral measures to assess the motivational processes

332 that underlie the participant's choice for or against political engagement during the survey (see S2). 
333 While these measures tap into different mental representations and cognitive processes, we expect

334 effects of similar strength across all types of measurement.

335

336 Intrinsic Motivation. To assess intrinsic motivation, one behavioral and one self-reported measure is

337 used. Four items, adopted from the Intrinsic Motivation Inventory (Sample item: "I enjoyed watching

338 this video very much"), were be aggregated into an unweighted summary index. Following the free-

339 choice paradigm (Cerasoli et al., 2014), the behavioral measurement queries whether respondents

340 voluntarily want to watch another similar video after the survey is concluded.

34I Quantity of Political Engagement. Measured as the respondent's choice to watch either a video with

342 political content or a video seemingly without any political content.

343 Quality of Political Engagement. Quality of political engagement will be assessed with a subjective

344 measure, an objective measure, and a behavioral measure. The subjective measure is the unweighted

345 summary index of two items assessing respondents' perception of the invested efforts while watching

346 the video (sample item: "I watched the video very attentively"). As objective measurement on the qual-

347 ity of cognitive processing, we assess whether respondents correctly answer three open-answered

348 questions about the elaborations on social policy in the video. The open-ended responses were clas-

349 sified based on a detailed codebook (see Supplement 3) by a coder who was unaware of the respond-

350 ents' treatment conditions. The resulting outcome measure is an additive index gauging the number

$35 \mathrm{I}$ of correct responses a respondent has provided. As behavioral measurement, whether respondents

352 have prematurely skipped the video is used (time on questionnaire page). 
Pre-Print

354

355

356

357

358

359

360

36I Power Analysis

362 Pre-registered power analyses suggest that with a total sample size of $\mathrm{N}=1,500$, effects can be detected

363 at power at or greater than .95 even when effects size are considerably smaller than suggested by

364 previous studies. Detailed information is reported in Supplement 4.

Manipulation Checks

Competence treatment. Unweighted summary index of two items measuring internal political efficacy

(sample item: "It is often difficult for me to understand political issues in detail").

Autonomy treatment. On the no-choice treatment, one item assesses whether respondents felt pressured to watch the video. On the autonomy-supportive treatment, one item assesses whether respondents feel they can recall many reasons for engaging with politics.

365

\section{Pre-registered analysis plan}

367 To estimate treatment effects, linear regression analyses with robust standard errors and one-sided

368 hypothesis tests were conducted. To reduce variance of the dependent variables and thus to increase

369 the efficiency of the effect estimates (Lin, 2013), the following pre-treatment covariates are included

370 in all analysis models along with multiplicative terms with the treatment indicator: Pre-treatment

37I levels of self-reported political motivation, device type, device operating system, rank of political

372 knowledge within the experimental group. In case of missing values on any covariate, sample means

373 (continuous variables)/modes (categorical variables) were be used for imputation. As linear regres-

374 sions are also applicable to estimate experimental treatment effects for binary outcome variables and

375 as their results are easier to interpret than coefficients from logistic regressions (Gomila, 2019), linear

376 regressions were be conducted for all outcome variables. 
Because multiple measurement instruments were employed to assess the concepts of interest

378 and because multiple hypotheses will be tested, in total 16 statistical tests are conducted. Supplement

3795 documents which indicators and statistical tests are employed for testing each hypothesis. Whereas

380 the expected positive effect of the no-choice conditions on the quantity political engagement does not

38I refer to a need-related stimulus, all remaining 15 tests can be understood as testing the tenet that

382 need-related experiences predict whether and how a person will engage with politics.

383 The survey questionnaire and the stimulus were programmed using the software UniPark

384 (files attached as Supplementary Material). Based on simulated responses on the survey question-

385 naire, an analysis pipelines was pre-preregistered (see Supplement 6). The analysis pipeline contains

386 all data processing steps and pre-specifies the data analysis, thereby largely eliminating researchers'

387 degree of freedom (Wuttke, 2019b), see https://osf.io/24xyq. Deviations from the pre-registered anal-

388 ysis pipeline that became necessary after data collection due to errors in the original scripts are doc-

389 umented in the analysis scripts.

390

391 Participants

392 The target population is the German online population who is entitled to vote. Participants were be

393 drawn from the Respondi Panel, which is a heterogenous online access panel with about 70.000 active

394 participants who were recruited offline and online. Socio-demographic quotas (age, education, gen-

395 der) were used to recruit a sample of 1,500 respondents that resembles the target population on the 396 sociodemographic criteria. 


\section{Exclusion Criteria}

399 All respondents with completed interviews were included except straightliners who, on all matrix

400 batteries, select all responses from the same row. The survey included an attention check that filter

40I out respondents who did not select the instructed response option in one of the survey questions.

402

\section{Results}

404 To examine whether need-supportive or need-thwarting experiences with politics affect whether and 405 how citizens engage with politics, we separately examine treatment effects on the various outcome 406 variables. Starting with intrinsic motivation, Figure 3 shows how experimentally induced satisfaction 407 of the needs for competence and autonomy affects self-reported and behavioral measures of intrinsic 408 motivation for political engagement. Based on linear regression models, Figure 3 shows predicted 409 mean differences between the need-supportive and need-thwarting treatment groups in each experi4I0 mental arm. Against expectations, no statistically significant differences between the treatment con4II ditions emerge. The consistent lack of treatment effects across conditions and outcome measures on 412 intrinsic motivation refutes hypotheses 1 , according to which need-supportive situational contexts 413 would increase intrinsic political motivation. Apparently, whether individuals recently had a positive 4I4 experience with the political domain had no ramifications on the intrinsic motivation for subsequent 415 encounters with politics. Because increased intrinsic motivation was anticipated to function as the 416 psychological precursor to hypothesized downstream effects on the quality and quantity of engage417 ment, these null effects may thus foreshadow absent effect of need-satisfaction also on the remaining 418 outcome variables. 
419 Figure 3. Need-related treatment effects on intrinsic motivation

420

421

422

423

424

425

426

427

428

429

430

431

432

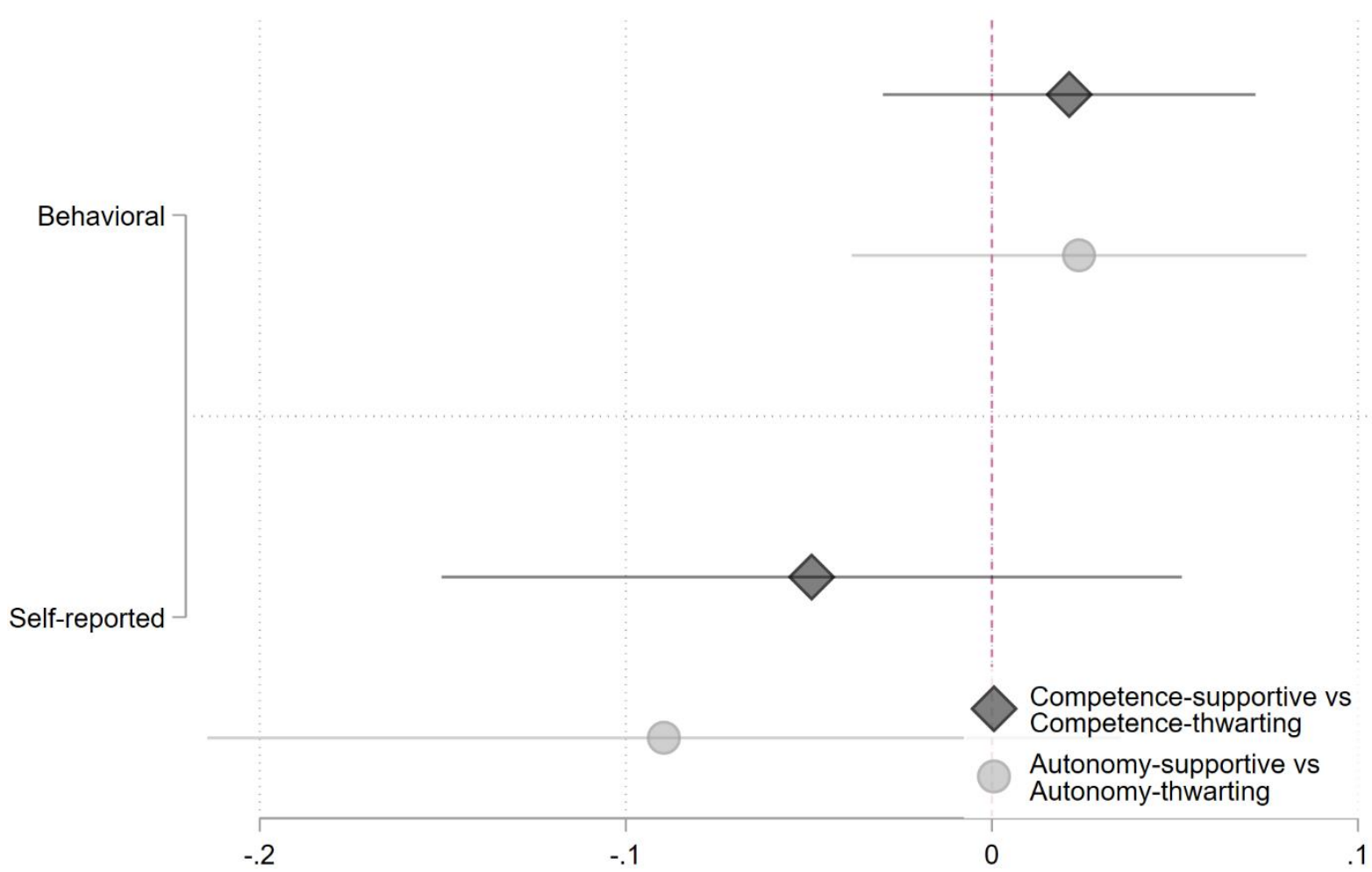

Note: Predicted mean differences from linear regression analyses. Behavioral measure: dummy variable; self-reported measure: z-score standardized.

Figure 4 shows whether previous domain-related need satisfaction affected the quantity of political engagement, that is the decision for or against watching a video with political content. Whether respondents were induced to receive political knowledge feedback that did or did not satisfy their need for competence apparently made no discernible difference in their inclination to choose political over non-political media content. Similarly, the confidence interval of the autonomy-supportive treatment effect's estimate also includes zero. However, for the autonomy-supportive treatment, a one-tailed significance test yields a statically significant difference with the control group ( $\mathrm{p}=.041) .53 .9$ [49.6$58.2,95 \% \mathrm{CI}]$ percent of respondents in the autonomy-supportive condition who were prompted to 
433 rehears intrinsic reasons for political engagement chose the political media option. In comparison, a

434 slightly lower share of respondents (47.0 [39.6-58.2] percent) chose the political options when further 435 instructions were given. These mean differences correspond to cohen's $d=.14$; a small effect size by 436 conventional standards which corresponds to having to treat 24 individuals in order to stipulate one 437 additional person in the autonomy-supportive condition to choose a political video compared to the 438 control group (Gruijters and Peters, 2017). There is thus partial evidence for behavior-eliciting effects 439 of the autonomy-supportive stimulus, but these effects are not robust and smaller than expected. In 440 combination with the expected but absent effect of the competence-related manipulation, overall, 44I these results thus do not yield consistent evidence for the notion that individuals with previous need442 supportive experiences with politics are more likely to seek political encounters than individuals who 443 experienced politics as undermining their basic psychological needs. 
447 Figure 4. Need-related treatment effects on quantity of political engagement

448

Video_Choice -

Competence-supportive vs

Competence-thwarting

Autonomy-supportive vs

Control

Autonomy-thwarting

vs Control

451

452 Effect sizes are considerably larger and clearly distinguishable from zero for the third treatment con-

453 dition, in which respondents were told that other media options existed but which they were not

454 allowed to choose for reasons outside their control. Respondents in the forced-choice (need-thwart-

455 ing) condition chose a political video much more frequently than the control group (70.2\% [66.2-74.3,

$45695 \% \mathrm{CI}]$ vs. $47.0 \%[42.7-51.2], \mathrm{p}<=0.0001)$. That the experimental stimulus thus often elicited the

457 intended behavioral response may not surprise, and this test does not serve as a test of the need-based

458 model of political motivation. Our main interest in the effects of the autonomy-thwarting condition

459 was on potential downstream consequences concerning how a behavior is conducted when it is 
460 enacted against the person's authentic will. Figure 5 reports on these down-stream effects on the 46I quality of behavior.

462 Figure 5 shows effects on the depth of respondents' engagement with the video using three

463 different outcome measures. Eight out of night experimental tests do not show the expected effects of 464 need-related experiences with politics on the quality of a person's engagement with politics. No sta-

465 tistically significant effects emerge on self-reported levels of effortful engagement (subjective meas466 ure). Similarly, there is no evidence that prior need-related experiences with politics had any discern467 able consequences for whether respondents skipped the political video or watching it at full length 468 (behavioral), again suggesting that need-related experiences had no ramifications for how the video 469 was processed cognitively. The exception from the array of null effects is that respondents in the com470 petence-supportive condition could more accurately recall political arguments from the video com47I pared to respondents who were induced to feel politically incompetent. Out of three knowledge ques472 tions, respondents in the need-thwarting condition accurately respond to $2.1[1.9-2.3,95 \% \mathrm{CI}]$ ques473 tions about the video compared to $2.2[1.9-2.3]$ in the need-supportive condition $(\mathrm{p}<0.0001$, one474 sided). This corresponds to an effect size of cohen's $d=0.17$ which indicates a small treatment effect. 475 The rather small effect size is also apparent when considering that differences of this size imply that 476 the distribution of the number of correct responses overlaps for 93 percent of respondents in both 477 treatment conditions. Another way to get a grasp of the effect size is to consider that there is a $55 \%$ 478 chance that a person picked at random from the treatment group will have a higher score than a 479 person picked at random from the control group; hence, only slightly larger than chance. Notwith480 standing this one significant, small effect, the bigger picture emerging from these findings does not 48I provide much evidence for the hypothesis that previous need-supportive experiences with politics 482 foster the inclination for deeper cognitive involvement when processing political information. 
483

484 Figure 5. Need-related treatment effects on quality of political engagement

485

486

487

488

489

490

491

492

493

494

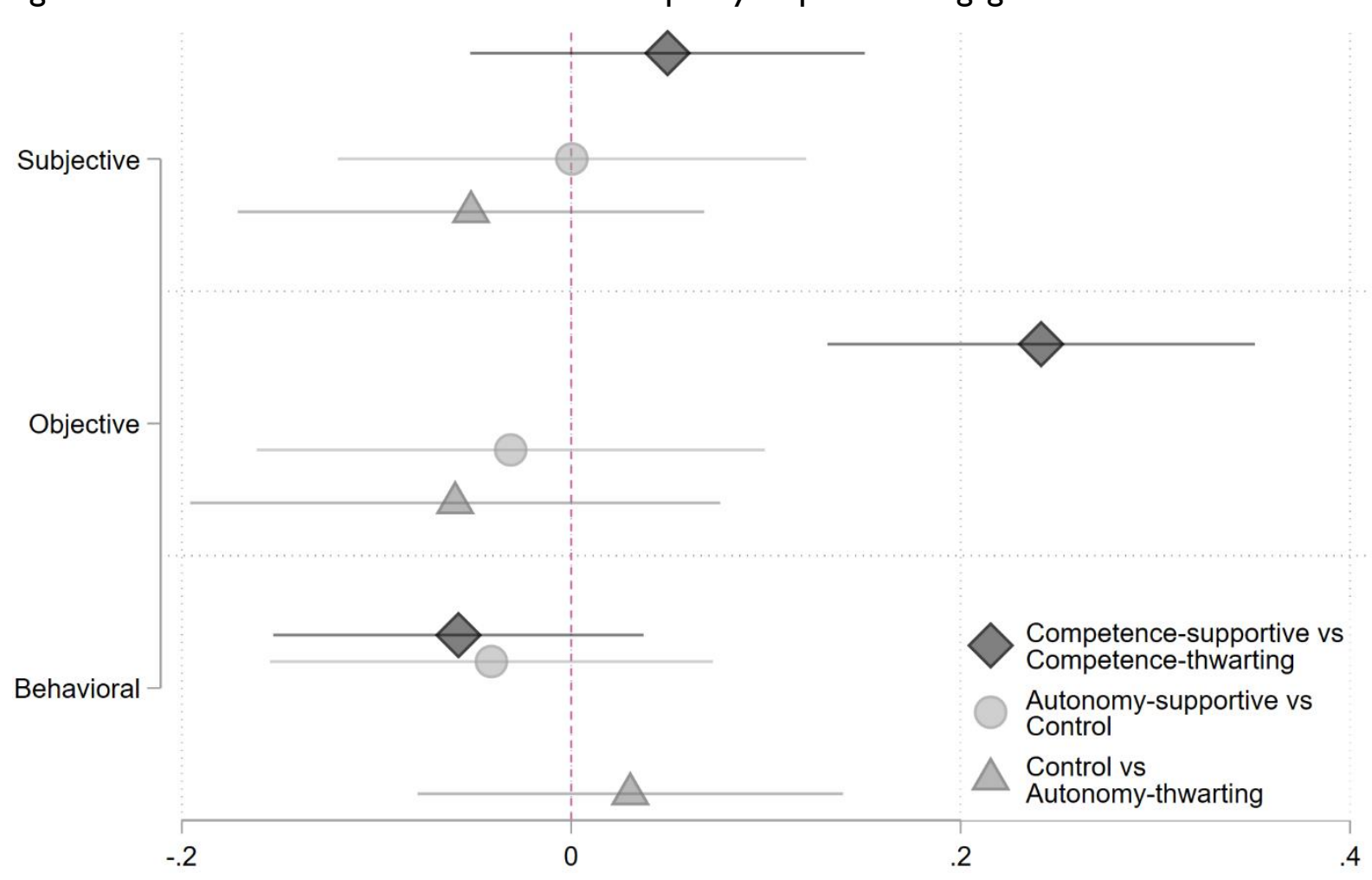

Note: Predicted mean differences from linear regression analyses. Scale of subjective measure: I-5, objective measure: $\mathbf{0 - 3}$, behavioral measure: $\mathbf{z}$-score standardized.

What are we to make out of the two significant findings against the broader pattern of null results? Above, multiple tests were reported on the same hypothesis based on the reasoning to thereby assess the robustness of the experimental findings to different variants of measurement and treatment inductions. For an overall assessment of the evidence base, it is thus the question whether these two test successes should be considered meaningful signals or statistical flukes that result from the multiplicity of tests. With the pre-registered alpha of $0.05,{ }^{1}$ the probability of incorrectly rejecting one null

\footnotetext{
${ }^{1}$ In total, 16 statistical tests were conducted but we exclude the significant no-choice effect on behavioral frequency here because this test does not concern the main theoretical argument.
} 
495 hypotheses with 15 tests is $1-(1-0.05)^{15}=53.7 \%$. Hence, without accounting for multiple com-

496 parisons it is more likely than not to observe a statistically significant effect estimate even when all

497 hypothesized effects are truely absent. When employing the conservative Holm-Bonferroni strategy

498 to adjust for multiple comparisons, the previously significant p-value of autonomy-supportive treat-

499 ment on video choice increases to $\mathrm{p}=.57$. Yet, the effect of competence-supportive treatment on the

500 objective measure of behavioral quality remains highly significant at $\mathrm{p}=.0 .0001$. Altogether, in 14 out

50I of 15 decisive tests the null hypothesis of no effects of need-related treatments on political motivation

502 could not be refuted. Only one test yields findings that are in line with the proposed theory. What

503 does this large array of null results imply for the credibility of the proposed theory?

504 Interestingly, post-hoc analyses show strong correlations between intrinsic motivation and

505 the quantity and quality of engagement (e.g., Pearsons R of self-reported intrinsic motivation and

506 subjective quality of engagement=.67), suggesting that intrinsic motivation indeed elicits the ex-

507 pected downstream effect on whether and how political behavior is conducted. Yet, the theory's cen-

508 tral tenet that need-satisfying previous encounters stimulated intrinsic political motivation and the

509 respective behavioral outcomes received little empirical support. Considering that only one small,

510 theory-congruent effect was found while one test after the other failed to provide the hypothesized

5II evidence for the need-based model of political motivation, the most straightforward conclusion is to

512 consider the derived theory as refuted. However, as no empirical test can prove a hypothesis true, no

513 pattern of null results necessarily commands the refutation of an hypotheses as long as explanations

5I4 other than the absence of real effect can also explain our failure to observe such effects in the experi-

5 I5 ment. In the remainder, I therefore systematically test measurement problems, design deficiencies,

516 lack of statistical power and treatment heterogeneity as potential sources of type II errors. The more

517 certain we can be that none of these issues prematurely lead us to reject the theorized hypotheses 
518 although they are true, the more confident we can be that, indeed, the presented null findings warrant

519 the conclusion that the proposed theory does not adequately describe how intrinsic motivation comes

520 about.

521 Measurement considerations concern the notion that the experiment might have elicited real

522 theory-consistent effects, yet the measurement instruments we to capture these effects, rendering the

523 experiment unhelpful in disentangling whether the hypothesized effects exist or not.

524 One plausible scenario is that treatment effects were present, and even so consequential that

525 they caused some individuals to prematurely terminate the survey before the outcome variable was

526 measured. As these attrition biases are well-documented in the field-experimental literature (Gerber

527 and Green, 2012), the pre-registration plan contained the presumption that the no-choice condition

528 might lead some participants to cancel survey participation. However, there is no evidence for differ-

529 ences in survey completion between respondents in the no-choice or the control group ( $\mathrm{p}=.91)$. Yet,

530 differences in survey completion become apparent when comparing both need-for-competence ma-

53I nipulations $(\mathrm{p}<.00001)$. Among respondents who received encouraging feedback 92.7\% [91.0-95.0,

$53295 \% \mathrm{CI}$ ] completed the survey. When respondents were told that their political knowledge is far be-

533 low-average, only $85.1 \%$ [82.6-87.6] made it to the end of the survey. To the extent that attrition is

534 correlated with the respondent's potential outcomes, the excludability assumption is violated, and the

535 experimental estimates are biased (Gerber and Green, 2012). Potentially, the treatment could have

536 driven those respondents to terminate the survey early, who would also have been most susceptible

537 to treatment effects on substantive outcome variables. Whereas attrition may thus have biased treat-

538 ment estimates, it is unlikely that these survey dropouts explain most of the null effects because the

539 difference in attrition rates by competence conditions is so low. Therefore, average treatment effect

540 would remain insignificant or small even if we impute extreme treatment effects on the outcome 
54I variables instead of missing values, as can be shown with simulation analysis. For instance, simulat-

542 ing that all respondents in the need-thwarting conditions with outcome missing values would have

543 decided against watching political content $(\mathrm{N}=37)$, the competence manipulation would have yielded

544 a small, barely significant effect on engagement frequency (cohen's $d=0.06$, imputed p-value $=.04$;

545 original $\mathrm{p}$-value $=.26$; both one-sided). The effect on the behavioral measure of intrinsic motivation

546 remains just above the significance threshold after replacing all missing values of the concerned re-

547 spondents in the need-thwarting condition with low motivation scores of 0 (imputed p-value=.06 ;

548 original $\mathrm{p}$-value $=.21$ ). Value imputation on continuous outcome variables shows that in extreme sce-

549 narios treatment-induced attrition could have hidden highly significant treatment effects, but these

550 scenarios with extreme value imputation are unlikely and the effect sizes would remain small (see

55I Supplement 7 for analysis on continuous variables). Altogether, there is the possibility that attrition

552 bias may have caused false negatives as systematic survey dropout out could have rendered some

553 truly statistically significant treatment effects as non-significant but attrition bias seems unlikely to

554 have overshadowed substantive treatment effects with meaningful effect sizes.

555 A second measurement problem that might overshadow true treatment effects is unreliable

556 measures of the relevant outcomes. Although the study relied on established and validated measure-

557 ment approaches to assess intrinsic motivation (self-reported intrinsic motivation: Ryan et al., 1991,

558 behavioral intrinsic motivation: Ryan and Deci, 2017), it is possible that these measures were less

559 reliable in the present survey context. Low reliability rates would be problematic because they add

560 noise to the observed values which impair the capacity to find traces of treatment effects in the out-

56I come measures. Specifically, multi-item measures could suffer from low internal consistency but

562 analyses show high reliability scores of the self-reported intrinsic motivation measures (Omega total:

$563.87[.85, .88]$, Cronbach's alpha: .86 [.85, .87], see McNeish, 2018). The objective measure of behavioral 
564 quality is particularly vulnerable to reliability problems as it required manual coding of the partici-

565 pants' open-ended responses. To assess coding reliability, 270 randomly selected responses were clas-

566 sified by a second coder. A comparison of both coders' classification yields very high reliability rates

567 (agreement rates for each response item: 93\%, 93\%, 98\%; kappa: 0.86, 0.86, 0.96). Altogether, these

568 results foster our confidence that low reliability of the outcome measures appears not to a major prob-

569 lem for capturing potential treatment effects. Up to now, therefore, the analysis demonstrated the

570 possibility that measurement issues may have slightly biased the experimental findings in one way or

57I another but major flaws were neither detected concerning neither survey attrition nor instrument

572 reliability.

573 All preceding analyses focused on average treatment effects, yet it is conceivable that treat-

574 ment effects materialized only in some subgroups. At the extreme, the experiment could have yielded

575 opposite effects depending on a background variable which offset each other when analyzing the

576 sample as a whole. For instance, the susceptibility to situational influences on political motivation

577 might depend on a person's dispositional motivational propensities. To examine potential treatment

578 heterogeneity depending on these and other potential moderators, one option is running a vast num-

579 ber of regression analyses with various model specifications that account for the numerous possible

580 interacting influences of the variables of interest. However, such approach runs into various problems

58I of overfitting, statistical power, computational problems and exacerbates the problem of multiple

582 comparisons mentioned above (van Klaveren et al., 2019). Data-driven strategies make more efficient

583 use of the data and are thus better suited for this kind of exploratory analysis. Therefore, I employ a

584 machine learning technique -causal forests (Athey et al., 2019; Wager and Athey, 2018)- that was

585 specifically developed for the purpose of discovering treatment heterogeneity in experimental set-

586 tings. As an ensemble model, causal forests consist of decision trees that partition the data on relevant 
587 covariates by their ability to explain heterogeneity in a quantity of interest such as the treatment ef-

588 fect. Like other random forests model, causal forest split the data into training and test datasets. In

589 addition, the causal forest model entails another split of the training dataset called the honesty ap-

590 proach that enables the calculation of asymptotically normal estimates and thus to report $95 \%$ confi-

59I dence intervals. Due to the sample splits, causal forests thus work best with larger sample sizes, yet it

592 is the best available option to explore potential treatment effects also in medium-sized samples as it

593 does not overfit the data and yields interpretable and reliable estimates.

594 To implement causal forest models, I assigned $60 \%$ of respondents to a training data set with

595 twelve attitudinal variables (four dimensions of political motivation, seven indicators of citizenship

596 norms, political knowledge) three socio-demographic variables (age, sex, education) and two tech-

597 nical para variables (device type, operating system), all of which were measured before a treatment

598 was administered. The learned model is then administered on the test dataset to predict heterogene-

599 ous treatment effects on unused data (for more information on model specification, see Supplement

600 8; I follow the implementations by Reimer and Chelton, 2019; White, 2018).

60I To demonstrate how the methods reveals treatment heterogeneity, I first examine treatment

602 effects of the no-choice condition on the frequency of political engagement in the experiment. Figure 6036 shows the relative importance of each variable to explain variation in treatment effects. Political

604 motivation variables are among the variables with most explanatory power, a finding that replicates 605 on other outcome variables. 
607 Figure 6. Relative variable importance for treatment heterogeneity

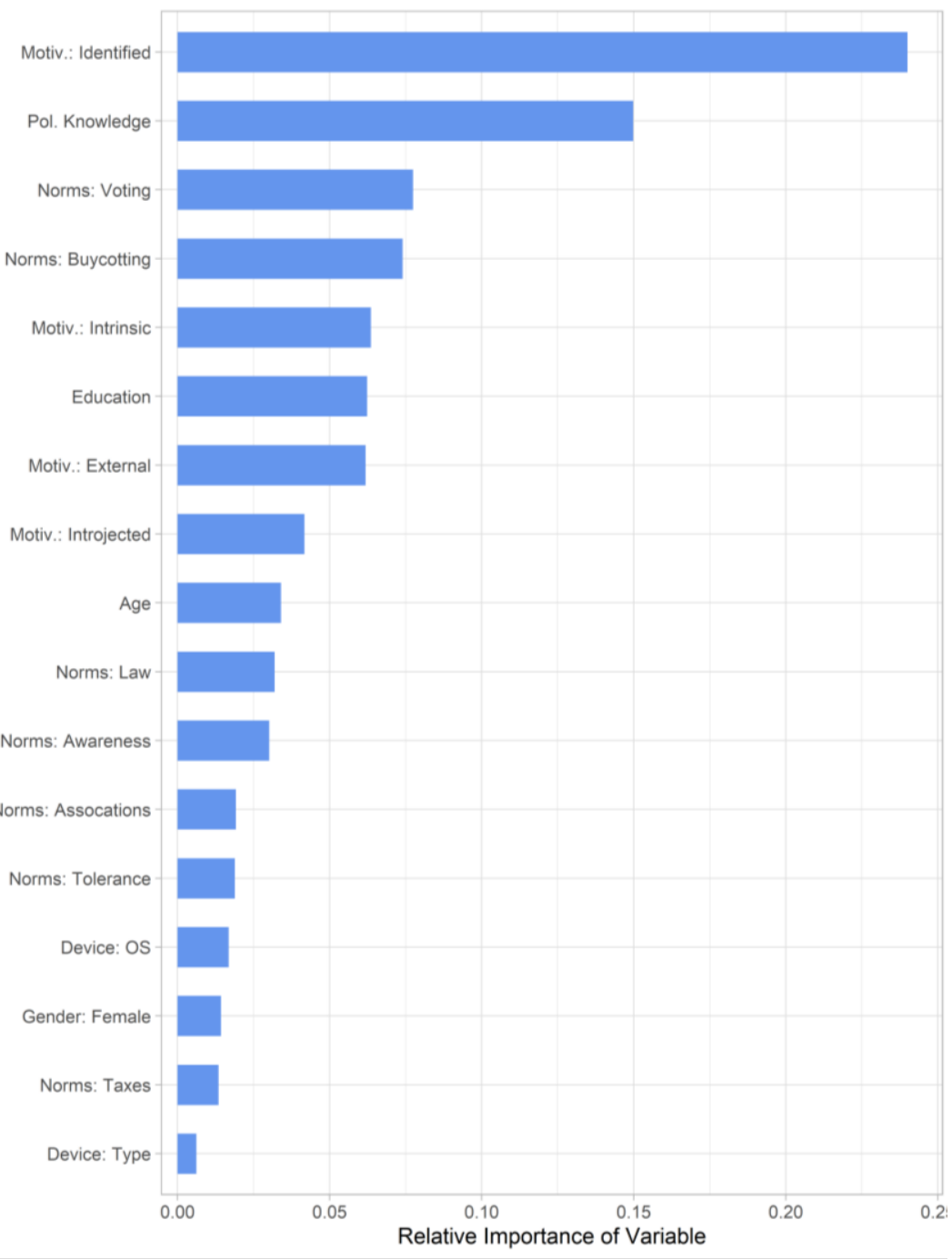

608

609

610 However, Figure 6 does not inform about the magnitude of treatment heterogeneity, and it is thus

6II unclear whether the heterogeneity is substantively meaningful. When conducting an omnibus test

6I2 on the presence of treatment heterogeneity, an omnibus test fails to reject the null hypothesis of no

613 treatment heterogeneity $(\mathrm{p}=.80)$. The lack of significant heterogeneity becomes also apparent in 
6I4 Figure 6 which displays the substantive magnitude of subgroup differences $4{ }^{2}$ For the strongest pre-

615 dictor of treatment heterogeneity, Figure 6 shows how predicted treatment effects differ at selected

616 values of identified political motivation, indicating no substantial heterogeneity. Meaningful hetero-

617 geneity cannot be detected for other outcome variables either (see Supplement 8). ${ }^{3}$ Altogether, there-

618 fore, even an exploratory method to recover any potential treatment heterogeneity that makes effi-

619 cient use of the available data reveals no evidence of meaningful treatment effects that were hidden

620 in the data. Therefore, treatment heterogeneity seems not to have overshadowed true effects,

62I strengthening the confidence that the experiment simply did not elicit theory-consistent effects.

622

623

624 Figure 7. Heterogeneous treatment effects by identified political motivation

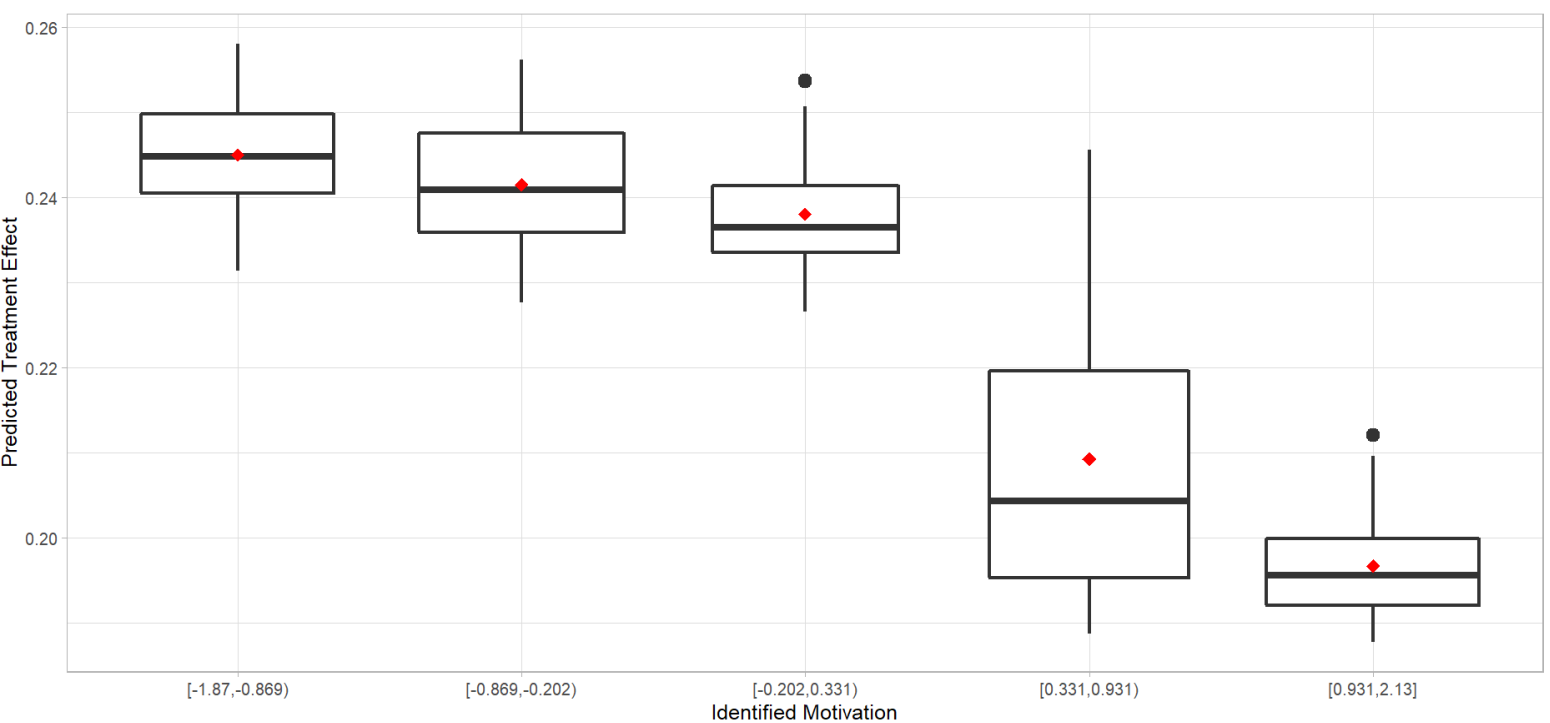

Note: Predicted treatment effects for five equally sized subgroups by pre-treatment levels of identified political motivation, using grf package for $\mathbf{R}$

628

\footnotetext{
${ }^{2}$ The omnibus test also fails to reject the null hypothesis of no treatment heterogeneity when only motivational variables are included as model features which has more power to detect potential heterogeneity on these variables.

${ }^{3}$ Causal forests were run only on the competence manipulation for which heterogeneous effects were most likely because neither autonomy-related treatment led succeeded in the subsequent manipulation checks.
} 
629 A final test is conducted to assess whether the reported null results warrants to refute the formulated 630 hypothesis or whether an alternative theory-consistent explanation could account for the null effects.

63I In particular, the previous analyses have established that the null hypothesis of no effect cannot be 632 rejected, yet the possibility remains that the expected effects did occur but were too small to detect 633 statistically. By calculating whether an estimate achieves a practically meaningful effect size, equiva-

634 lence tests allow distinguishing whether a null effect is either inconclusive or too small to make a 635 substantial difference (Lakens et al., 2018). Even though it is impossible to prove the absence of an 636 effect, we can establish whether an effect is practically absent and thus statistically equivalent with 637 zero.

638 Determining whether a null effect is either inconclusive or practically insignificant requires 639 specifying the smallest effect size of interest for a given test. Consider the effect on the behavioral 640 measure of intrinsic motivation, that is whether respondents chose to watch yet another political 64I video after the survey questionnaire is completed. We might categorize treatment effects as negligible 642 when the shares of respondents choosing to watch another political video do not differ by 10 percent643 age points or more between experimental conditions. Figure 7 shows the results of an equivalence 644 test of the need for competence manipulation on the behavioral measure of intrinsic motivation, us645 ing the 10-percentage point threshold. The graph shows that the reported estimate is consistent with 646 a true population estimate that is 0 or around 0 and we can be confident to rule out that the effect is 647 large enough to consider it substantively meaningful. Put differently, the effect is statistically equiva648 lent to zero. As documented in Supplement 9, we reach the same conclusion of statistical equivalence 649 for all conducted tests using reasonable thresholds. Therefore, even though some theory-consistent 650 effects might have occurred we can thus confidently reject that the need-related treatment elicited 65I practically meaningful effects on the relevant outcome measures. 
Pre-Print

652

653 
654 Figure 8. Testing the equivalence of intrinsic motivation (behavioral measure) in both treatment 655 groups, SESOI=10\%p.

656

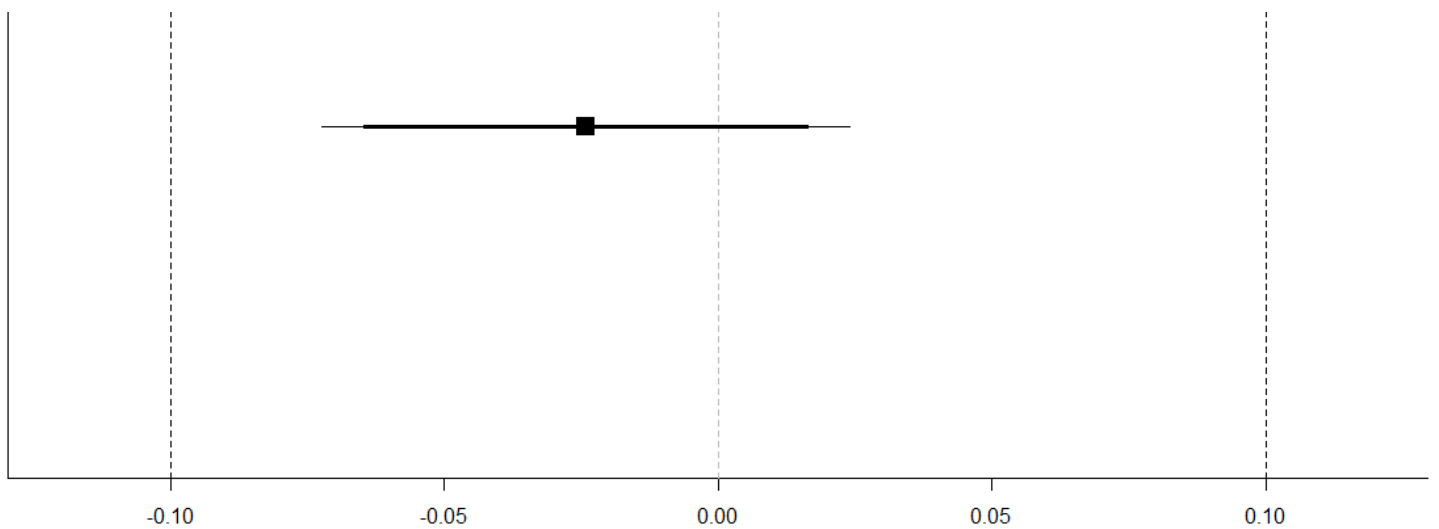

657

Proportion Difference

What does the absence of meaningful theory-consistent effects imply for the proposed need-

662 based model of political motivation? The informational value of the presented findings for judging

663 the tested theory depends on the experiment's internal and external validity. In this study, each ex-

664 perimental condition was intended to induce a certain psychological state among respondents which

665 then was expected to elicit motivational downstream effects in line with the theory. Internal validity

666 is thus impaired when the stimuli failed to elicit the intended psychological state. In the following, I

667 therefore test for each experimental condition whether these requirements for an informative hy668 pothesis test were met.

669 The autonomy-supportive condition was intended to remind respondents of good reasons to 670 engage with politics and thus more closely align political engagement with the respondents' sense of 67I selves so that a decision for political engagement seems concordant with the respondents' need for 672 autonomy (similar: Kadous and Zhou, 2019). However, the manipulation check indicates that the 673 experimental manipulation did not succeed in making respondents more aware of reasons for 
674 political engagement. ${ }^{4}$ Respondents in the autonomy-supportive condition did not report at higher

675 rates that they could name many reasons for why politics is enjoyable compared to the control group

$676(t(1443)=0.74, p=.46)$. The failed manipulation check thus casts doubt that the autonomy-support-

677 ive manipulation worked as intended. ${ }^{5}$ Importantly, if the priming paradigm was ineffective in stim-

678 ulating autonomous reasons for political engagement, then the insignificant test result cannot be con-

679 sidered informative tests on the hypotheses under investigation because one would not have expected

680 the hypotheses to hold if respondents do not differ by treatment conditions in how autonomous they

68I experience their own behavior.

682 The autonomy-thwarting manipulation was intended to make respondents feel that political 683 engagement is not a matter of choice but required even against their will so that the enforced political

684 engagement is experienced as undermining respondents' need for autonomy. However, the evidence

685 suggests that this manipulation did not have the intended effect either. First, even though respond-

686 ents in the autonomy-thwarting conditions were 2.3 times more likely to choose a political video than

687 other respondents, 29.7 percent of respondents still resisted the instructions and chose a nonpolitical

688 video. Apparently, a substantial segment of the respondents did not consider the survey instructions

689 binding. Second, respondents in the autonomy-thwarting conditions did not report more often that

690 they felt under pressure to watch the video compared to the control condition $(t(1441)=-0.09, p=$

691 .93). To conclude, the experimental manipulation apparently failed to elicit the perception of auton692 omy-undermining pressure.

\footnotetext{
${ }^{4}$ Note that this survey item contained a wording mistake which impaired the item's intelligibility and may thus have introduced unintended measurement error.

${ }^{5}$ The implemented priming manipulation was selected due to its demonstrated efficacy in previous motivation studies (Kadous and Zhou, 2019). However, recent meta-scientific research shows that many priming studies exhibit low replicability rates (e.g., Cesario, 2014), suggesting that the effectiveness of such manipulations is more precarious and contextdependent than suggested in previous literature.
} 
694 isfaction, it is thus little wonder that no downstream effect on political engagement occurred. With

695 the available data, we cannot know whether an effect would be haven observed if the treatment suc-

696 ceeded in manipulating situational need satisfaction. Hence, whether satisfaction of the need for au-

697 tonomy affects politics motivations remains unanswered and the autonomy-related experiments thus

698 do not qualify as informative tests of the hypotheses under observation.

699 Things stand differently for the competence manipulation. As intended, the difficulty of the

700 knowledge quiz varied between treatment conditions. Respondents in the need-for-competence sup-

70I portive conditions accurately responded more frequently to questions in the easier knowledge quiz

702 than respondents in the need-thwarting condition with more difficult questions $(\mathrm{t}(1626)=9.84, \mathrm{p}<$

$703.00001)$. More importantly-after having received the manipulated quiz feedback-respondents in the

704 need-supportive condition reported higher levels of internal political efficacy $(\mathrm{t}(1558)=3.03, \mathrm{p}=$

705 .0025). So, respondents were successfully induced to feel more or less competent with regard to the

706 political domain and thus the experiment succeeded in manipulating the theorized need-based pre-

707 cursor to political engagement. On average, respondents in both need-for-competence conditions

708 thus solely differ in whether they recently experienced the political domain as either satisfying or

709 undermining their need for competence so that the expected downstream effects on political engage-

7I0 ment should have occured. Hence, the experiment's competence-related manipulation meets the con-

7II dition of an informational theory test as the experimentally induced differences between respondents

7I2 in need satisfaction have not led to the motivational and behavioral outcomes that were predicted by

7I3 the need-based model of political motivation.

$7 \mid 4$

715 
Pre-Print

\section{Discussion}

717 To understand why some people experience political engagement as inherently satisfying while oth-

718 ers find it boring or burdensome, this study has laid out a theoretical framework for understanding

719 the motivational processes that underlie political engagement as its own reward. This synthesis of

720 existing motivation theories enhances the conceptual political science toolkit, sheds new light on pre-

721 vious findings and contributes novel ideas for the explanation of a poorly understood political phe-

722 nomenon, based on insights that have proven useful in other domains of life. Starting from the pleas-

723 ure principle's notion that individuals will re-engage with activities they have previously experienced

724 as positive and rewarding, the proposed theory builds on the concept of basic psychological needs to

725 predict which situational features people find satisfying. The need-based theory of political motiva-

726 tion thus posits that citizens will be intrinsically motivated to engage with politics when they previ-

727 ously experienced political activities as satisfying basic psychological needs. Whether and how citi-

728 zens engage with the political domain is thus argued to reflect desires and experiences that are deeply

729 ingrained in the human psyche.

730 The theory's prediction was put to an empirical test in a preregistered, high-powered survey-

73I experiment with two experimental arms that were intended to manipulate the satisfaction of a rele-

732 vant basic need. Yet, the autonomy-related conditions apparently failed to induce need-thwarting or

733 need-satisfying experiences. Therefore, the requirements for an informational hypothesis test are not

734 met in this experimental arm and it remains unclear whether previous autonomy-related experiences

735 with politics affect subsequent political behavior. However, considering that the experimental design

736 was carefully crafted and built on previous literature with similar manipulations, the failed induction

737 attempts still teach about the difficulty to deliberately induce need-related psychological states. As

738 argued in the manuscript, the effect of an objectively given situation on a person's need satisfaction 
739 depends on the perception and experience of the respective situation. Hence, if need satisfaction is

740 difficult to manipulate systematically even in a controlled survey-experimental environment, then

74I need satisfaction may be considered even less predictable in the real world, suggesting that need-

742 based theories and applications of it may be more precarious and context-dependent than previous

743 literature suggests.

744 Nonetheless, the need-for-competence manipulation does represent an informative test of the 745 theory, casting further doubt on the usefulness of basic needs to explain political motivation. In five

746 out of six analytical tests, the need manipulation did not bring about the expected motivational or

747 behavioral outcomes. Notably, the negative findings hold across different measurement strategies and

748 after conducting extensive exploratory analysis to minimize the likelihood of false-negative conclu-

749 sions. While it remains possible that treatment-induced attrition may have hidden small treatment

750 effects, overall the exploratory analyses suggest that treatment heterogeneity, measurement reliability

75I and statistical power are not likely to have caused type II errors, thus strengthening the confidence

752 that the expected effects of the need-related manipulation simply did not reliably materialize. Alto-

753 gether, the available data thus suggests refuting the hypotheses that need-for-competence supportive

754 experiences will lead to higher levels of intrinsic motivation, which, in turn, will stimulate political

755 engagement among respondents. Similarly, there is only limited and less than expected evidence that

756 need-related experiences have ramifications for the quality by which political behavior is conducted.

757 What does the fact that most hypotheses were refuted when put to an empirical test empiri-

758 cally imply for the credibility of the need-based theory of political motivation? Naturally, a single

759 experiment can neither confirm nor refute a theory (Oreskes, 2019), but it may signal the need to

760 abandon or revise elements of it. Most clearly, the evidence indicates that the proposed theory does

76I not yield accurate prediction when applied to the need for competence which is particularly 
762 surprising when considering the previous literature on political efficacy (e.g., Bandura, 2010; Preece,

763 2016; Prior, 2019; Schwarz and Schuman, 1997), which rendered need for competence a likely candi-

764 date for theory-consistent effects on the political domain. Nonetheless, it remains possible that the

765 theory finds empirical support when adequately tested with other need candidates such as autonomy

766 or relatedness. However, another strategy for revision could entail to maintain the basic tenets of the

767 pleasure principle but to abandon need-based concepts and, instead, build on other concepts such as

768 core motives (Fiske, 2014) or insights from Gestalt psychology (Kruglanski et al., 2018) to explain the

769 conditions under which people perceive politics as pleasurable. Altogether, the demonstrated results

770 undermine confidence in the proposed need-based theory of political motivation, at least suggesting

77I a narrower scope than originally assumed.

772 One final aspect worth mentioning concerns the experiment's external validity. Survey- and

773 laboratory experiments often face the criticism that the psychological processes elicited in an artificial

774 environment might not resemble those in the real world, suggesting that effects might occur outside

775 but not within the lab. As a case in point, the failed autonomy manipulation indicates that many

776 respondents perceived the video and the following instructions as yet another survey task, suggesting

777 that respondents might not have perceived the situation as resembling real-world scenarios. Still, only

778 survey- and laboratory experiments allow the manipulation of distinct psychological states in a con-

779 trolled environment, rendering the inquiry and manipulating of such psychological processes in the

780 field even more difficult. Altogether, these difficulties shows why the study of political engagement

78I as an end in itself has still received relatively scant attention compared to the relevance of intrinsic

782 motivation for an active citizenry. In this vein, the theoretical discussions presented in this study and

783 the presented study design may help stimulate future research by demonstrating dead ends and fruit-

784 ful avenues for further research. Specifically, having shown what works and what does not work may 
785 help in revising thinking about intrinsic political motivation and thus in the accumulation of 786 knowledge about. political engagement for its own reward.

787

788

789 
790

791

792

793

794

795

796

797

798

799

800

801

802

803

804

805

806

807

808

809

810

811

812

813

814

815

816

817

818

819

820

821

\section{Acknowledgements}

I am grateful for assistance in preparing the manuscript by Marius Albrecht, for comments provided by the participants of the Political Psychology and the (Post-)Doctoral Colloquia Mannheim and ISPP Conference 2019 as well as for feedback by Jochen Gebauer, Chris Anderson, and Jeremy Freese.

\section{References}

\section{References}

Aczel B, Szaszi B, Sarafoglou A, et al. A consensus-based transparency checklist. Nature Human Behaviour: $1-3$.

Allen CPG and Mehler DMA (2018) Open Science challenges, benefits and tips in early career and beyond. Amabile TM (1985) Motivation and creativity: Effects of motivational orientation on creative writers. Journal of personality and social psychology 48(2): 393-399.

Athey S, Tibshirani J and Wager S (2019) Generalized random forests. The Annals of Statistics 47(2): 11481178.

Bandura A (2010) Self-efficacy: The exercise of control. New York: Freeman.

Bishop GF (1987) Context Effects on Self-Perceptions of Interest in Government and Public Affairs. In: Hippler H-J (ed.) Social information processing and survey methodology: Rev. versions of papers presented at an International Conference on Social Information Processing and Survey Methodology held in July, 1984 in Mannheim. New York: Springer, pp. 179-199.

Blais A and Daoust J-F (2020) The motivation to vote. Vancouver: UBC Press.

Bloom P (2011) How pleasure works: The new science of why we like what we like.

Blühdorn I (2019) The dialectic of democracy: modernization, emancipation and the great regression. Democratization: $1-19$.

Bougher LD (2017) Revisiting parental influence in individual political development: Democratic parenting in adolescence. Applied Developmental Science 111(1): 1-17.

Bowey JT, Birk MV and Mandryk RL (2015) Manipulating Leaderboards to Induce Player Experience. $A n$ nual Symposium on Computer-Human Interaction in Play: 115-120.

Burton KD, Lydon JE, D'Alessandro DU, et al. (2006) The differential effects of intrinsic and identified motivation on well-being and performance: prospective, experimental, and implicit approaches to self-determination theory. Journal of personality and social psychology 91(4): 750-762.

Camerer CF, Dreber A, Holzmeister F, et al. (2018) Evaluating the replicability of social science experiments in Nature and Science between 2010 and 2015. Nature Human Behaviour 2(9): 637. 
822

852

853

854

855

856

857
Cerasoli CP, Nicklin JM and Ford MT (2014) Intrinsic motivation and extrinsic incentives jointly predict performance: A 40-year meta-analysis. Psychological Bulletin 140(4): 980-1008 (accessed 19 September 2017). Cerasoli CP, Nicklin JM and Nassrelgrgawi AS (2016) Performance, incentives, and needs for autonomy, competence, and relatedness: A meta-analysis. Motivation and emotion 40(6): 781-813.

Chatzisarantis NLD, Hagger MS, Kamarova S, et al. (2012) When effects of the universal psychological need for autonomy on health behaviour extend to a large proportion of individuals: A field experiment. British Journal of Health Psychology 17(4): 785-797.

Chen B, Vansteenkiste M, Beyers W, et al. (2014) Basic psychological need satisfaction, need frustration, and need strength across four cultures. Motivation and emotion 39(2): 216-236.

Christakis NA (2019) Blueprint: The evolutionary origins of a good society. New York, NY: Little, Brown Spark. Deci EL, Eghrari H, Patrick BC, et al. (1994) Facilitating Internalization: The Self-Determination Theory Perspective. Journal of personality 62(1): 119-142.

Deci EL, Koestner R and Ryan RM (1999) A meta-analytic review of experiments examining the effects of extrinsic rewards on intrinsic motivation. Psychological Bulletin 125(6): 627-668.

Deci EL and Ryan RM (2000) The "What" and "Why" of Goal Pursuits: Human Needs and the Self-Determination of Behavior. Psychological Inquiry 11(4): 227-268.

Dweck CS (2017) From needs to goals and representations: Foundations for a unified theory of motivation, personality, and development. Psychological Review 124(6): 689-719.

Fiske ST (2014) Social beings: Core motives in social psychology. Hoboken, NJ: Wiley.

Freud S (1961) Beyond the pleasure principle. New York: W. W. Norton.

Galais C (2018) How to make dutiful citizens and influence turnout: The effects of family and school dynamics on the duty to vote. Canadian Journal of Political Science/Revue canadienne de science politique: 1-19.

Gerber AS and Green DP (2012) Field experiments: Design, analysis, and interpretation. New York: W. W. Norton.

Gillet N, Vallerand RJ, Lafrenière M-AK, et al. (2013) The mediating role of positive and negative affect in the situational motivation-performance relationship. Motivation and emotion 37(3): 465-479.

Gomila R (2019) Logistic or linear? Estimating causal effects of treatments on binary outcomes using regression analysis.

Grant AM and Berry JW (2011) The Necessity of Others is The Mother of Invention: Intrinsic and Prosocial Motivations, Perspective Taking, and Creativity. Academy of Management Journal 54(1): 73-96.

Green DP and Shapiro I (1994) Pathologies of rational choice theory: A critique of applications in political science. New Haven, London: Yale University Press.

Gruijters S and Peters G-J (2017) Gauging the impact of behavior change interventions: A tutorial on the Numbers Needed to Treat. PsyArXiv. Available at: https://psyarxiv.com/2bau7/download?format=pdf.

Hamlin A and Jennings C (2011) Expressive Political Behaviour: Foundations, Scope and Implications. British Journal of Political Science 41(03): 645-670. 
858

859

860

861

862

863

864

865

866

867

868

869

870

871

872

873

874

875

876

877

878

879

880

881

882

883

884

885

886

887

888

889

890

891

892

893

Higgins ET (2012) Beyond pleasure and pain: How motivation works. Oxford, New York: Oxford University Press.

Holbein JB (2017) Childhood skill development and adult political participation. American Political Science Review 111(03): 572-583.

Holbein JB, Schafer JP and Dickinson DL (2019) Insufficient sleep reduces voting and other prosocial behaviours. Nature Human Behaviour 38: 829.

Kadous K and Zhou Y (2019) How Does Intrinsic Motivation Improve Auditor Judgment in Complex Audit Tasks? Contemporary Accounting Research 36(1): 108-131.

Kruglanski AW, Fishbach A, Woolley K, et al. (2018) A structural model of intrinsic motivation: On the psychology of means-ends fusion. Psychological Review 125(2): 165-182.

Kurzban R (2016) The sense of effort. Current Opinion in Psychology 7: 67-70.

Kurzban R, Duckworth A, Kable JW, et al. (2013) An opportunity cost model of subjective effort and task performance. Behavioral and Brain Sciences 36(6): 661-679.

Lakens D, Scheel AM and Isager PM (2018) Equivalence Testing for Psychological Research: A Tutorial. Advances in Methods and Practices in Psychological Science 1(2): 259-269.

Lasorsa DL (2003) Question-Order Effects in Surveys: The Case of Political Interest, News Attention, and Knowledge. Journalism \& Mass Communication Quarterly 80(3): 499-512.

Lasorsa DL (2009) Political Interest, Political Knowledge, and Evaluations of Political News Sources: Their Interplay in Producing Context Effects. Journalism \& Mass Communication Quarterly 86(3): 533-544.

Lin W (2013) Agnostic notes on regression adjustments to experimental data: Reexamining Freedman's critique. The Annals of Applied Statistics 7(1): 295-318 (accessed 28 February 2019).

Marx J and Tiefensee C (2015) Auf die Couch! Beziehungsprobleme zwischen Rational Choice und Politischer Psychologie. In: Faas T, Frank C and Schoen H (eds) Politische Psychologie: Nomos, pp. 511-532.

Maslow AH (1970) Motivation and personality. New York: Longman.

McNeish D (2018) Thanks coefficient alpha, we'll take it from here. Psychological methods 23(3): 412-433.

Mehr SA, Singh M, Knox D, et al. (2019) Universality and diversity in human song. Science (New York, N.Y.) 366(6468).

Milyavskaya M, Galla B, Inzlicht M, et al. (2018a) More Effort, Less Fatigue: How Interest Increases Effort and Reduces Mental Fatigue. PsyArXiv. Available at: https://psyarxiv.com/8npfx/.

Milyavskaya M, Inzlicht M, Johnson T, et al. (2018b) Reward sensitivity following boredom and cognitive effort: A high-powered neurophysiological investigation. Neuropsychologia.

Murayama K (2019) A reward-learning framework of autonomous knowledge acquisition: An integrated account of curiosity, interest, and intrinsic-extrinsic rewards.

Nelson SK, Della Porta MD, Jacobs Bao K, et al. (2015) 'It's up to you': Experimentally manipulated autonomy support for prosocial behavior improves well-being in two cultures over six weeks. The Journal of Positive Psychology 10(5): 463-476. 
894

895

896

897

898

899

900

901

902

903

904

905

906

907

908

909

910

911

912

913

914

915

916

917

918

919

920

921

922

923

924

925

926

927

928

929

930

Opp K-D (2015) Norms. In: Wright JD (ed.) International encyclopedia of the social \& behavioral sciences: Amsterdam: Elsevier, pp. 5-10.

Oreskes N (2019) Why trust science? Princeton, New Jersey: Princeton University Press.

Patall EA, Cooper H and Robinson JC (2008) The effects of choice on intrinsic motivation and related outcomes: A meta-analysis of research findings. Psychological Bulletin 134(2): 270-300.

Piaget J (1952) The origins of intelligence in children. New York: international universities press.

Preece JR (2016) Mind the Gender Gap: An Experiment on the Influence of Self-Efficacy on Political Interest. Politics \& Gender 12(1): 198-217.

Prior M (2019) Hooked: How political interest fuels our democracy. Cambridge: Cambridge University Press.

Reimer J and Chelton T (2019) Revisiting Social Pressure and Voter Turnout: Causal Inference with Supervised Learning Methods. Available at: https://humboldt-wi.github.io/blog/research/applied_predictive_modeling_19/social_pressure/(accessed 21 November 2019).

Ryan RM and Deci EL (2017) Self-determination theory: Basic psychological needs in motivation, development, and wellness. New York, NY: Guilford Publications Inc; The Guilford Press.

Ryan RM, Koestner R and Deci EL (1991) Ego-involved persistence: When free-choice behavior is not intrinsically motivated. Motiv Emot 15(3): 185-205.

Schwarz N and Schuman H (1997) Political Knowledge, Attribution and Inferred Interest in Politics: The Operation of Buffer. International Journal of Public Opinion Research 9(2): 191-195.

Shani D (2009) On the origins of political interest. Dissertation, Princeton University. Princeton.

Sheldon KM, Elliot AJ, Kim Y, et al. (2001) What is satisfying about satisfying events? Testing 10 candidate psychological needs. Journal of Personality and Social Psychology 80(2): 325-339 (accessed 17 December 2018).

Silvia PJ (2005) What is interesting? Exploring the appraisal structure of interest. Emotion (Washington, D.C.) 5(1): 89-102.

Skinner BF (1976) About behaviorism. New York, NY: Vintage Books.

Spray CM, John Wang CK, Biddle SJH, et al. (2006) Understanding motivation in sport: An experimental test of achievement goal and self determination theories. European Journal of Sport Science 6(1): 43-51.

van Klaveren D, Balan TA, Steyerberg EW, et al. (2019) Models with interactions overestimated heterogeneity of treatment effects and were prone to treatment mistargeting. Journal of clinical epidemiology 114: 72-83. Wager S and Athey S (2018) Estimation and Inference of Heterogeneous Treatment Effects using Random Forests. Journal of the American Statistical Association 113(523): 1228-1242.

White MH (2018) Explicitly Optimizing on Causal Effects via Causal Random Forest: A Practical Introduction And Tutorial. Available at: https://www.markhw.com/blog/causalforestintro (accessed 21 November 2019).

White RW (1959) Motivation reconsidered: The concept of competence. Psychological Review 66(5): 297. Wuttke A (2019a) Political engagement's non-political roots: examining the role of basic psychological needs in the political domain. Motivation and Emotion. 
93I Wuttke A (2019b) Why Too Many Political Science Findings Cannot Be Trusted and What We Can Do About 932 It: A Review of Meta-Scientific Research and a Call for Academic Reform. Politische Vierteljahresschrift $93360(1): 1-19$.

934

935 


\section{SI: Consort Diagram}

937 Figure 1 shows the experimental design. Moreover, it shows the targeted samples sizes in each exper-

938 imental arm and in each experimental group. For more information about sample size calculation,

939 see $S 4$ : Power analysis.

940

94I Figure SI-I Consort diagram showing the distribution of respondents across experimental groups

942
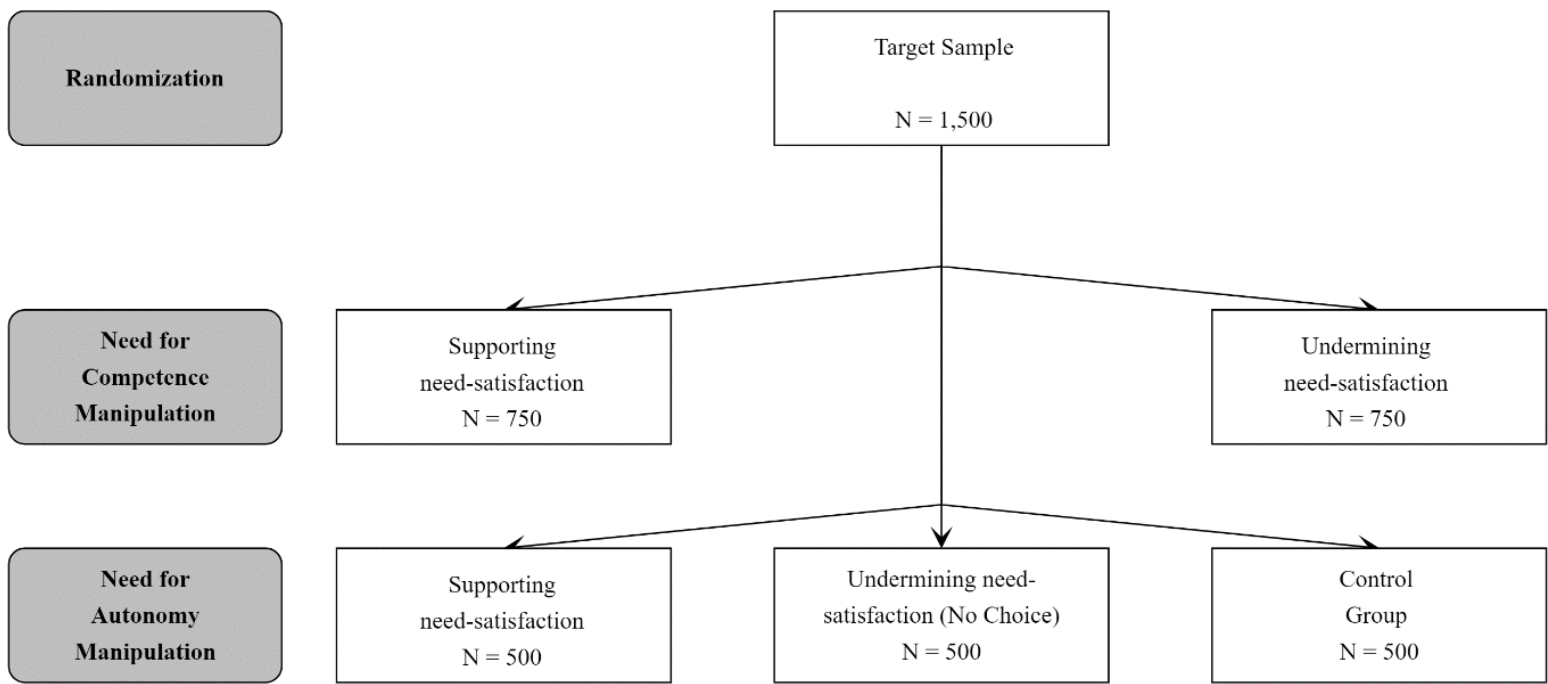
S2: Questionnaires

946 This supplement contains questionnaire. See Supplementary Material for further material, including

947 an Unipark project file that allows to re-run the survey using the Questback Survey Software.

948

949

950

951

952

953

954

955

956

957

958

959

960

961

962

963

964

965

966

967

968

969

970

971

\section{German Questionnaire}

\section{Themenk: Willkommen und Datenschutz Intro}

Vermutete Dauer: $\quad 20$ Sekunden [Konservativ, da es meist überlesen wird]

\section{Fragetext:}

\section{Wissenschaftliche Studie}

Die folgende Befragung ist Teil einer wissenschaftlichen Studie der Universität Mannheim zu Medien und politischem Verhalten in modernen Demokratien. Ihre Antworten sind Grundlage für unsere Forschung. Je sorgfältiger und aufmerksamer Sie teilnehmen, desto zuverlässiger werden die gewonnenen Forschungsergebnisse sein.

\section{Ton einschalten}

Im Zuge der Befragung haben Sie die Gelegenheit, ein Video zu sehen. Bitte sehen Sie es sich aufmerksam an. Schalten Sie daher jetzt bereits den Ton Ihres Computers an. Es ist wichtig, dass Sie das Video sehen und hören können.

\section{Datenschutz}

Im Zuge der technischen Abwicklung der Befragung (z.B. während des Beantwortens der Umfrage) aus technischen Gründen auch personenbezogene Daten (z.B. IP-Adresse) erhoben werden. Zudem wird im Zuge dieser Befragung ein YouTube Video eingeblendet. Sollten Sie dieses Video abspielen und den entsprechenden Datenschutzbestimmungen zustimmen, können auch hier personenbezogene Daten technischer Art (z.B. IP-Adresse) gespeichert werden. Die wissenschaftliche Auswertung Ihrer Antworten in dieser Befragung erfolgt ausschließlich anonym.

Weitere Informationen zum Studienzweck erhalten Sie nach Beendigung des Fragebogens.

\begin{tabular}{l} 
Themenk: Soziodemographie $\quad$ Item: Geschlecht \\
\hline Vermutete Dauer: 10 \\
Filter: \\
Varnames: \\
Sex
\end{tabular}

\section{Darstellung:}

must answer; Einfachauswahl untereinander; Plausitext, wenn keine Angabe: Bitte beachten Sie, dass eine Antwort für die Fortsetzung der Umfrage notwendig ist. Sollten Sie ihren Schulabschluss im Ausland erworben haben, geben Sie bitte einen entsprechenden deutschen Abschluss an.

\section{Ursprung:}

GLES

\section{Textintro:}

Geben Sie bitte Ihr Geschlecht an.

- männlich

- weiblich 
I0II

1012

1013

1014

1015

1016

Themenk: Soziodemographie

\section{Vermutete Dauer:}

Filter:

Varnames:

Age

\section{Darstellung:}

must answer; Einfachauswahl untereinander; Plausitext, wenn keine Angabe: Bitte beachten Sie, dass eine Antwort für die Fortsetzung der Umfrage notwendig ist. Sollten Sie ihren Schulabschluss im Ausland erworben haben, geben Sie bitte einen entsprechenden deutschen Abschluss an.

\section{Ursprung:}

GLES

\section{Textintro:}

Bitte geben Sie Ihr Alter in Jahren an.

$-18-29$

- 30-39

- 40-49

- 50-59

- 60 und älter

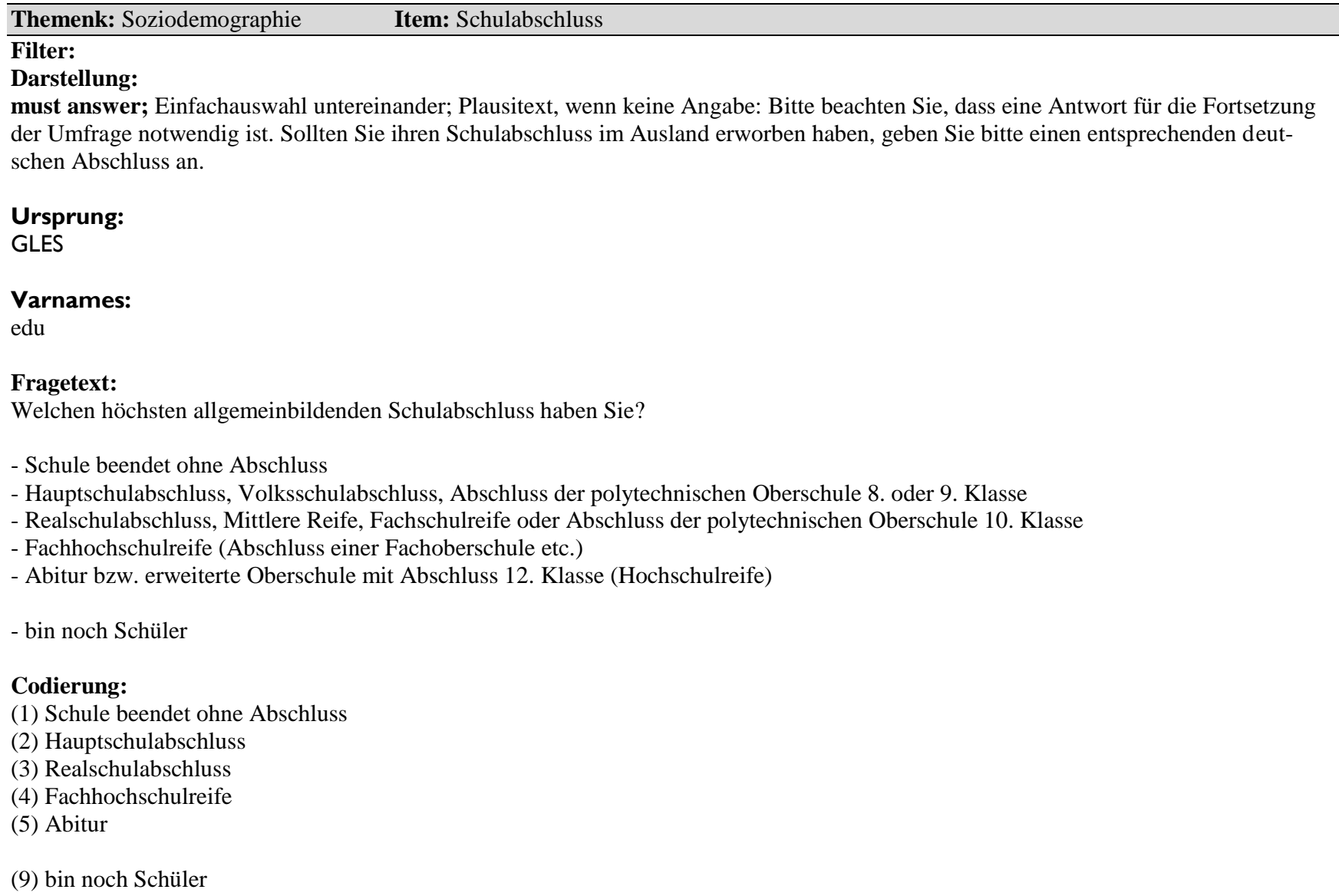


1062

1063

1064

1065

1066

1067

1068

1069

1070

I07|

1072

1073

1074

1075

1076

1077

1078

1079

1080

1081

1082

1083

1084

1085

1086

1087

1088

1089

1090

1091

1092

1093

1094

1095

1096

1097

1098

1099

1100

IIOI

1102

1103

1104

1105

1106

1107

1108

1109

1110

\section{$\rightarrow$ Check for Quota and Filtering}

Themenk: Erklärende Variable $\quad 30$ Sekunden
Vermutete Dauer:
Filter:
Varnames:
pre_mot_*
Darstellung:
Standard-Matrix
Textintro:
Menschen können sich auf unterschiedliche Weise politisch beteiligen oder sich mit Politik auseinandersetzen. Sie können zum Beispiel
über Politik diskutieren, in einer Bürgerinitiative mitarbeiten, politische Nachrichten hören, sehen oder lesen, an Demonstrationen teil-
nehmen.

Bitte geben Sie an, inwieweit die folgenden Aussagen auf Sie persönlich zutreffen oder nicht zutreffen.

\section{Fragetext:}

Wenn ich mich politisch beteilige oder mit Politik auseinandersetze, tue ich das, weil...

- $\quad$ ich es interessant finde zu verfolgen, was in der Politik passiert [intrinsisch, pre_mot_intrinsicl]

- $\quad$ ich mir selbst Druck mache, politisch auf dem Laufenden zu sein. [introjeziert, pre_mot_introjected I]

- $\quad$ andere Menschen mir sagen, dass ich es tun sollte.

[external, pre_mot_exernall]

- $\quad$ ich mich selbst als politischen Menschen begreife. [identifiziert, pre_mot_identified I]

- $\quad$ ich stolz bin, wenn ich etwas über Politik verstehe.

[introjeziert, pre_mot_introjected2]

- Politik für mich ein Herzensanliegen ist

[identifiziert, pre_mot_identified2]

- Um sicherzugehen, dass diese Befragung von einem Menschen ausgefüllt wird, klicken Sie hier bitte auf 'teils/teils'. [attentioncheck]

\section{Codierung:}

(I) trifft überhaupt nicht auf mich zu

(2) trifft eher nicht auf mich zu

(3) teils/teils

(4) trifft eher auf mich zu

(5) trifft voll und ganz auf mich zu

\section{$\rightarrow$ Screenout if attention check was failed}


III I

1112

1113

III4

III5

III6

1117

1118

1119

II 20

II 2 I

1122

1123

1124

1125

1126

1127

1128

1129

1130

II3

1132

1133

II34

1135

1136

II37

1138

1139

II40

$114 \mid$

1142

II 43

I 44

II 45

II 46

II47

II48

I 49

II50

II5I

II52

1153

II 54

II55

II56

1157

1158

1159

1160

II6I

1162

1163

1164

1165

1166

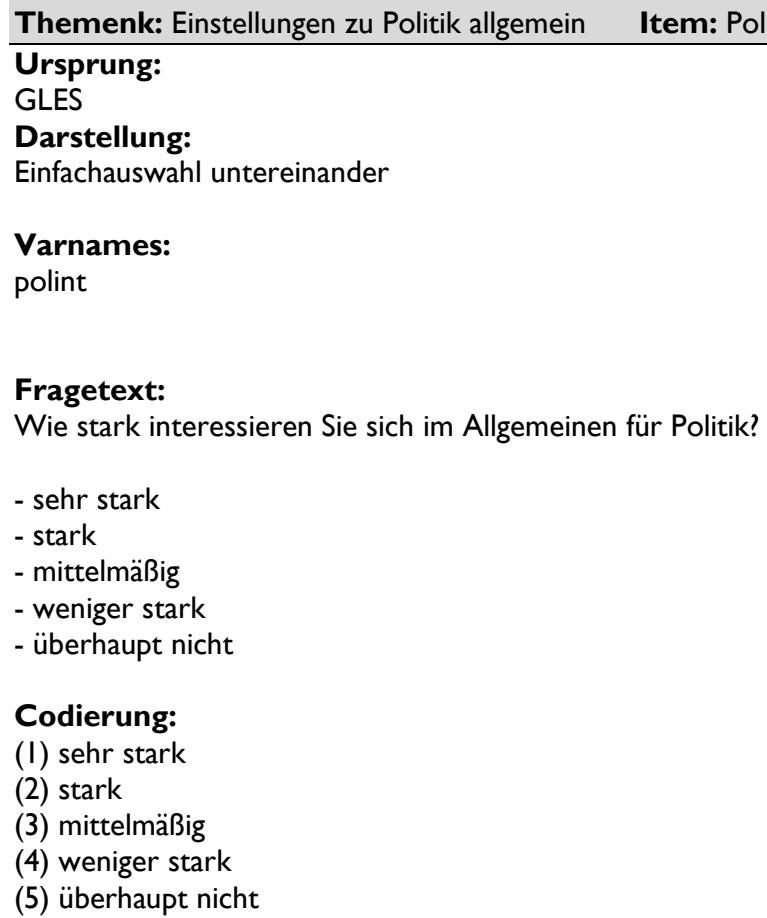

Wenn ich mich politisch beteilige oder mit Politik auseinandersetze, tue ich das, weil...

- $\quad$ es meinen Prinzipien entspricht, mich mit Politik auseinanderzusetzen.

[identifiziert, pre_mot_identified3]

- Menschen respektiert werden, wenn sie viel über Politik wissen.

[external, pre_mot_exernal2]

- $\quad$ ich Politik spannend finde. [intrinsisch, pre_mot_intrinsic2]

- $\quad$ ich so Kritik von Freunden und Verwandten vermeiden kann. [external, pre_mot_exernal3] 
1174

1175

1176

1177

1178

1179

1180

II8I

1182

1183

1184

1185

1186

1187

1188

1189

1190

II9|

1192

1193

1194

1195

1196

1197

1198

1199

1200

1201

1202

1203

1204

1205

1206

1207

1208

1209

1210

1211

1212

1213

1214

1215

1216

1217

1218

1219

1220

1221

1222

1223

- $\quad$ man Politik verfolgen sollte, selbst wenn man gerade keine Lust darauf hat.

[introjeziert, pre_mot_introjected3]

- $\quad$ es mir Freude bereitet, mich mit Politik auseinanderzusetzen.

[intrinsisch, pre_mot_intrinsic3]

\section{Codierung:}

(I) trifft überhaupt nicht auf mich zu

(2) trifft eher nicht auf mich zu

(3) teils/teils

(4) trifft eher auf mich zu

(5) trifft voll und ganz auf mich zu

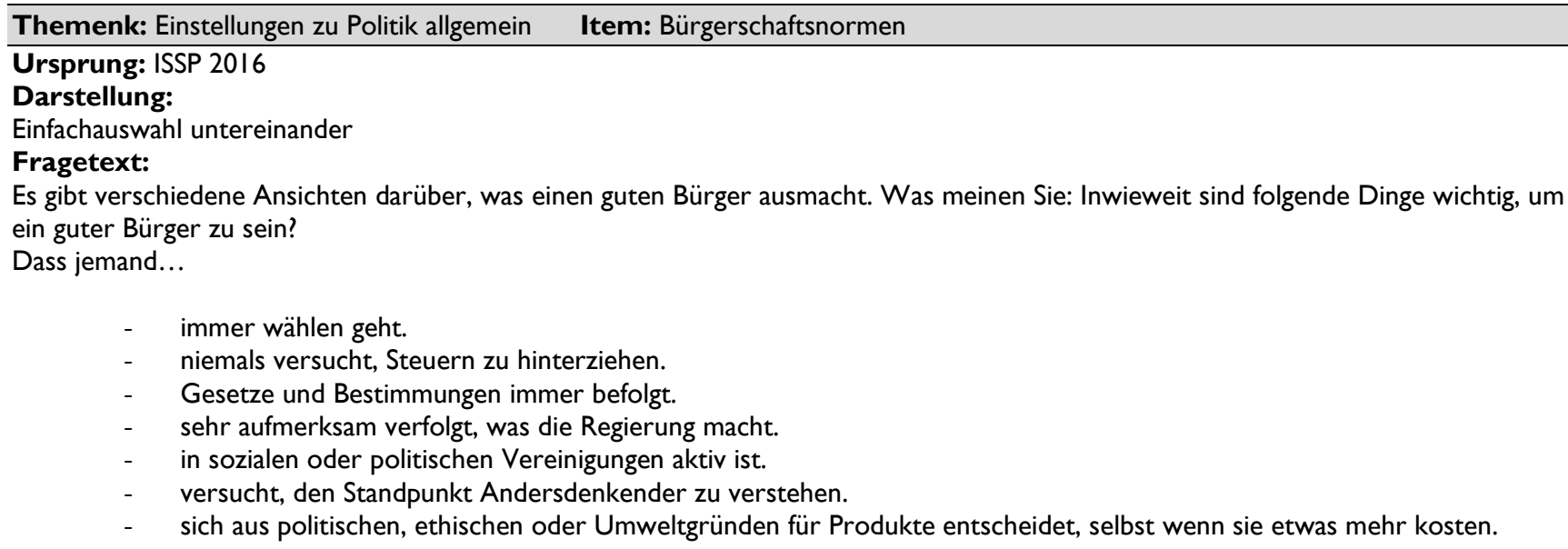


Fragetext:

Wenn ich mich politisch beteilige oder mit Politik auseinandersetze, tue ich das, weil...

- $\quad$ ich Politik oft aufregend finde.

[intrinsisch, pre_mot_intrinsic4]

- $\quad$ ich mich schämen würde, wenn ich über Politik nicht informiert bin.

[introjeziert, pre_mot_introjected4]

- Politik zu meiner Persönlichkeit gehört.

[identifiziert, pre_mot_identified4]

- $\quad$ Andere sonst auf mich herabblicken würden.

[external, pre_mot_exernal4]

- $\quad$ ich mir selbst beweisen will, dass ich mich auch mit Dingen wie Politik auseinandersetze.

[introjeziert, pre_mot_introjected5]

- $\quad$ mir Politik einfach wichtig ist.

[identifiziert, pre_mot_identified5]

- $\quad$ ich den Eindruck habe, dass es von mir erwartet wird.

[external, pre_mot_exernal5]

1241

1242

1243

1244

1245

1246

1247

1248

1249

1250

I25 |

1252

1253

1254

1255

1256

1257

1258

1259

1260

|26|

1262

1263

1264

1265

1266

1267

1268

1269

1270

I27|

1272

\section{Codierung:}

(I) trifft überhaupt nicht auf mich zu

(2) trifft eher nicht auf mich zu

(3) teils/teils

(4) trifft eher auf mich zu

(5) trifft voll und ganz auf mich zu

Themenk: Experiment Item: Political knowledge quiz I [need-supportive, Comp + ]

Vermutete Dauer: 30 Sekunden

Filter:

Respondents need-for-competence-supportive condition

Varnames:

comp_sup_quiz_politician

Darstellung:

\section{Textintro:}

\section{Fragetext:}

Wir möchten gerne wissen, ob Sie mehr oder weniger als andere Menschen über Politik wissen. Ein kurzes Quiz.

Bitte markieren Sie alle Politikerinnen und Politiker, die Mitglied der SPD sind.

Bilder in need-for-competence-supportive condition:

[Bekannte PolitikerInnen der SPD]

Themenk: Experiment $\quad$ Item: Political knowledge quiz I [need-supportive, Comp-]
Vermutete Dauer: 30 Sekunden
Filter:
Respondents need-for-competence-thwarting condition


Varnames:

comp_thwart_quiz_politician

\section{Darstellung:}

\section{Textintro:}

\section{Fragetext:}

Wir möchten gerne wissen, ob Sie mehr oder weniger als andere Menschen über Politik wissen. Ein kurzes Quiz. Bitte markieren Sie alle Politikerinnen und Politiker, die Mitglied der SPD sind.

Bilder in need-for-competence-thwarting condition:

[Weniger bekannte PolitikerInnen der SPD]

Themenk: Experiment Item: Political knowledge quiz 2 [need-supportive, Comp+]

Vermutete Dauer: 10 Sekunden

Filter:

Respondents need-for-competence-supportive condition

Varnames:

comp_sup_quiz_estimate

\section{Darstellung:}

Schieberegler

\section{Textintro:}

\section{Ursprung:}

GLES

\section{Ausfüllhinweis:}

Wenn Sie es nicht wissen, geben Sie Ihre beste Schätzung ab.

\section{Fragetext:}

Bei Wahlen zum Deutschen Bundestag gilt eine Prozenthürde, die Parteien überschreiten müssen um im Bundestag vertreten zu sein. Ab wie viel Prozent der Zweitstimmen kann eine Partei auf jeden Fall Abgeordnete in den Bundestag entsenden?

Vermutete Dauer: 10 Sekunden

Filter:

Respondents need-for-competence-thwarting condition

Varnames:

comp_thwart_quiz_estimate

Darstellung:

Schieberegler

0 bis 1000

Textintro:

\section{Ausfüllhinweis:}

Beziehen Sie sich auf die Anzahl der Mitglieder im gegenwärtigen 19. Deutschen Bundestag.

Fragetext:

Der Deutsche Bundestag ist ein wichtiges gesetzgebendes Gremium. 
Wie viele Abgeordnete entscheiden im gegenwärtigen Bundestag über unsere Gesetze? Wenn Sie die Anzahl der Bundestagsmitglieder nicht kennen, geben Sie Ihre beste Schätzung ab.

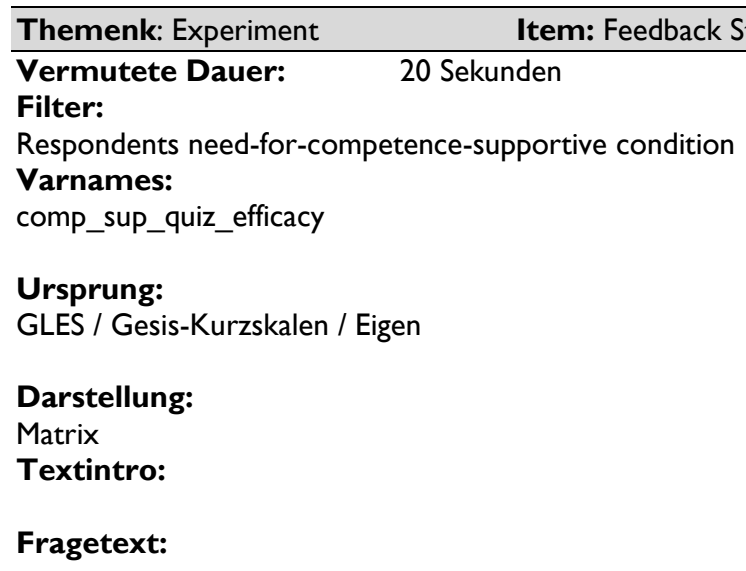

Ihr persönlliches Quizresultat: Überdurchschnittliches Wissen über Politik.

Unser Algorithmus hat Ihre Antworten mit den bisherigen Antworten anderer Teilnehmer verglichen. Herzlichen Glückwunsch! Offenbar kennen Sie sich mit Politik besser aus als andere Befragte. Toll.

In den bisher gesammelten Wissensquiz-Daten schneiden Sie besser ab als 72\% der bisherigen Befragten. Politik gehört offenbar zu lhren Stärken.

Soweit die Daten. Wir wollen aber wissen, was Sie selbst über sich denken!

Bitte geben Sie an, inwieweit folgende Aussagen auf Sie zutreffen.

- Wichtige politische Fragen kann ich gut verstehen und einschätzen.

[reverse, comp_sup_quiz_efficacyl]

- $\quad$ Über politische Angelegenheiten bin ich in der Regel umfassend informiert. [comp_sup_quiz_efficacy2]

\section{Codierung:}

(1) trifft überhaupt nicht auf mich zu

(2) trifft eher nicht auf mich zu

(3) teils/teils

(4) trifft eher auf mich zu

(5) trifft voll und ganz auf mich zu

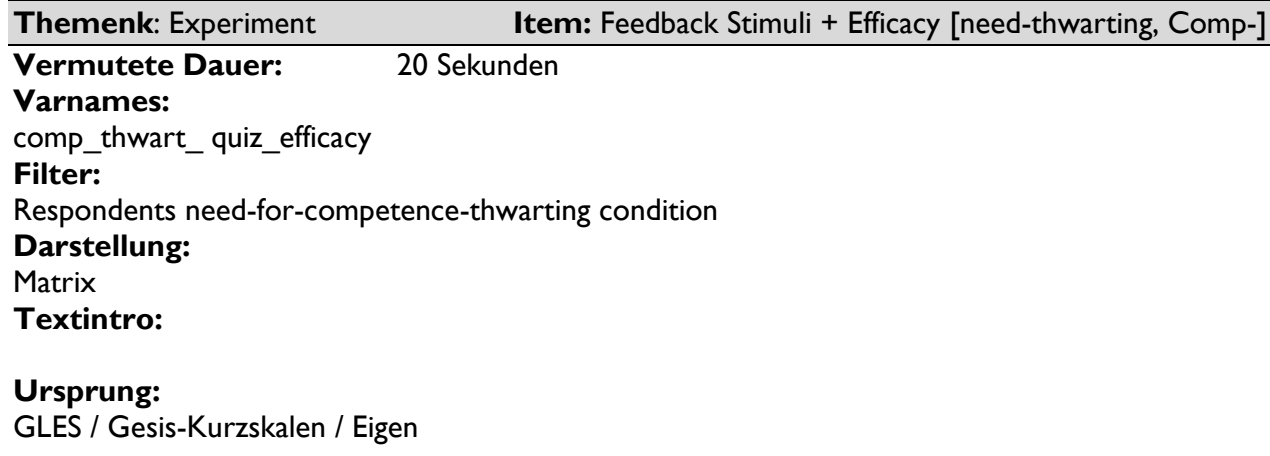


1394

1395

1396

1397

1398

1399

1400

| 40 |

1402

1403

1404

1405

1406

1407

1408

1409

1410

|4| |

1412

1413

1414

1415

1416

1417

1418

1419

1420

| 42 |

1422

1423

1424

1425

1426

1427

1428

1429

1430

143 |

1432

1433

1434

1435

1436

1437

1438

1439

1440

| 44 |

1442

1443

1444

1445

1446

1447

1448

1449

\section{Fragetext:}

Ihr persönliches Quizresultat: Unterdurchschnittliches Wissen über Politik.

Unser Algorithmus hat ihre Antworten mit den bisherigen Antworten anderer Teilnehmer verglichen. Leider hat sich dabei ergeben, dass Sie deutlich weniger über Politik wissen als andere Befragungsteilnehmer.

Mit Blick auf die bisher gesammelten Daten schneiden Sie im politischen Wissensquiz schlechter ab als $72 \%$ der bisherigen Befragten.

Politik gehört offenbar nicht zu Ihren Stärken.

Soweit die Daten. Wir wollen aber wissen, was Sie selbst über sich denken!

Bitte geben Sie an, inwieweit folgende Aussagen auf Sie zutreffen.

- Wichtige politische Fragen kann ich gut verstehen und einschätzen.

[comp_thwart_quiz_efficacyl]

- Über politische Angelegenheiten bin ich in der Regel umfassend informiert .

[comp_thwart_quiz_efficacy2]

Codierung:

(1) trifft überhaupt nicht auf mich zu

(2) trifft eher nicht auf mich zu

(3) teils/teils

(4) trifft eher auf mich zu

(5) trifft voll und ganz auf mich zu

Themenk: Experiment Item: IntrMot Stimulus [need-supportive, Aut+]

Vermutete Dauer: 30 Sekunden

Filter:

Varnames:

Darstellung:

Multiple Choice

Textintro:

Viele Menschen berichten, dass die Auseinandersetzung mit Politik mitunter Freude und Befriedigung bereitet. Hier sehen Sie einige Gründe, aus denen Menschen sich gerne mit Politik befassen.

Bitte überlegen Sie, ob auch Sie schon einmal Spaß oder Interesse an der Auseinandersetzung mit Politik hatten.

Markieren Sie alle Aussagen, denen Sie zustimmen können.

- $\quad$ Es bereitet Freude, über Politik zu lernen und zu verstehen, wie die Dinge zusammenhängen.

- Das Spektakel in der Politik zu verfolgen ist oft unterhaltsam, denn letztlich ist Politik wie ein großer Zirkus.

[aut_sup_agreel] [aut_sup_agree2]

- Politik ist interessant, weil von politischen Entscheidungen so viel abhängt.

[aut_sup_agree3]

Themenk: Experiment

Item: Stimulus + DV: Neigung zu politischem Medienkonsum

Vermutete Dauer: 20 Sekunden

Filter:

Varnames:

exp_aut_cont_sup_choice_video, exp_aut_thwart_choice_video

Darstellung:

Einfachauswahl untereinander

Textintro: 
1450

145 |

1452

1453

1454

1455

1456

1457

1458

1459

1460

| 46 |

1462

1463

1464

1465

1466

1467

1468

1469

1470

|47|

1472

1473

1474

1475

1476

1477

1478

1479

$\mid 480$

|48|

1482

1483

1484

1485

1486

1487

1488

1489

1490

|49]

1492

1493

1494

1495

1496

1497

1498

1499

1500

$150 \mid$

1502

1503

1504

1505

1506

\section{Fragetext:}

Zufallsauwahl eines Frames: [Kontrollgruppe / Treatmentgruppe I / Treatmentgruppe 2 / Treatmengruppe 3]

Antwortoptionen:

(A) YouTube-Video: Lustiger alter Mann

(B) WDR-Mitschnitt: Populäre Abendsendung

(C) Politisches Video: Sozialgesetzgebung

(D) Politisches Video: Appell für mehr Gerechtigkeit

Kontrollgruppe +

Need-supportive:

Need-thwarting:

Topic: meta data, dependent variable Item: Experimental stimulus

Vermutete Dauer:

60 Sekunden

Filter:

\section{Darstellung:}

Einfachauswahl untereinander

Textintro:

Fragetext:

Bitte schalten Sie den Ton an. Starten Sie dann das Video und schauen Sie es, so lange Sie wollen.

Einbetten: https://www.youtube.com/watch?v=mQHHb0II05Y

Zu speichernde Variable: Dauer des Verbleibs auf dieser Seite

Topic: meta data, dependent variable, behavioral measure $\quad$ Item: intrinsic motivation, free choice activity

\section{No Choice}

\section{Filter:}

Varnames:

exp_intr_behavioral

Comment:
Wir möchten verstehen, wie Menschen im Internet Videos konsumieren. Daher werden wir Ihnen auf der nächsten Fragebogenseite ein Video zeigen. Es ist wichtig, dass Sie dafür bitte jetzt den Ton ihres Computers anschalten.

Wir haben mehrere Videos vorbereitet, aus denen die Teilnehmer dieser Befragung auswählen können. Entscheiden Sie sich, welchen Film Sie sehen möchten. Dieses Video wird dann auf der nächsten Seite des Fragebogens abgespielt. nächsten Fragebogenseite ein Video zeigen. Es ist wichtig, dass Sie dafür bitte jetzt den Ton ihres Computers

Für diese Studie haben wir vier Videos vorbereitet, aus denen Studienteilnehmer auswählen dürfen. Einige Teilnehmern dürfen aus allen Videos wählen, andere Teilnehmer müssen eines der politischen Videos sehen.

Ein Zufallsgenerator hat bestimmt, dass Sie zur Gruppe gehören, die ein politischen Video wählen muss. Auch wenn alle Auswahloptionen eingeblendet sind, müssen sie aus Studienzwecken ein "Politisches Video" auswählen und ansehen. Unsere Software erfasst, ob Sie einen Film aus der Gruppe „Politische Videos“ Entscheiden Sie sich, welches Video sie sehen möchten. Dieses Video wird dann auf der nächsten Seite des Fragebogens abgespielt. 
Presentation: Radio-Button

\section{Fragetext:}

Haben Sie Lust, am Ende dieser Befragung noch ein weiteres Video dieser Art zu sehen, oder wollen Sie lieber die Befragung schnell beenden? Sie erhalten keine zusätzlichen Vergütung, können aber ein weiteres Video dieser Art anschauen, falls Sie Lust dazu haben.

- Ja, ich möchte später freiwillig noch ein ähnliches Video sehen.

- $\quad$ Nein, ich möchte kein solches Video mehr sehen.

Topic: cognitive processing, dependent variable Item: Depth of processing

\section{Vermutete Dauer: $\quad 60$ Sekunden}

Varnames:

exp_quality_obj_pos, exp_quality_obj_con

Kommentar:

Darstellung: three small text boxes

\section{Fragetext:}

Wir möchten erfahren, wie Sie die Ausführungen des Herrn im Video zu Lohnnebenkosten einschätzen.

Erklären Sie kurz in einem oder in wenigen Stichworten.

- $\quad$ Laut Video, wie wirkt eine Senkung der Lohnnebenkosten aus Sicht des Arbeitnehmers? [exp_quality_objl]

- $\quad$ Laut Video, was sind Lohnnebenkosten aus Sicht des Arbeitgebers? [exp_quality_obj2]

- Laut Video, wer muss die Deckungslücke in den Sozialausgaben nach einer Lohnnebenkostensenkung bezahlen? [exp_quality_obj3]

\footnotetext{
Topic: dependent variable, self-report Item: task-related intrinsic motivation \& manipul. check (perception of choice)

Vermutete Dauer: $\quad 60$ Sekunden

Filter:

Varnames:

Comment: adopted from (Deci et al., 1994)

Presentation: Matrix

\section{Fragetext:}

Wir haben noch einige Frage zu dem Video, das sie gesehen haben. Bitte geben Sie an, inwieweit folgende Aussagen auf Sie zutreffen.

(A) Ich hatte wirklich Lust, das Video anzusehen.

[Intrinsic Motivation; exp_intr_subj1]

(B) Ich habe das Video aufmerksam angeschaut.

[DV: Quality of Engagement exp_qual_subj1]

(C) Mir fallen viele gute Gründe ein, warum man sich mit Politik Freude interessant kann. [sic]

[Manipulation Check: autonomy-supportive group; exp_aut_manip_autsup]

(D) Ich würde das Video als sehr interessant beschreiben.

[Intrinsic Motivation; exp_intr_subj1]

(E) Ich habe mich unter Druck gesetzt gefühlt, das Video anzuschauen.

[Manipulation Check: no choice group; exp_aut_manip_nochoice]

(F) Ich war froh, als das Video zu Ende war.

[Reverse Coded, Intrinsic Motivation; exp_intr_subj3]

(G) Durch das Video konnte ich etwas Interessantes lernen.
} 
[Intrinsic Motivation; exp_intr_subj4]

(H) Den Inhalt des Videos habe ich nur oberflächlich wahrgenommen.

[Reverse Coded, DV: Quality of Engagement; exp_qual_subj2]

(I) trifft überhaupt nicht auf mich zu

(2) trifft eher nicht auf mich zu

(3) teils/teils

(4) trifft eher auf mich zu

(5) trifft voll und ganz auf mich zu

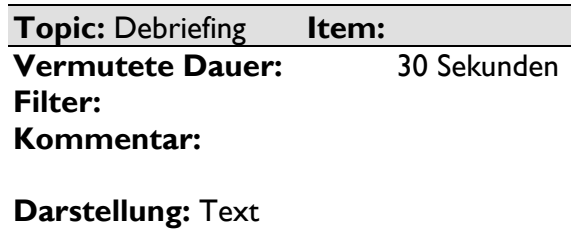
zwangsläufig das tatsächliche Niveau Ihres Wissens über Politik! Mit diesem Experiment möchten wir untersuchen, wie persönliche Selbstwahrnehmung politisches Verhalten beeinflusst.

Bitte haben Sie Verständnis, dass wir aus praktischen Gründen unabhängig von Ihren Angaben kein zweites Video zeigen können. Diese Frage diente lediglich zur Messung ihrer Bereitschaft, ähnliche Medieninhalte zu konsumieren.

Bei Fragen können Sie sich gerne an den Studienverantwortlichen wenden: alexander.wuttke@unimannheim.de 
Themenk: welcome and data privacy Intro

Duration: 20 seconds[conservative, because mostly skipped]

\section{Scientific Study}

The following survey is part of a scientific study at the University of Mannheim on media and political behavior in modern democracies. Your answers are the basis for our research. The more careful and attentive you participate, the more reliable will the won research results be.

1611

1612

Unmute

1614

1615

1616

In the course of the survey, you will have the opportunity, to watch a video. Please watch it carefully. Therefore, turn on the volume of your computer now. It is important that you are able to watch and listen to the video.

\section{Protection of Data Privacy}

In the course of technical processing of the survey (e.g. while answering the survey) on technical reasons also personal data (e.g. IPaddress) will be compiled. In the course of this survey, additionally a YouTube video will be showed. When you play the video and agree with the corresponding data privacy terms, also personal data of technical character (e.g. IP-address) could be saved. The scientific evaluation of your answers on this survey will be carried out exclusively anonymous.

You will receive more information on the study at the end of the questionnaire.

\begin{tabular}{|c|c|}
\hline Themenk: Sozio-demographics & Item: Sex \\
\hline $\begin{array}{l}\text { Duration: } \quad 10 \text { seconds } \\
\text { Filter: } \\
\text { Varnames: } \\
\text { Sex }\end{array}$ & \\
\hline Presentation: & \\
\hline $\begin{array}{l}\text { Source: } \\
\text { GLES }\end{array}$ & \\
\hline $\begin{array}{l}\text { Text introduction: } \\
\text { Please specify your sex. }\end{array}$ & \\
\hline $\begin{array}{l}\text { - male } \\
\text {-female }\end{array}$ & \\
\hline Themenk: Sozio-demographics & Item: Age \\
\hline $\begin{array}{l}\text { Duration: } \quad 10 \text { seconds } \\
\text { Filter: } \\
\text { Varnames: } \\
\text { Age }\end{array}$ & \\
\hline
\end{tabular}

the survey. If you have acquired your school leaving certificate outside of Germany, please state the respective German certificate. 
GLES

Text introduction:

Please indicate your age.

$-18-29$

$-30-39$

$-40-49$

$-50-59$

-60 and older

Themenk: Sozio-demographics Item: Graduation

Filter:

Presentation

must answer; single response list (vertical); plausibility check: Please note that an answer to this question is mandatory for continuing the survey. If you have acquired your school leaving certificate outside of Germany, please state the respective German certificate.

\section{Source: \\ GLES}

\section{Varnames:}

edu

\section{Question text:}

What's your highest level of general education?

- Finished school without school leaving certificate

- Lowest formal qualification of Germany's tripartite secondary school system, after 8 or 9 years of schooling ("Hauptschulabschluss,

Volksschulabschluss")

- Intermediary secondary qualification, after 10 years of schooling ("Mittlere Reife, Realschulabschluss, or Polytechnische Oberschule mit Abschluss 10. Klasse")

1692

1693

1694

1695

1696

1697

1698

1699

- Certificate fulfilling entrance requirements to study at a polytechnical college ("Fachhochschulreife (Abschluss einer Fachoberschule etc.)")

- Higher qualification, entitling holders to study at a university ("Abitur or Erweiterte Oberschule mit Abschluss 12. Klasse (Hochschulreife)")

- still at school

1700

I70I

1702

1703

1704

1705

1706

\section{Code:}

(I) Finished school without school leaving certificate

(2) Lowest formal qualification of Germany's tripartite secondary school system, after 8 or 9 years of schooling ("Hauptschulabschluss, Volksschulabschluss")

(3) Intermediary secondary qualification, after 10 years of schooling ("Mittlere Reife, Realschulabschluss or Polytechnische Oberschule mit Abschluss 10. Klasse")

(4) Certificate fulfilling entrance requirements to study at a polytechnical college/university of applied sciences ("Fachhochschulreife (Abschluss einer Fachoberschule etc.)")

(5) Higher qualification, entitling holders to study at a university ("Abitur or Erweiterte Oberschule mit Abschluss I2. Klasse (Hochschulreife)")

(9) Still at school

\section{$\rightarrow$ Check for Quota and Filtering}


1715

1716

1717

1718

1719

1720

1721

1722

1723

1724

1725

1726

1727

1728

1729

1730

173|

1732

1733

1734

1735

1736

1737

1738

1739

1740

I74I

1742

1743

1744

1745

1746

1747

1748

1749

1750

I75I

1752

1753

1754

1755

1756

1757

1758

1759

1760

|76|

1762

1763

1764

1765

1766

1767

1768

1769

1770

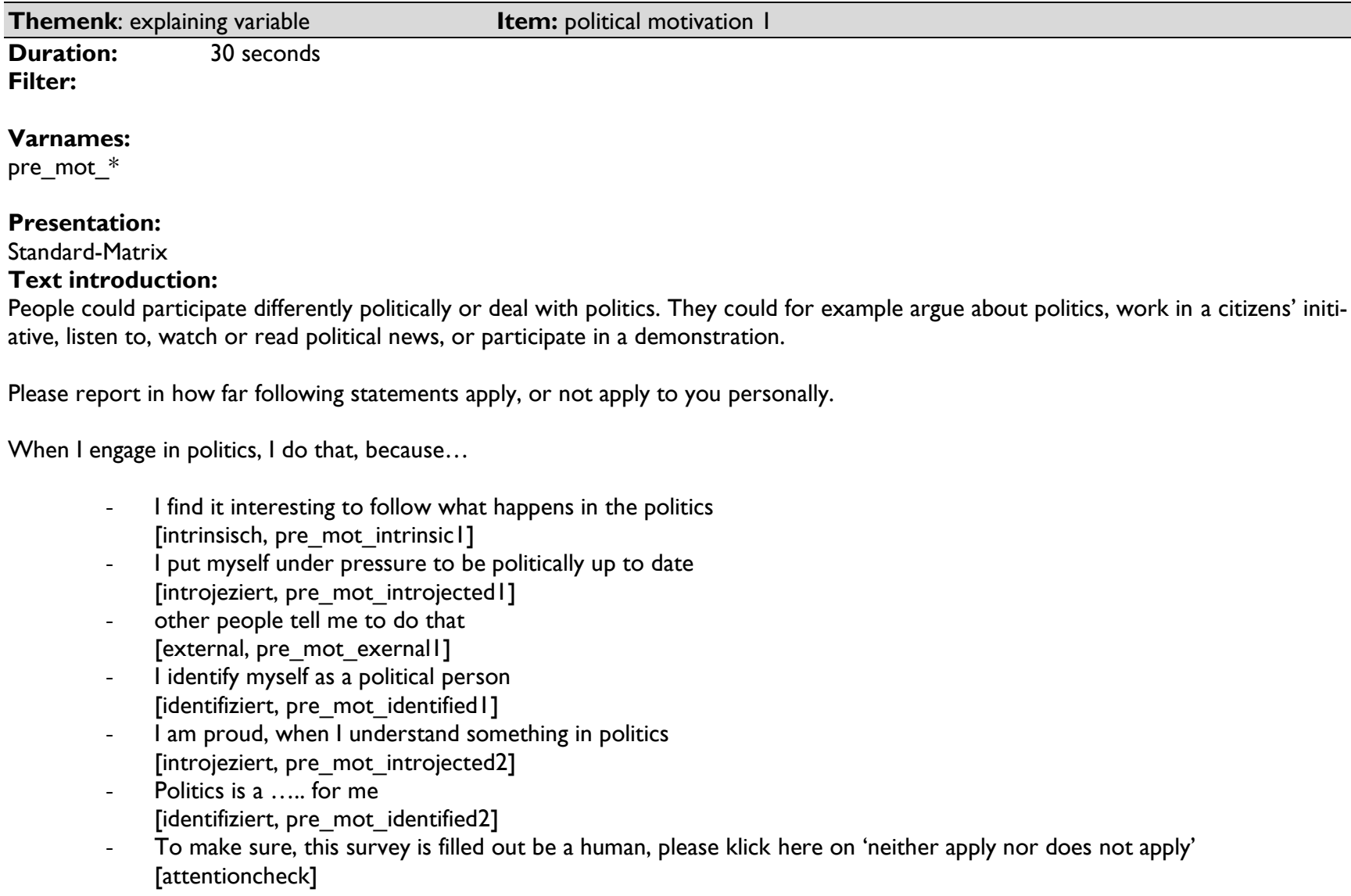

\section{Code:}

(I) does not apply at all to me

(2) does not apply to me

(3) neither applies nor does not apply

(4) applies to me

(5) strongly applies to me

$\rightarrow$ Screenout if attention check was failed

Themenk: attitudes towards democracy in general Item: political interest in general

\section{Source:}

GLES

Presentation:

Radio box

Varnames:

polint 
|77|

1772

1773

1774

1775

1776

1777

1778

1779

1780

I78|

1782

1783

1784

1785

1786

1787

1788

1789

1790

I79]

1792

1793

1794

1795

1796

1797

1798

1799

1800

$180 \mid$

1802

1803

1804

1805

1806

1807

1808

1809

1810

I8I I

1812

1813

1814

1815

1816

1817

1818

1819

1820

$182 \mid$

1822

1823

1824

1825

1826

1827

\section{Question text:}

How strongly are you interested in politics in general?

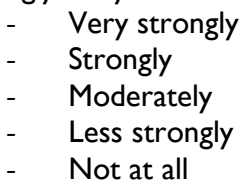

\section{Code:}

(I) very strongly

(2) strongly

(3) moderately

(4) less strongly

(5) not at all

\section{Themenk: explaining variable}

Item: political motivation 2

\section{Filter:}

\section{Varnames:}

pre_mot_intrinsic

\section{Presentation:}

Standard-Matrix

Text introduction:

Here you again see various reasons people engage in politics.

Please report in how far following statements apply, or not apply to you personally.

\section{Question text:}

When I engage in politics, I do that, because...

- $\quad$ it fits my principals, to engage in politics.

[identifiziert, pre_mot_identified3]

- people get respect, when they know lots about politics.

[external, pre_mot_exernal2]

- I find politics interesting.

[intrinsisch, pre_mot_intrinsic2]

- I can avoid critic by friends and family this way.

[external, pre_mot_exernal3]

- $\quad$ One should stay informed about politics, even if one is not interested in it at the moment. [introjeziert, pre_mot_introjected3]

- I feel joy, engaging in politics.

[intrinsisch, pre_mot_intrinsic3]

\section{Code:}

(I) does not apply at all to me

(2) does not apply to me

(3) neither applies nor does not apply

(4) applies to me

(5) strongly applies to me 
1828

1829

1830

$183 \mid$

1832

1833

1834

1835

1836

1837

1838

1839

1840

|84|

1842

1843

1844

1845

1846

1847

1848

1849

1850

$185 \mid$

1852

1853

1854

1855

1856

1857

1858

1859

1860

|86|

1862

1863

1864

1865

1866

1867

1868

1869

1870

|87|

1872

1873

1874

1875

1876

1877

1878

1879

1880

|88|

1882

1883

1884

\section{Themenk: attitudes towards democracy in general Item: Norms of citizenship}

Source: ISSP 2016

Presentation:

Radio box

Question text:

There are different views on what makes a good citizen. What do you think: In how far are the following things important to be a good citizen?

That someone...

- always votes.

- $\quad$ never tries, to make fiscal fraud.

- $\quad$ Always obeys laws and regulations.

- Pays attention on what the government does.

- Participates actively $\mathrm{n}$ social or political associations.

- Tries to understand the opinion of people with different opinions.

- Decides for products because of political, ethical or environmental reasons, even if they are a bit more expensive.

Skale

I not important at all

2

4

5

7 very important

\section{Themenk: explaining variable}

Item: political motivation 3

Duration: 30 seconds

Filter:

Varnames:

pre_mot_intrinsic

Presentation:

Standard-Matrix

\section{Text introduction:}

For a last time, you see here reasons why people engage in politics.

Please report in how far following statements apply, or not apply to you personally.

\section{Question text:}

When I engage politically, I do it because....

- I find politics thrilling.

[intrinsisch, pre_mot_intrinsic4]

- I would be ashamed, if I was not informed about politics.

[introjeziert, pre_mot_introjected4]

- Politics belongs to my personality.

[identifiziert, pre_mot_identified4]

- Otherwise other people would look down on me.

[external, pre_mot_exernal4] 
- I want to proof to myself, that I engage also in things like politics.

[introjeziert, pre_mot_introjected5]

- Politics is simply important to me.

[identifiziert, pre_mot_identified5]

- $\quad$ I got the impression, that people expect that from me. [external, pre_mot_exernal5]

\section{Code:}

(I) does not apply at all to me

(2) does not apply to me

(3) neither applies nor does not apply

(4) applies to me

(5) strongly applies to me

\title{
Themenk: experiment Item: Political knowledge quiz I [need-supportive, Comp+]
}

\section{Duration: $\quad 30$ seconds}

Filter:

Respondents need-for-competence-supportive condition

\section{Varnames:}

comp_sup_quiz_politician

Presentation:

\section{Text introduction:}

\section{Question text:}

We would like to know whether you know more or less about politics than other people. A short quiz. Please mark all politicians who are member of the SPD.

Pictures in need-for-competence-supportive condition:

[famous SPD politicians]

\author{
Themenk: experiment Item: Political knowledge quiz I [need-supportive, Comp-]

Duration: 30 seconds \\ Filter: \\ Respondents need-for-competence-thwarting condition \\ Varnames: \\ comp_thwart_quiz_politician

\section{Presentation:}

\section{Text introduction:}

\section{Question text:} \\ We would like to know whether you know more or less about politics than other people. A short quiz. Please mark all politicians that \\ are member of the SPD.
}


Pictures in need-for-competence-thwarting condition:

Themenk: experiment Item: Political knowledge quiz 2 [need-supportive, Comp+]

Duration: 10 seconds

Filter:

Respondents need-for-competence-supportive condition

Varnames:

comp_sup_quiz_estimate

Presentation:

Slider

Text introduction:

Source:

GLES

Hint:

If you do not know, please give your best estimate.

\section{Question text:}

In elections for the Bundestag there is a threshold parties have to pass in order to enter the Bundestag. Do you know what percentage of the second votes a party needs to get in order to enter the Bundestag?

Themenk: experiment Item: Political knowledge quiz 2 [need-thwarting, Comp-]

Duration: 10 seconds

Filter:

Respondents need-for-competence-thwarting condition

Varnames:

comp_thwart_quiz_estimate

Presentation:

Slider

0 through 1000

Text introduction:

Hint:

Refer to the number of members in the current 19th German Bundestag.

Question text:

The Bundestag is an important legislative committee.

How many deputies in the current Bundestag make laws? If you don't know, please give your best estimate.

Themenk: experiment Item: Feedback Stimuli + Efficacy [need-supportive, Comp+]

Duration: 20 seconds

Filter:

Respondents need-for-competence-supportive condition

Varnames:

comp_sup_quiz_efficacy

Source:

GLES / Gesis-Kurzskalen / Eigen

Presentation: 
Matrix

Text introduction:

\section{Question text:}

Your personal quiz result: knowledge about politics above average.

Our algorithm has compared your responses to the responses of other participants.

Congratulations! Apparently, you know more about politics than other respondents. Great.

Considering all data we have collected so far, you fare better on the political knowledge quiz than $72 \%$ of participants.

Obviously, politics is one of your strengths.

But this is only what our data says. We want to know what you think about yourself!

In your own perception, how well do the following statements apply to you?

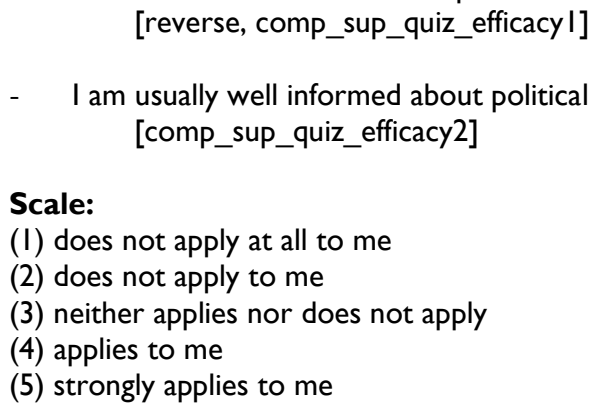

Themenk: experiment Item: Feedback Stimuli + Efficacy [need-thwarting, Comp-]

\section{Duration: 20 seconds}

Varnames:

comp_thwart_quiz_efficacy

Filter:

Respondents need-for-competence-thwarting condition

Presentation:

Matrix

Text introduction:

\section{Source:}

GLES / Gesis-Short scales

\section{Question text:}

Your personal quiz result: knowledge about politics below average.

Our algorithm has compared your responses to the responses of other participants.

Unfortunately, it shows that you know far less about politics than other respondents.

Considering all data we have collected so far, you fare worse on the political knowledge quiz than $72 \%$ of participants.

Obviously, politics is not one of your strengths.

Yet, this is only what our data says. We want to know what you think about yourself!

In your own perception, how well do the following statements apply to you?

- I can understand and evaluate political issues easily.

[reverse, comp_sup_quiz_efficacyl]

- I am usually well informed about political affairs. [comp_sup_quiz_efficacy2] 
Scale:

(I) does not apply at all to me

(2) does not apply to me

(3) neither applies nor does not apply

(4) applies to me

(5) strongly applies to me

Themenk: experiment Item: IntrMot Stimulus [need-supportive, Aut+]

Duration: 30 seconds

Filter:

Varnames:

\title{
Presentation:
}

Multiple Choice

Text introduction:

Many people report that engagement with politics can provide joy and satisfaction. Here you see various reasons why some people like engaging with politics.

Please consider whether you have also found joy in political engagement before. Tick all statements that apply to you.

- It provides pleasure to learn about politics and to understand how the things go together. [aut_sup_agreel]

- Following the spectacle in politics is often entertaining because, in the end, politics is like a grand circus. [aut_sup_agree2]

- Being informed about politics is satisfying because so much depends on political decisions.

\author{
Themenk: experiment Item: Stimulus + DV: Neigung zu politischem Medienkonsum \\ Duration 20 seconds \\ Filter: \\ Varnames: \\ exp_aut_cont_sup_choice_video, exp_aut_thwart_choice_video \\ Presentation: \\ Radio box \\ Text introduction:

\section{Question text:} \\ Random selection of a frame: [control group / treatment group I / treatment group 2 / treatment group 3] \\ Question choices: \\ (A) YouTube-video: funny old man \\ (B) WDR-recording: popular evening show \\ (C) Political video: social legislation \\ (D) Political video: call for more social justice
}

We would like to understand how people consume video content on the internet. Accordingly, we will present you a video on the next page of this questionnaire. Therefore, it is important that you now turn on your volume of your computer.

We have prepared multiple videos from which participants of this survey can choose. Please decide, which movie you would like to watch. This video will then be presented on the next page of the questionnaire. 
2111

2112

2113

2114

2115

2116

2117

2118

2119

2120

$2|2|$

2122

2123

2124

2125

2126

2127

2128

2129

2130

$2|3|$

2132

2133

2134

2135

2136

2137

2138

2139

2140

$2|4|$

2142

2143

2144

2145

2146

2147

2148

2149

2150

2151

2152

2153

2154

2155

2156

2157

2158

2159

2160

2161

2162

2163

2164

2165

2166
Need-thwarting:

Topic: meta data, dependent variable Item: Experimental stimulus

Duration: 60 seconds

Filter:

Presentation:

Radio box

Text introduction:

Question text:

Please turn on the volume and watch this video as long as you want.

Embedding: https://www.youtube.com/watch?v=mQHHb0II05Y

Variable to save: time on this site

Topic: meta data, dependent variable, behavioral measure Item: intrinsic motivation, free choice activity

Duration: 10 seconds

Filter:

Varnames:

exp_intr_behavioral

Comment:

Presentation: Radio-Button

Question text:

Would you like to watch another video of this kind at the end of this survey or would you prefer to quickly finish this survey? You will not be granted any extra compensation but you can watch another video of this kind if you want to.

- Yes, voluntarily I would like to watch another video of this kind later.

- $\quad$ No, I do not want to watch more videos of this kind.

Topic: cognitive processing, dependent variable Item: Depth of processing

\section{Duration: $\quad 60$ seconds}

Varnames:

exp_quality_obj_pos, exp_quality_obj_con

Comment:

Presentation: three small text boxes

\section{Question text:}

\begin{abstract}
No Choice
We would like to understand how people consume video content on the internet. Accordingly, we will
present you a video on the next page of this questionnaire. Therefore, it is important that you now turn on
No Choice
We would like to understand how people consume video content on the internet. Accordingly, we will
present you a video on the next page of this questionnaire. Therefore, it is important that you now turn on the volume of your computer.

freely choose, other participants have to watch one of the political videos. random generator has determined that you are part of the group of respondents that has to choose a

For research purposes you have to select a movie with political content and watch it even though there are other nur software records, whether you select a movie from the group "political videos".
e decide, which video you want to watch. This video will then be presented to you on the next page of ptions. Our software records, whether you select a movie from the group "political videos".
Please decide, which video you want to watch. This video will then be presented to you on the next page of this questionnaire. se. Some participants can
\end{abstract}


We would like to know, how you evaluate the remarks of the man in the video on incidental wage costs.

Explain shortly in one or a few bullet points.

Concerning to the video, how seems a reduction of the incidental wage costs for employees?

[exp_quality_objl]

2170

Topic: dependent variable, self-report Item: task-related intrinsic motivation \& manipul. check (perception of choice)

\section{Duration: $\quad 60$ Sekunden}

\section{Filter:}

Varnames:

Comment: adopted from (Deci et al., 1994)

\section{Presentation: Matrix}

\section{Question text:}

We have some questions on the video you have watched. Please state how well the following statements apply to you.

(A) I really wanted to watch this video. [Intrinsic Motivation; exp_intr_subj1]

(B) I watched the video attentively.

[DV: Quality of Engagement exp_qual_subj1]

C) I can think of many good reasons why one should engage in politics.

[Manipulation Check: autonomy-supportive group; exp_aut_manip_autsup]

(D) I would describe the video as very interesting

[Intrinsic Motivation; exp_intr_subj1]

(E) I felt under pressure to watch the video.

[Manipulation Check: no choice group; exp_aut_manip_nochoice]

(F) I was glad when the video was over.

[Reverse Coded, Intrinsic Motivation; exp_intr_subj3]

(G) The video helped me to learn interesting things.

[Intrinsic Motivation; exp_intr_subj4]

(H) I only processed the content of the video superficially.

[Reverse Coded, DV: Quality of Engagement; exp_qual_subj2]

\section{Scale:}

(I) does not apply at all to me

(2) does not apply to me

(3) neither applies nor does not apply

(4) applies to me

(5) strongly applies to me

\section{Topic: Debriefing Item:}

Duration: 30 Sekunden




\section{Filter:}

\section{Comment:}

\section{Presentation: Text}

\section{Question text:}

\section{Important Information: Declaration about Experiment in Survey}

Thank you for your participation. You have participated in a social-scientific survey. Two experiments were part of this survey:

First, it was randomly allocated who received which accompanying information on the video that you have watched during the survey.

With this experiment we want to investigate how situational differences influence the proclivity to engage with politics.

Second, the content and the feedback to the political knowledge quiz was randomly generated. The feedback to the quiz was independent of your actual responses and does not necessarily reflect your actual level of knowledge about politics. With this experiment we investigate how self-image affects political behavior.

Please have understanding that, independently of your specifications, we cannot show you a second video due to practical reasons. This question was merely employed to measure your willingness of consuming similar media content.

If you have any question, please feel free to contact the principal investigator: alexander.wuttke@uni-mannheim.de 


\section{S3: Coding Instructions}

The objective measure of behavioral quality relies on open-ended question gauging whether respondents can accurately respond to the question about the video content. Manual coding was employed to code whether a response was accurate or not. Because the survey responses are German the coding instructions below which were given to the coder are also in German.

Codierungsanweisung: Offene Frage zu Lohnnebenkosten

\section{Originalvideo}

https://www.youtube.com/watch?v=mQHHb0ll05Y

Frage I: Laut Video, wie wirkt eine Lohnnebenkostensenkung aus Sicht des Arbeitnehmers?

,Eine Senkung der Lohnnebenkosten ist eine Lohnsenkung. Sonst gar nichts. [...] Freuen Sie sich nie wieder über eine Senkung der Lohnnebenosten. Es ist eine Lohnsenkung. Sie zahlen hinterher drauf.‘ (sek 52)

\section{Auch zulässige Antworten}

kostenerhöhend, nicht sehr positiv, nicht optimal, Höhere Ausgaben, weniger Gehalt, Unfair, Blöd, Schlecht, er muss mehr bezahlen, hat weniger Geld

\section{Nicht zulässig}

gut für den Arbeitgeber, Kostensenkend für AG, Minderung der Lohnkosten, Teil des Lohns, Lohn

Frage 2: Laut Video, was sind Lohnnebenkosten aus Sicht des Arbeitgebers?

,Für einen Arbeitgeber sind Lohnnebenkosten einfach ein Teil des Lohns. Welcher Teil des Lohns gesenkt wird ist dem Arbeitgeber ziemlich egal. Hauptsache ist, der muss weniger Geld bezahlen, damit Sie für ihn arbeiten. ' (sek 12) 


\section{Auch zulässige Antworten}

Eine Zahlung die weh tut, Betriebskosten, Kosten, Kosten für Sozialversicherungsbveiträge, nervig,

\section{Nicht zulässig}

Steuern

Frage 3: Laut Video, wer muss die Deckungslücke in den Sozialausgaben nach einer Lohnnebenkostensenkung bezahlen?

,Jetzt raten Sie mal wer das ist [der die Lücke bezahlt]. Kleiner Tipp: Es ist nicht Ihr Arbeitgeber. [...] Sie zahlen hinterher drauf" (sek 52).

\section{Auch zulässige Antworten}

Ich, nicht der Arbeitgeber, Steuerzahler

\section{Nicht zulässig}

der Staat

\section{Notiz}

Bis zu Nr. „I703““ (Ifdn I3) gab es einen Codierungsfehler in Frage I. Statt, Laut Video, wie wirkt eine Lohnnebenkostensenkung aus Sicht des Arbeitnehmers?" hieß es, Laut Video, wie wirkt eine Lohnnebenkostensenkung aus Sicht des Arbeitnehmers?’. Alle diese I 3 ersten Personen auf dieser Frage I mit Missing Value (.) versehen.

\section{Missing Values}

-66 wird als Missing Value (.) codiert.

-99 wird als 0 kodiert (keine richtige Angabe). 


\section{S4: Power analysis}

This supplement entails multiple steps to describes the strategy for determining the adequate sample size of the proposed study. In the first step, a review of existing studies provides information on the sizes of experimental effects as reported in previous studies whose treatments share certain features with the treatments of the proposed study. In a second step, sample size calculations are conducted at different levels of detectable effect sizes at a pre-specified level of statistical power. The sample size estimates that were derived from the power analysis are then compared with the estimates collected in the review of existing studies to ensure that the intended sample size enables the detection of treatment effects equal to or smaller than the effect sizes reported in previous studies.

When basing sample size calculations on effect sizes in published literature, one needs to take systematic publication biases in the body of scholarly literature into account.(Camerer et al., 2018) In particular, meta-scientific research shows that effect sizes reported in original social science studies are usually larger than effect sizes obtained in subsequent replication attempts.(Camerer et al., 2018) Moreover, reported effect sizes in published studies are usually lower when the analytical strategy was pre-registered compared to studies without pre-registered analysis protocol.(Allen and Mehler, 2018) Hence, meta-scientific research suggests that effect sizes are even more likely to be inflated in non-pre-registered studies, which is the case for all the studies reviewed below. Considering these uncertainties in extrapolating future effect sizes from previously reported effect sizes, in a third step this Supplement documents power calculations which report the likelihood that the proposed study can detect effect sizes that are considerably lower than those reported in the existing literature. Hence, these calculation help to assess the probability of detecting effect sizes that are small but substantially meaningful, irrespective of previously reported effect sizes. 
The following sample size calculations employ a conservative approach. For one, the strategy behind the conducted power analysis targets at detecting effect sizes that are smaller than those in the published literature the power analysis. Moreover, the design can also be considered as conservative due to the statistical techniques that are employed. The statistical tests underlying the power analysis are simple tests of means and proportions (e.g. t-test) which yield unbiased estimates but do not make efficient use of the data. In contrast, in line with the pre-registered analysis pipeline the analyses conducted in the proposed study will include pre-treatment covariates in the model according to the Lin method which also yields unbiased but more precise estimates.(Lin, 2013) Hence, the power in the proposed study will be even higher than suggested in the following power analysis.

Overview of effect sizes in previously published studies

Hypothesis I: Need-supportive situational contexts increase intrinsic political motivation.

\section{Study by Bowed et al. (need for competence manipulation)}

The experimental manipulation of the perceived situational satisfaction of the need for competence that is employed in the proposed study is inspired by a study by Bowed et al. who manipulated rankings in the leaderboard of an online game to induce varying levels of perceived competence and perceived enjoyment.Bowey et al. Specifically, players engaged in various rounds of an online game. After each of these rounds, the players were shown their relative success on a visual leaderboard. The participant's position on the leaderboard was randomly assigned, indicating either relative success or failure in the game. The study reports an effect size of $\eta 2=.15(\mathrm{~F} 1,135=23.8, \mathrm{p}<.001)$ on perceived competence, which translates into Cohen's $\mathbf{d}=\mathbf{0 . 8 4}$. The authors report an effect size of $\eta 2=.09(\mathrm{~F} 1,135=11.9, \mathrm{p}=.001)$ on enjoyment (an indicator of intrinsic motivation) which translates into Cohen's $\mathbf{d}=\mathbf{0 . 6 3}$. Hence, for the domain of computer games, the study by Bowed et al. provides effect estimates 
on two variables: perceived competence and intrinsic motivation. Both of these variables are also measured in the proposed study. In the proposed study, perceived efficacy functions as a manipulation check of the need for competence manipulation. Intrinsic motivation functions as the dependent variable.

It remains uncertain whether the effect sizes will be larger or smaller as a result of the proposed study's different context. On the one hand, one might expect smaller sizes relative to the study by Bowed et al. as the participants in their study might have undergone a more immersive experience (playing several rounds of an online game) compared to the short knowledge quiz conducted in the proposed study. On the other hand, one might expect larger effect sizes than in the Bowed et al. study as the competence-related feedback regarding political knowledge might elicit stronger psychological responses than competence-related feedback on a generic computer game for two reasons. First, knowledge of political matters is widely regarded as socially desirable, therefore potentially triggering a sense of pride or shame. Second, assessing low levels of knowledge on political issues has greater environmental relevance compared to low skills on a generic computer game, thereby potentially having greater implications for the self-image of participants. Altogether, the study by Bowed et al. is one indicator of the effect sizes to expect regarding the need for competence manipulation. Nonetheless, it remains somewhat uncertain how the different study context may affect the effect sizes.

\section{Need for competence and political interest}

In the proposed study, the need for competence manipulation consists of two elements: both the difficulty of political knowledge questions and the feedback to political knowledge questions is manipulated. Prior research has established that each of these manipulations is capable of 
influencing a person's perceived competence and interest in politics. However, prior research has not employed both elements in combination. We may expect that combining both elements yields additive and potentially multiplicative effects on intrinsic motivation.

Bishop 1987(Bishop, 1987) reports three studies, in which participants receive easy or hard political knowledge questions before responding to a political interest question. Bishop reports statistically significant differences in each of the studies at an effect size of cohen's $\mathbf{d}=\mathbf{0 . 3 9}$, cohen's $\mathbf{d}=\mathbf{0 . 1 4}$ and cohen's $\mathbf{d}=\mathbf{0 . 2 2}$ respectively. Similarly, Lasorsa has shown in two studies(Lasorsa, 2003, 2009) that reported levels of political interest are markedly higher when preceded by fairly difficult political knowledge questions compared to no preceding political knowledge questions. In the first study,(Lasorsa, 2003) 206 out of 295 respondents (70\%) reported high levels of political interest in the control condition whereas only 136 of 272 respondents (50\%) reported high levels of political interest when the interest question was proceeded by fairly difficult political knowledge questions. In a second study, "86.1\% of those who did not first encounter the political knowledge questions (n=353) reported high political interest, whereas only $\mathbf{7 4 . 1 \%}$ of those who encountered the knowledge questions $(\mathrm{n}=320)$ reported high interest $\left(X^{2}=\right.$ 18.96, df = 1, Fisher's Exact Test, $\mathrm{p}<.001$ )".(Lasorsa, 2009) Altogether, these studies suggest sizable effects on reported levels of political interest when the interest item was preceded by political knowledge questions that many respondents may have experienced as undermining their perceived levels of political competence. Note, however, that the stimuli in the reviewed studies were arguably weaker than the one intended in the proposed study. The Bishop et al. study only employs one of the experimental stimuli (varying difficulty of knowledge questions) intended to use in the proposed study. (The Bishop et al. study did not provide manipulated competence feedback). What is more, the studies by Larosorsa did not manipulate competence feedback and only compared an experimental group who either received knowledge questions with a control group 
who did not receive knowledge question. In contrast, the proposed study will administer hard vs. easy knowledge questions to both experimental groups, thereby amplifying differences between the experimental groups.

A study by Preece(Preece, 2016) provided manipulated competence feedback without manipulating item difficulty. Because the study does not report standard deviations of the experimental groups, it is not possible to estimate standardized effect sizes. However, it is apparent that the effect of manipulated competence feedback ('Great job! You did very well on this difficult quiz. Very few people do well on it.' vs no feedback) on political interest is sizeable. On a 5-point scale, the level of political interest increases from 1.92 to 2.31 (two-side p-value $=0.022$ ). Note that, again, the experimental stimulus in the study by Preece is arguably weaker than in the proposed study. First, in the study by Preece the praisereceiving group is compared to a control group who received no feedback whereas in the proposed study the second experimental group receives negative feedback, potentially undermining perceived competence. Second, the study by Preece only manipulated competence feedback but did not vary item difficulty in the knowledge quiz. With these caveats in minds, altogether the studies by Preece and Bishop show that the manipulation of what I interpret as one's situational satisfaction of need for competence has sizeable effects on a person's self-reported level of political interest.

\section{Study by Grant/Berry (Need-for-autonomy manipulation, Aut-)}

The no-choice condition intended to manipulate situational satisfaction of the need for autonomy is inspired by a study by Grant/Berry (Study 3) who offered participants to choose from two tasks.(Grant and Berry, 2011) Whereas participants in both conditions of that study, in fact, solved the identical task, participants in the no-choice condition were told that the chosen task was not available anymore and that they would 
have to solve the less appealing task. Compared to participants who seemingly solved the task of their choice (mirroring the control group in the proposed study), participants in the no-choice condition reported lower levels of intrinsic motivation after they concluded the task. The estimated effect size of the autonomy-thwarting manipulation on intrinsic motivation was cohen's $\mathbf{d}=\mathbf{0 . 5 6}$.

\section{Study by Gillet et al. (Need-for-autonomy manipulation, Aut+)}

The autonomy-supportive condition is modeled after examples in previous research which reported detectable effects of rehearsing intrinsic reasons for engagement on various outcomes such as well-being.Amabile; Burton et al., 2006; Gillet et al., 2013 Most closely related to the outcome variable of the proposed study is a study by Gillet et al. who examined the effects of rehearsing intrinsic reasons for solving an anagram task on the levels of intrinsic motivation reported by the participants after engaging in that task.(Gillet et al., 2013) Mean levels of autonomous motivation increased from $\mathrm{M}=3.38$ in the control condition to $\mathrm{M}=4.07$ among respondents who experienced the autonomy-supportive manipulation, corresponding to an effect size of Cohen's $\mathbf{d = 0 . 5 0}$.

\section{Meta-analysis on choice and intrinsic motivation (Need-for-autonomy manipulation, Aut-)}

Meta-analyzing 41 studies on the role of choice in stimulating intrinsic motivation, Patall et al.(Patall et al., 2008) found an average effect size of cohen's $\mathbf{d}=\mathbf{0 . 3 6}$. Using trim-and-fill analyses to account for publication bias, the meta-analysis suggests an overall effect size of cohen's $\mathbf{d = 0 . 2 4}$. However, whereas various of the studies included in the meta-analysis compare conditions in which choices or no choices were present the proposed study emphasizes controlling situational constraints by explicitly pointing participants in the no-choice conditions to the absence of choice, thereby potentially increasing the external locus of control and further increasing differences in need satisfaction between participants 
in the autonomy-undermining condition compared to the autonomy-supporting condition. Hence, while the meta-analysis provides an indication of the relationship between choice and intrinsic motivation there is reason to expect that, mediated by need satisfaction, the provision of choice vs the absence of choice may exert stronger effects on intrinsic motivation in the proposed study compared to the meta-analysis.

\section{H2: Need-supportive environment and frequency of political behavior}

Various studies compare the proclivity to engage with a specific behavior in need-supportive vs. need-thwarting environments. A metaanalysis by Patall(Patall et al., 2008) on the relationship between autonomy-supportive contexts and the participants' willingness to continue an activity even when it is not required by the experimenter any more exhibits an effect size of Cohen's d=0.29.

\section{H3/H4 Need-supportive context and quality of behavior}

The tenet that need-supportive contexts facilitate behavioral performance is well established in the psychological literature albeit not yet applied to the political domain. A recent meta-analysis finds medium-sized effects of autonomy- and competence-supportive experimental manipulations on behavioral performance: "perceived autonomy emerged as a moderate predictor of performance $(\mathrm{k}=46, \mathrm{~N}=11,937, \mathrm{q}=.28)$, and the absence of zero in the $95 \%$ confidence interval indicates the population relationship between the two is positive (95\% CI $=.23-.33)$. [...] Perceived competence emerged as the strongest need satisfaction predictor of performance $(\mathrm{k}=70, \mathrm{~N}=20,924, \mathrm{q}=.37)$, and the absence of overlapping confidence intervals with both autonomy and relatedness needs indicates the effect is significantly larger than both $(95 \% \mathrm{CI}=.34-$ .40)."(Cerasoli et al., 2016) In the following, we review those studies that resemble the experimental design of the proposed study most closely. 
Autonomy-supportive condition and its influence on the quality of behavior (Aut+, H3b)

The autonomy-supportive condition is modeled after examples in previous research which showed detectable effects of rehearsing intrinsic reasons for engagement on various outcomes such as well-being.Amabile; Burton et al., 2006; Gillet et al., 2013 Most closely related to the outcome variable of the proposed study is a study by Kadous/Zhou(Kadous and Zhou, 2019) who prompted participants to rehearse reasons for auditing before the participants conducted said behavior. Kadous/Zhou show that participants engage in deeper information processing when conducting an audit task in the autonomy-supportive condition at effects sizes of Cohen's $\mathbf{d}=\mathbf{0 . 6 1}$ (DV: deep issues) and Cohen's $\mathbf{d}=\mathbf{0 . 5 5}$ (DV: total valid issues). Whereas the experimental stimulus of the proposed study and the study by Kadous/Zhou is similar, it should be noted that differences exist with regards to outcome variable and with regards to the experimental context. However, it is not self-evident whether these differences will impede or reinforce experimental effects.

Meta-analysis on choice and effort (Need-for-autonomy manipulation, Aut-)

Meta-analyzing twelve effect sizes on the role of choice in stimulating effort, Patall et al.(Patall et al., 2008) found an average effect size of

Cohen's $\mathbf{d}=\mathbf{0 . 2 2}$. However, whereas various of the studies included in the meta-analysis compare condition in which the participants were given choices vs. were not given choices the proposed study emphasizes the controlling constraints of the situation more strongly by explicitly pointing participants in the no-choice conditions to the absence of choice, thereby potentially increasing the external locus of control and further increasing differences in need satisfaction between participants in the autonomy-undermining condition compared to the autonomy-supporting condition. Hence, there is reason to expect that, mediated by need satisfaction, the provision of choice vs the absence of choice may exert stronger effects on effort in the proposed study compared to the meta-analysis. 
Study by Grant/Berry (Need-for-autonomy manipulation, Aut-)

The study by Grant/Berry(Grant and Berry, 2011) (Study 3) on creativity yielded an average effect size of autonomy-thwarting contexts (withdrawn vs. granted choice) of Cohen's $\mathbf{d}=\mathbf{0 . 4 1}$ on the quality of the behavioral task where quality (creativity) was as measured as the novelty and usefulness of business idea, rated by independent coders .

\section{Overview of effect sizes}

Table S4-1 provides an overview of the reported effect sizes in studies with experimental conditions that share certain features with the experimental stimuli administered in the proposed study. With the exception of the study by Bishop which reported small-sized effects, most of the studies report medium-sized effects. Note that several of the reported effect sizes relate to experimental treatments that are arguably weaker compared to the stimuli in the proposed study because, e.g., these studies only administered one element of the experimental stimuli to the participant whereas the proposed study combines multiple elements to enhance the experimental effects.

\section{S4- I. Overview of Effect Sizes in Existing Literature}

\begin{tabular}{lllllll}
\hline $\begin{array}{l}\text { Similar } \\
\text { to hy- }\end{array}$ & Similar & Experi- & DV & Study & $\begin{array}{l}\text { Effect size } \\
\text { (Cohen's }\end{array}$ & $\begin{array}{l}\text { Effect size } \\
\text { (other met- }\end{array}$ \\
$\begin{array}{l}\text { pothe- } \\
\text { sis... }\end{array}$ & test... & nipulation & & d) & ric) \\
\hline
\end{tabular}




\begin{tabular}{|c|c|c|c|c|c|c|c|}
\hline $\mathrm{HI}$ & 2 & $\begin{array}{l}\text { Need for } \\
\text { Compe- } \\
\text { tence }\end{array}$ & $\begin{array}{l}\text { Intrinsic } \\
\text { Motiva- } \\
\text { tion }\end{array}$ & Bishop & $\begin{array}{l}.39 / .14 / \\
.22\end{array}$ & & $\begin{array}{l}\text { Weaker } \\
\text { stimulus }\end{array}$ \\
\hline $\mathrm{HI}$ & 2 & $\begin{array}{l}\text { Need for } \\
\text { Compe- } \\
\text { tence }\end{array}$ & $\begin{array}{l}\text { Intrinsic } \\
\text { Motiva- } \\
\text { tion }\end{array}$ & Lasorsa & & $\begin{array}{l}70 \% \text { vs } 50 \% \\
\text { of exp. } \\
\text { group report } \\
\text { interest in } \\
\text { politics }\end{array}$ & $\begin{array}{l}\text { Weaker } \\
\text { stimulus }\end{array}$ \\
\hline $\mathrm{HI}$ & 2 & $\begin{array}{l}\text { Need for } \\
\text { Compe- } \\
\text { tence }\end{array}$ & $\begin{array}{l}\text { Intrinsic } \\
\text { Motiva- } \\
\text { tion }\end{array}$ & Lasorsa & & $\begin{array}{l}86 \% \text { vs } 74 \% \\
\text { of exp. } \\
\text { group report } \\
\text { interest in } \\
\text { politics }\end{array}$ & $\begin{array}{l}\text { Weaker } \\
\text { stimulus }\end{array}$ \\
\hline $\mathrm{HI}$ & 2 & $\begin{array}{l}\text { Need for } \\
\text { Compe- } \\
\text { tence }\end{array}$ & $\begin{array}{l}\text { Intrinsic } \\
\text { Motiva- } \\
\text { tion }\end{array}$ & Preece & & $\begin{array}{l}\text { I. } 92 \text { vs } 2.31 \\
(p=0.021) \\
\text { on a } 5 \text {-point } \\
\text { scale }\end{array}$ & $\begin{array}{l}\text { Weaker } \\
\text { stimulus }\end{array}$ \\
\hline $\mathrm{HI}$ & 4 & $\begin{array}{l}\text { Need for } \\
\text { Compe- } \\
\text { tence }\end{array}$ & $\begin{array}{l}\text { Intrinsic } \\
\text { Motiva- } \\
\text { tion }\end{array}$ & Gillet et al. & .50 & & \\
\hline $\mathrm{HI}$ & 4 & $\begin{array}{l}\text { Need for } \\
\text { Autonomy } \\
\text { (No } \\
\text { Choice) }\end{array}$ & $\begin{array}{l}\text { Intrinsic } \\
\text { Motiva- } \\
\text { tion }\end{array}$ & $\begin{array}{l}\text { Grant/ } \\
\text { Berry }\end{array}$ & .56 & & \\
\hline $\mathrm{HI}$ & 4 & $\begin{array}{l}\text { Need for } \\
\text { Autonomy }\end{array}$ & $\begin{array}{l}\text { Intrinsic } \\
\text { Motiva- } \\
\text { tion }\end{array}$ & Patall & .24 & & $\begin{array}{l}\text { Weaker } \\
\text { stimulus }\end{array}$ \\
\hline $\mathrm{H} 2$ & 6 & $\begin{array}{l}\text { Need for } \\
\text { Autonomy }\end{array}$ & $\begin{array}{l}\text { Fre- } \\
\text { quency of } \\
\text { Behavior }\end{array}$ & Patall & .29 & & \\
\hline
\end{tabular}




\begin{tabular}{|c|c|c|c|c|c|c|c|}
\hline $\mathrm{H} 3 \mathrm{a}$ & $7 / 8$ & $\begin{array}{l}\text { Need for } \\
\text { Autonomy }\end{array}$ & $\begin{array}{l}\text { Quality of } \\
\text { behavior }\end{array}$ & Cerasoli & & $\begin{array}{l}\mathrm{k}=70, \mathrm{~N}= \\
20,924, \mathrm{q}= \\
.37\end{array}$ & $\begin{array}{l}\text { Meta- } \\
\text { analysis }\end{array}$ \\
\hline $\mathrm{H} 3 \mathrm{~b}$ & $9 / 10$ & $\begin{array}{l}\text { Need for } \\
\text { Compe- } \\
\text { tence }\end{array}$ & $\begin{array}{l}\text { Quality of } \\
\text { behavior }\end{array}$ & Cerasoli & & $\begin{array}{l}\mathrm{k}=46, \mathrm{~N}= \\
\mathrm{II}, 937, \mathrm{q}= \\
.28\end{array}$ & $\begin{array}{l}\text { Meta- } \\
\text { analysis }\end{array}$ \\
\hline $\mathrm{H} 3 \mathrm{~b}$ & 9 & $\begin{array}{l}\text { Need for } \\
\text { Autonomy } \\
\text { (Aut-sup- } \\
\text { portive) }\end{array}$ & $\begin{array}{l}\text { Quality of } \\
\text { Behavior }\end{array}$ & $\begin{array}{l}\text { Kadous/ } \\
\text { Zhou }\end{array}$ & $.6 \mathrm{I} / .55$ & & \\
\hline $\mathrm{H} 4$ & 13 & $\begin{array}{l}\text { Need for } \\
\text { Autonomy } \\
\text { (No } \\
\text { Choice) }\end{array}$ & $\begin{array}{l}\text { Quality of } \\
\text { behavior }\end{array}$ & Patall & .22 & & $\begin{array}{l}\text { DV: } \\
\text { effort }\end{array}$ \\
\hline $\mathrm{H} 4$ & 13 & $\begin{array}{l}\text { Need for } \\
\text { Autonomy } \\
\text { (No } \\
\text { Choice) }\end{array}$ & $\begin{array}{l}\text { Quality of } \\
\text { behavior }\end{array}$ & Grant/Berry & .41 & & \\
\hline
\end{tabular}

\section{Sample size estimation}

Figure S4-1 shows the results of a power analysis conducted with $\mathrm{G}^{*}$ Power 3.1. Figure 1 reports for various effect sizes the required sample sizes to detect an effect with a power of .95. Many of the effect sizes reported in previous studies are around or larger than Cohen's d=0.4 which would correspond to a required $\mathrm{N}=136$ per experimental condition (total $\mathrm{N}=272$ with two experimental arms). 
Figure S4-I Detectable effect sizes at different sample sizes

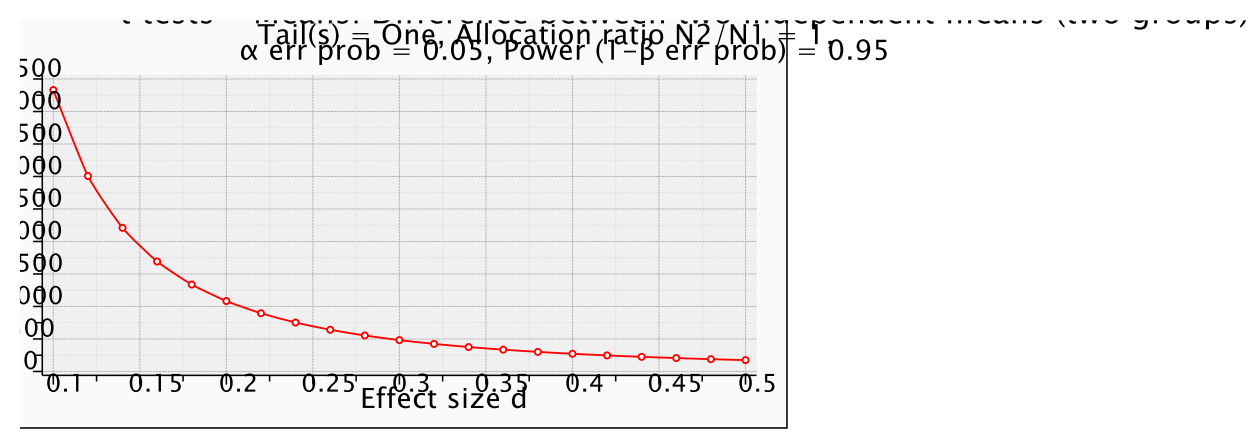

However, because meta-scientific evidence suggests that the effect sizes reported in published studies are usually inflated compared to the true population parameter there is reason to plan with sample sizes that enable to detect effect sizes smaller than those reported in the existing literature. Considering financial and practical constrains, we are able to run the size a sample size of up to 1,500 participants. The following analyses will examine the lowest detectable effect sizes with a sample size of 1,500 participants at power=.95.

In these analyses, we need to consider that the experimental design of the proposed study consists of a three-arm design in the manipulation of need for autonomy and of a two-arm design in the manipulation of need for competence (see consort diagram in Figure 2). 
Figure S4-2 Consort diagram showing distribution of respondents across experimental groups

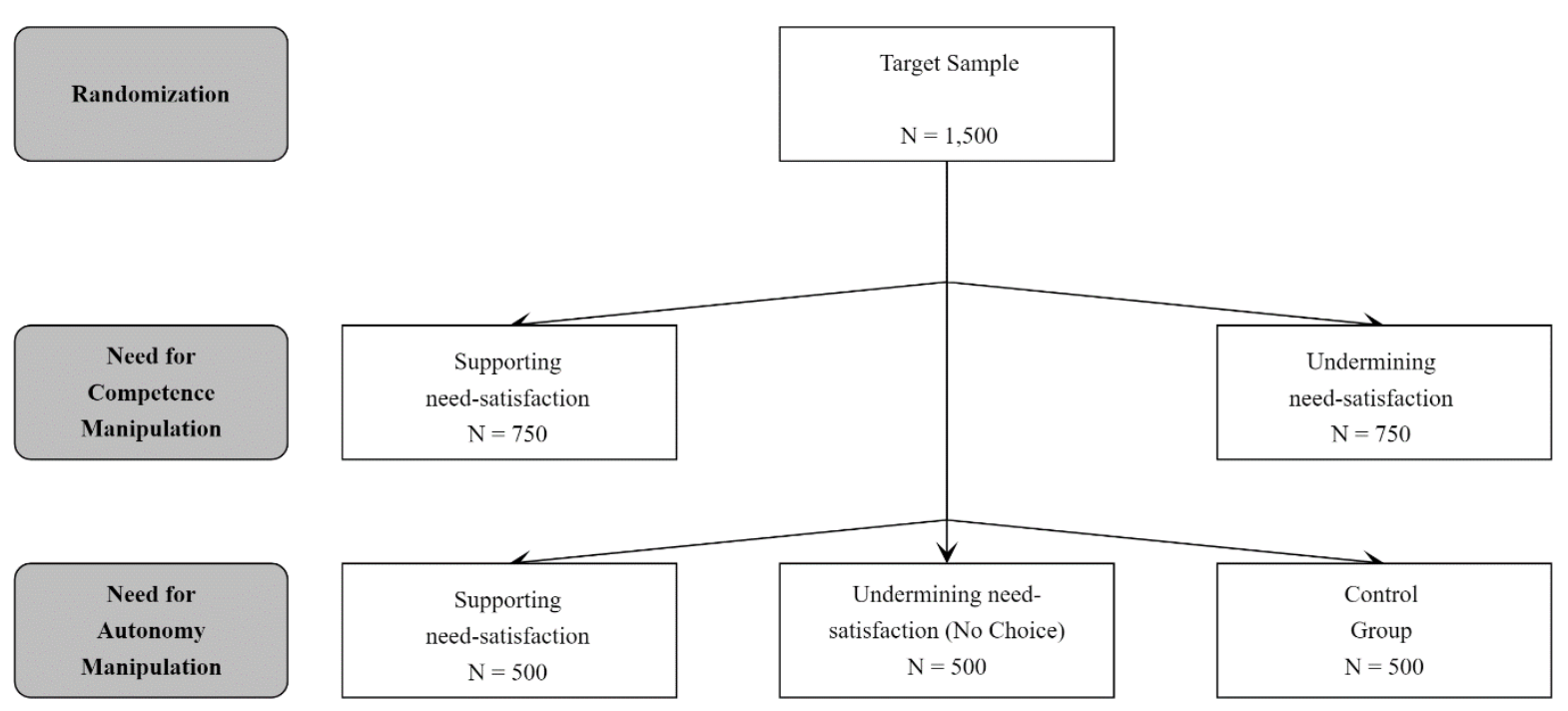

Because the need for autonomy manipulation consists of three experimental conditions, a total sample size of 1,5000 corresponds to a size of $\mathrm{N}=500$ of each experimental group in that experimental stage. Because the need for competence manipulation consists of two experimental conditions, a total sample size of 1,5000 corresponds to a size of $\mathrm{N}=750$ of each experimental group in that experimental stage. The fact that the experimental groups in the need for autonomy manipulation and in the need for competence manipulation have different sample sizes implies that the power to detect experimental effects differs between the need for competence manipulation and the need for autonomy manipulation. 
Figures 3 and 4 depict power analyses for the need for competence manipulation. Specifically, Figure S4-3 and 4 show which effect sizes will be detectable with 750 respondents in each experimental group. Note that one-tailed tests are employed because the proposed study prespecifies the direction of the expected experimental effects. The power analysis Figure 3 shows that an effect size as large as Cohen's $\mathbf{d}=\mathbf{0 . 1 7}$ will be detectable at a power of .95 . Hence, with great likelihood, the proposed study will be able to detect experimental effects that are much lower than the effect sizes reported in previously published literature. In the same vein, if the effect sizes will be larger, then the experimental power to detect these effects will be above the .95 . For instance, effect sizes as large as Cohen's $\mathbf{d = 0 . 1 9}$ will be detectable at a power of .98 .

Figure S4-3 Power to detect a significant difference in means for need-for competence manipulation with 750 respondents in each experimental group

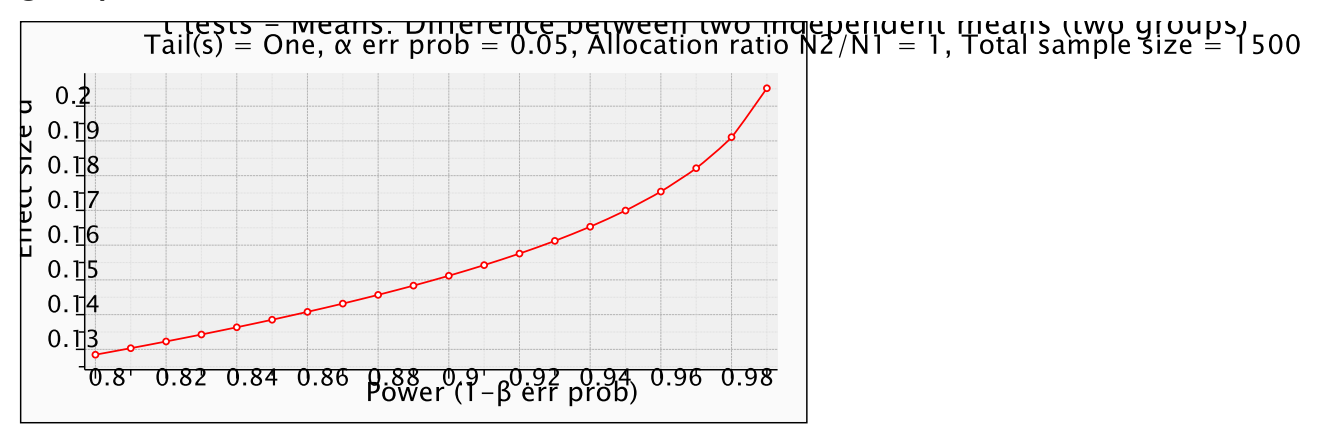


Various tests in the proposed study are conducted on binary dependent variables (see S5: Overview of statistical tests). Therefore, power analyses are required that take the dichotomous scale of the dependent variable into account. For instance, tests 5 and 6 assess whether individuals choose to watch political media vs. ostensibly non-political media content, captured in a binary variable. Hence, Figure C-4 depicts a power analysis to detect differences in proportions. Assuming that a proportion of $40 \%$ in one experimental group, the analysis will be able to detect differences between the groups at a power of .95 when the proportion in the other treatment group is at $31.7 \%$ or lower. Unfortunately, there is no prior literature available with a sufficiently similar research design that could inform about likely effect sizes. However, the power analysis shows that the analysis will be able to detect differences in proportions between experimental groups that are substantially meaningful and reasonably close. 
Figure S4-4 Power to detect a significant difference in proportions for need-for competence manipulation with 750 respondents in each experimental group

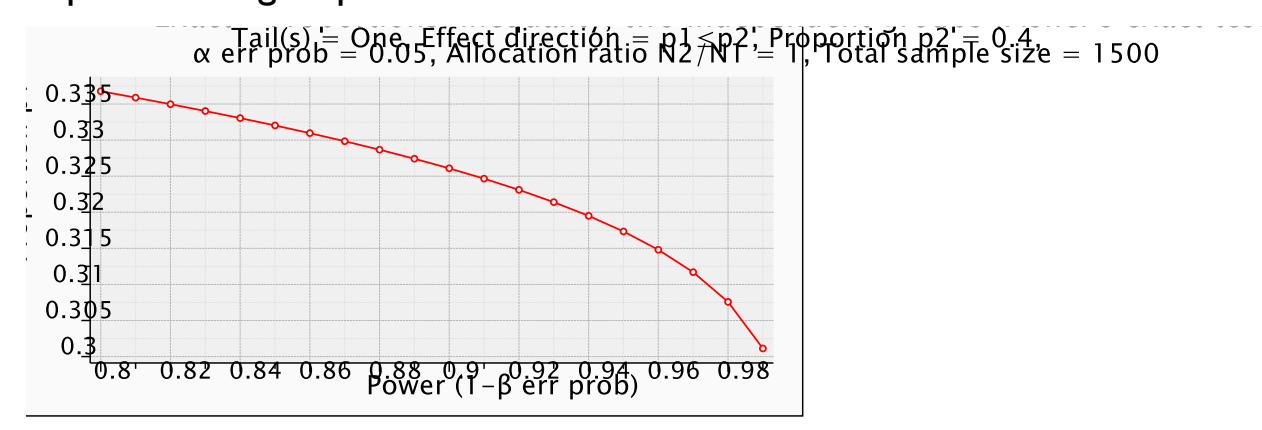

Figures S4-5 and S4-6 show power analysis for the need for autonomy manipulation in which each experimental group consists of 500 participants. Hence, the detectable effect sizes at a power of .95 slightly larger compared to the need for competence manipulation. For instance, at a power of .95 the analysis will be able to detect mean differences that correspond to effect sizes as large Cohen's $=.208$. Hence, the detectable effect sizes in the need for autonomy manipulation are still smaller than the effect sizes reported in previous literature, particularly when taking into account that previous studies often administered arguably weaker experimental stimuli. Figure 6 shows that the analysis will be able to detect differences in proportion when the proportion in one experimental group is at $40 \%$, and the proportion in the other experimental group is at $29.9 \%$ or smaller. 
Figure S4-5 Power to detect a significant difference in means for need for autonomy manipulation with 500 respondents in each experimental group

Tail(s) $=$ One, $\alpha$ err prob $=0.05$, Allocation ratio $\mathrm{N} 2 / \mathrm{N} 1=1$, Total sample šize $=1000$

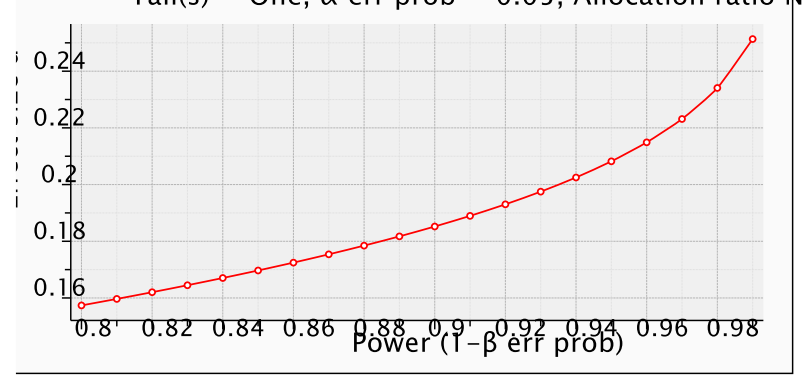


Figure S4-6 Power to detect a significant difference in proportions for need for autonomy manipulation with 500 respondents in each experimental group

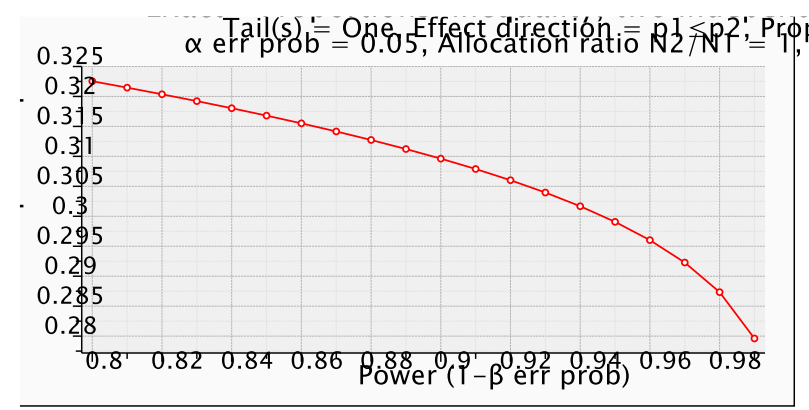




\section{S5: Overview of statistical tests}

Because multiple measurement instruments will be employed to assess the concepts of interest and because multiple hypotheses will be tested, in total 13 statistical tests will be conducted. Table D-1 lists all statistical tests that will be conducted. Table D- 1 is used a reference in the preregistered analysis pipeline (Stata syntax).

Table S5-I Power to detect a significant difference in proportions for need for autonomy manipulation with 500 respondents in each experimental group

\begin{tabular}{|c|c|c|c|c|}
\hline $\begin{array}{l}\text { Test } \\
\text { Name }\end{array}$ & $\begin{array}{l}\text { Test } \\
\#\end{array}$ & Hyp & DV & $\begin{array}{l}\text { Compared } \\
\text { Groups }\end{array}$ \\
\hline $\begin{array}{l}\text { Int-Mot-Be- } \\
\text { hav-Comp } \\
\text { Int-Mot- } \\
\text { SelfRep- } \\
\text { Comp } \\
\text { Int-Mot-Be- } \\
\text { hav-Aut } \\
\text { Int-Mot- } \\
\text { SelfRep- } \\
\text { Comp }\end{array}$ & 4 & $\begin{array}{l}\text { H I: Need-supportive situational contexts increase } \\
\text { intrinsic political motivation. } \\
\text { H I: Need-supportive situational contexts increase } \\
\text { intrinsic political motivation. } \\
\text { H I: Need-supportive situational contexts increase } \\
\text { intrinsic political motivation. } \\
\text { H I: Need-supportive situational contexts increase } \\
\text { intrinsic political motivation. } \\
\text { H2a: Individuals who previously experienced the } \\
\text { political domain as satisfying their need for compe- } \\
\text { tence, want to engage with politics more }\end{array}$ & $\begin{array}{l}\text { Intrinsic Motivation: Behavioral Indica- } \\
\text { tor } \\
\text { Intrinsic Motivation: Self-reported } \\
\text { Intrinsic Motivation: Behavioral Indica- } \\
\text { tor } \\
\text { Intrinsic Motivation: Self-reported } \\
\text { Quantity of Engagement: Choice of Po- } \\
\text { litical Media Content (yes/no) }\end{array}$ & $\begin{array}{l}\text { Comp+ vs } \\
\text { Comp- } \\
\text { Comp+ vs } \\
\text { Comp- } \\
\text { Aut+ vs. Aut- }\end{array}$ \\
\hline
\end{tabular}




\begin{tabular}{l|l} 
Quant-Aut & 6 \\
Qual-Subj- & 7 \\
Comp & 7 \\
Qual-Obj- & \\
Comp & 8 \\
Qual-Obj- & 9 \\
Comp & 10 \\
Qual-Subj- & \\
Aut \\
Qual-Subj- \\
Aut
\end{tabular}

frequently than individuals with need-thwarting domain-related experiences.

$\mathbf{H 2 b}$ : Individuals in an autonomy-supportive context want to engage with politics more frequently than individuals in neutral situational contexts.

H3a: Individuals who previously experienced the political domain as satisfying their need for competence, are more inclined to invest cognitive efforts in processing the political information conveyed in the video than individuals with need-thwarting domain-related experiences.

H3a: Individuals who previously experienced the political domain as satisfying their need for competence, are more inclined to invest cognitive efforts in processing the political information conveyed in the video than individuals with need-thwarting domain-related experiences.

H3a: Individuals who previously experienced the political domain as satisfying their need for competence, are more inclined to invest cognitive efforts in processing the political information conveyed in the video than individuals with need-thwarting domain-related experiences.

$\mathbf{H} 3$ b: Individuals in autonomy-supportive contexts are more inclined to invest cognitive efforts in processing the political information conveyed in the video than individuals in neutral situational contexts.

H3b: Individuals in autonomy-supportive contexts are more inclined to invest cognitive efforts in
Quantity of Engagement: Choice of Political Media Content (yes/no)

Quality of Engagement: Subj. Measure of Effort

Quality of Engagement: Objective Measure of Effort

Quality of Engagement: Behavioral Measure of Effort

Quality of Engagement: Behavioral Measure of Effort

Quality of Engagement: Subj. Measure of Effort
Aut+ vs. Con-

trol

Comp+vs

Comp-

Comp+vs

Comp-

Comp+ vs

Comp-

Aut+ vs. Con-

trol

Aut+ vs. Control 


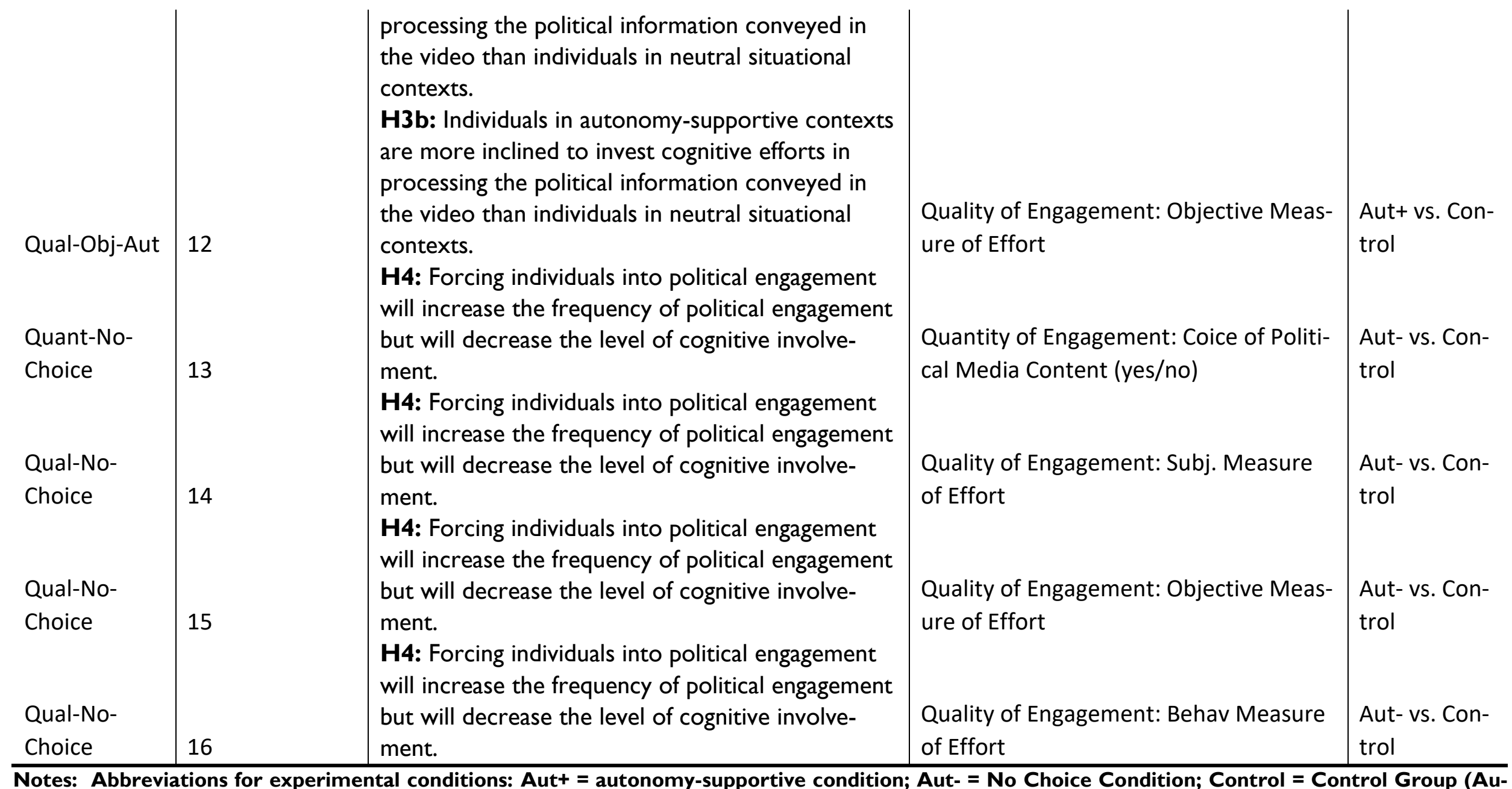

Notes: Abbreviations for experimental conditions: Aut+ = autonomy-supportive condition; Aut- = No Choice Condition; Control = Control Group (Autonomy Condition); Comp+ = need-for-competence-supportive condition; Comp - = need-for-competence-thwarting condition 


\section{S6: Transparency Report}

To improve and document the transparency of research reports in social and behavioral research, various authors (Aczel et al.) have developed a consensus-based transparency check list. The responses below document the study's degree of transparency according to v1 of the transparency check list.

\section{PREREGISTRATION SECTION}

(I) Prior to analyzing the complete data set, a time-stamped preregistration was posted in an independent, third-party registry for the data analysis plan. Yes

(2) The manuscript includes a URL to all preregistrations that concern the present study. Yes

(3) The study was preregistered... before any data were collected

The preregistration fully describes...

(4) all inclusion and exclusion criteria for participation (e.g., English speakers who achieved a certain cutoff score in a language test). Yes

(5) all procedures for assigning participants to conditions. Yes

(6) all procedures for randomizing stimulus materials. Yes

(7) any procedures for ensuring that participants, experimenters, and data-analysts were kept naive (blinded) to potentially biasing information. Yes

(8) a rationale for the sample size used (e.g., an a priori power analysis). Yes

(9) the measures of interest (e.g., friendliness). Yes

(10) all operationalizations for the measures of interest (e.g., a questionnaire measuring friendliness). Yes

(II) the data preprocessing plans (e.g., transformed, cleaned, normalized, smoothed). Yes

(I2) how missing data (e.g., dropouts) were planned to be handled. Yes

(13) the intended statistical analysis for each research question (this may require, for example, information about the sidedness of the tests, inference criteria, corrections for multiple testing, model selection criteria, prior distributions etc.). Yes

\section{METHODS SECTION}

\section{The manuscript fully describes...}

(I4) the rationale for the sample size used (e.g., an a priori power analysis). Yes

(I5) how participants were recruited. Yes 
(16) how participants were selected (e.g., eligibility criteria). Yes

(17) what compensation was offered for participation. No

(18) how participant dropout was handled (e.g., replaced, omitted, etc). Yes

(19) how participants were assigned to conditions. Yes

(20) how stimulus materials were randomized. Yes

(2I) whether (and, if so, how) participants, experimenters, and data-analysts were kept naive to potentially biasing information. Yes

(22) the study design, procedures, and materials to allow independent replication. Yes

(23) the measures of interest (e.g., friendliness). Yes

(24) all operationalizations for the measures of interest (e.g., a questionnaire measuring friendliness). Yes

(25) any changes to the preregistration (such as changes in eligibility criteria, group membership cutoffs, or experimental procedures)? Yes

\section{RESULTS AND DISCUSSION SECTION}

The manuscript...

(26) distinguishes explicitly between "confirmatory" (i.e., prespecified) and "exploratory" (i.e., not prespecified) analyses. Yes

(27) describes how violations of statistical assumptions were handled. No

(28) justifies all statistical choices (e.g., including or excluding covariates; applying or not applying transformations; use of multi-level models vs. ANOVA). Yes

(29) reports the sample size for each cell of the design. Yes

(30) reports how incomplete or missing data were handled. No

(3I) presents protocols for data preprocessing (e.g., cleaning, discarding of cases and items, normalizing, smoothing, artifact correction). Yes

\section{DATA, CODE, AND MATERIALS AVAILABILITY SECTION}

The following have been made publicly available...

(32) the (processed) data, on which the analyses of the manuscript were based. Yes

(33) all code and software (that is not copyright protected). Yes

(34) all instructions, stimuli, and test materials (that are not copyright protected). Yes

(35) Are the data properly archived (i.e., would a graduate student with relevant background knowledge be able to identify each variable and reproduce the analysis)? Yes 
(36) The manuscript includes a statement concerning the availability and location of all research items, including data, materials, and code relevant to the study. Yes

\section{S7: Supplement Treatment-induced attrition and imputation}

The main text reported evidence which suggested that the competence manipulation might have affected the probability to affect the survey. As a result, missing values on the outcome variables might be affected by treatment status which may induce bias in the estimation of the experimental treatment effects. The main text reports analyses that shows what happens when we impute missing values. In all analyses, values for imputed for as many respondents necessary so that in both treatment conditions there would be an equal share of respondents with non-missing values. Respondents for imputation were drawn randomly from all respondents in the need-thwarting group with missing value on the respective outcome variable. Table 1 shows, for each outcome variables, details of the imputation process and the estimated effect size of the need for competence manipulation on the imputed outcome variable.

S7- I Imputation of Outcome Variables and Experimental Tests

\begin{tabular}{l|lllll} 
Outcome & $\begin{array}{l}\text { Number of } \\
\text { Respondents } \\
\text { with Imputa- } \\
\text { tions }\end{array}$ & $\begin{array}{l}\text { Imputed } \\
\text { Value }\end{array}$ & $\begin{array}{l}\text { P-value of ef- } \\
\text { fect on im- } \\
\text { puted out- } \\
\text { come }\end{array}$ & $\begin{array}{l}\text { P-value of ef- } \\
\text { fect on im- } \\
\text { puted out- } \\
\text { come }\end{array}$ & Cohen's d \\
\hline $\begin{array}{l}\text { Quality (Be- } \\
\text { havioral) } \\
\text { Quality (Sub- } \\
\text { jective) }\end{array}$ & 37 & 30 (seconds) & .83 & .88 & - \\
$\begin{array}{l}\text { Intrinsic Moti- } \\
\text { vation (Self-re- } \\
\text { ported) }\end{array}$ & 59 & $\begin{array}{l}\text { I (Lowest } \\
\text { possible } \\
\text { value) } \\
\text { I (Lowest } \\
\text { possible } \\
\text { value) }\end{array}$ & .00001 & .17 & 0.24 \\
\hline
\end{tabular}




\section{S8: Heterogeneous treatment effects using random forests}

To detect treatment heterogeneity, I conducted causal forest analyses using grf package version 0.10 .4 . The number of trees to be calculated was set to 4,000 , using automated tuneparameter and leaving the remaining model options on default values. Because the manipulation checks for the autonomy-related conditions failed, analyses of treatment heterogeneity were only conducted for the competence manipulation. Table S8-1 shows the p-value of an omnibus test of whether the null hypothesis of no treatment heterogeneity can be rejected, suggested no evidence for treatment heterogeneity in any of the tests.

S8-I Imputation of Outcome Variables and Experimental Tests

\begin{tabular}{l|l} 
Outcome & $\mathrm{p}$-value \\
\hline $\begin{array}{l}\text { Frequency } \\
\begin{array}{l}\text { Intrinsic Motivation } \\
\text { (Behavioral) }\end{array}\end{array}$ & 0.86 \\
$\begin{array}{l}\text { Intrinsic Motivation } \\
\text { (Subjective) }\end{array}$ & 1.00 \\
$\begin{array}{l}\text { Quality } \\
\text { (Objective) }\end{array}$ & 0.64 \\
$\begin{array}{l}\text { Quality } \\
\text { (Subjective) }\end{array}$ & 0.99 \\
\hline
\end{tabular}




\section{S9: Equivalence tests}

To conduct equivalence tests, it is necessary to specific the 'smallest effect size of interest' (SESOI) that needs to be reasoned for each test of interest. The following plots show the results of equivalence for each test with the respective SESOI. Because the manipulation checks for the autonomy-related conditions failed, equivalence tests were only conducted for the competence manipulation

$\begin{array}{ll}\text { Test } & \text { I } \\ \text { DV } & \text { Intrinsic Motivation: Behavioral Indicator } \\ \text { SESOI } & 10 \% \\ \text { Justification } & \text { Even lower than suggested in previous experiment } \\ \text { Result } & \text { Statistical equivalence }\end{array}$

S9-I Equivalence test

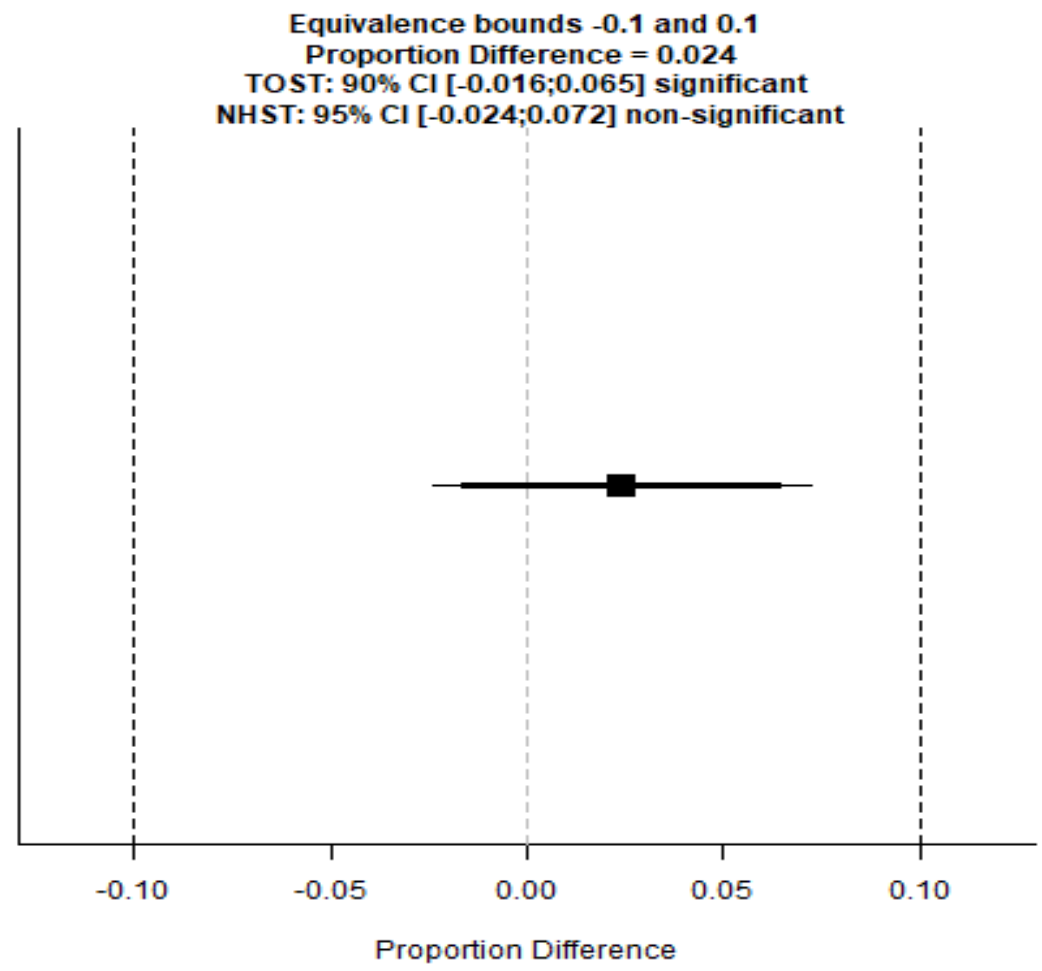


DV Intrinsic Motivation: Self-reported

SESOI $\quad 0.14$

Justification Lowest effect estimate retrieved in previous studies

Result Statistical equivalence

S9-2 Equivalence test

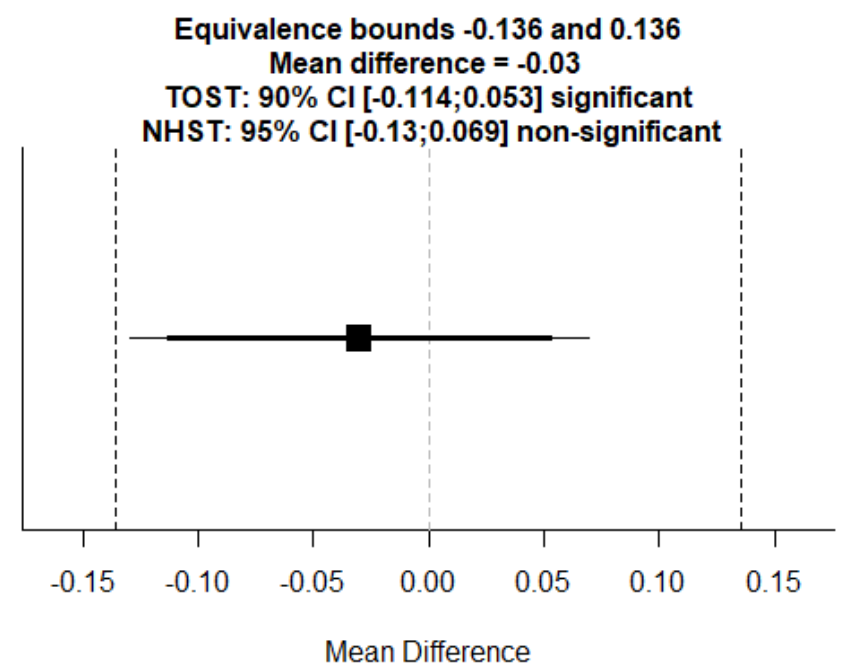

Test 5

DV Quantity of Engagement

SESOI $\quad 10 \%$

Result Statistical equivalence

S9-3 Equivalence test

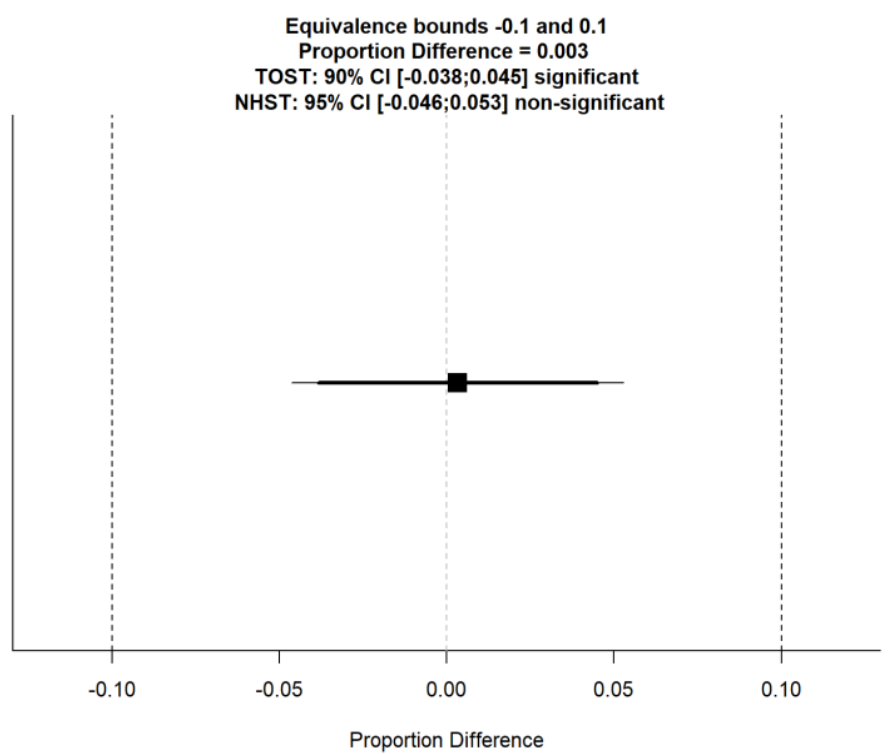


Result

Statistical equivalence

\section{S9-4 Equivalence test}

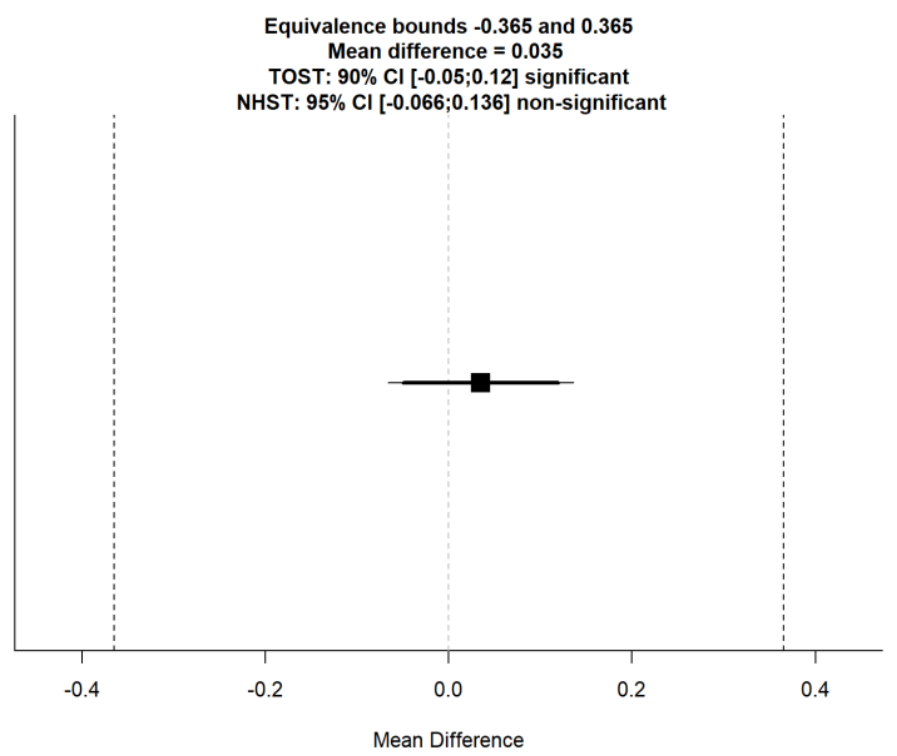

Test 8

DV Quality of Engagement: Objective Measure of Effort

SESOI difference of 0.5 more /fewer correct responses

Result Statistical equivalence

\section{S9-4 Equivalence test}

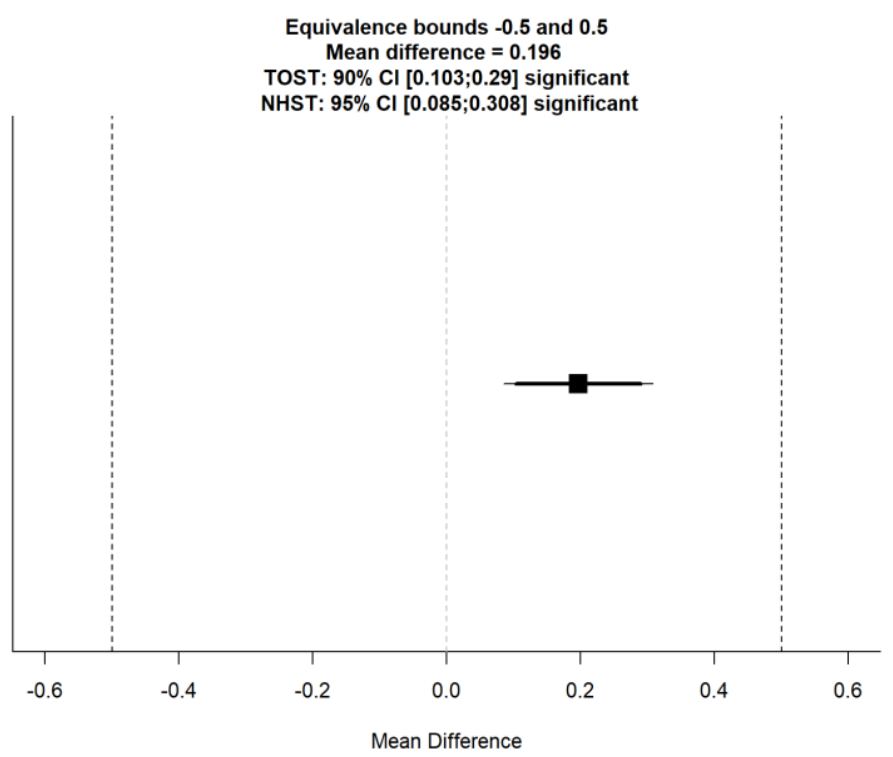

